\title{
The systematic assessment of the short-term risk for patient violence on acute psychiatric wards
}

Citation for published version (APA):

Abderhalden, C. (2008). The systematic assessment of the short-term risk for patient violence on acute psychiatric wards. [Doctoral Thesis, Maastricht University]. Datawyse / Universitaire Pers Maastricht. https://doi.org/10.26481/dis.20080306ca

Document status and date:

Published: 01/01/2008

DOI:

$10.26481 /$ dis.20080306ca

Document Version:

Publisher's PDF, also known as Version of record

\section{Please check the document version of this publication:}

- A submitted manuscript is the version of the article upon submission and before peer-review. There can be important differences between the submitted version and the official published version of record.

People interested in the research are advised to contact the author for the final version of the publication, or visit the DOI to the publisher's website.

- The final author version and the galley proof are versions of the publication after peer review.

- The final published version features the final layout of the paper including the volume, issue and page numbers.

Link to publication

\footnotetext{
General rights rights.

- You may freely distribute the URL identifying the publication in the public portal. please follow below link for the End User Agreement:

www.umlib.nl/taverne-license

Take down policy

If you believe that this document breaches copyright please contact us at:

repository@maastrichtuniversity.nl

providing details and we will investigate your claim.
}

Copyright and moral rights for the publications made accessible in the public portal are retained by the authors and/or other copyright owners and it is a condition of accessing publications that users recognise and abide by the legal requirements associated with these

- Users may download and print one copy of any publication from the public portal for the purpose of private study or research.

- You may not further distribute the material or use it for any profit-making activity or commercial gain

If the publication is distributed under the terms of Article $25 \mathrm{fa}$ of the Dutch Copyright Act, indicated by the "Taverne" license above, 


\section{The systematic assessment of the short-term risk for patient violence on acute psychiatric wards}


The systematic assessment of the short-term risk for patient violence on acute psychiatric wards Christoph Abderhalden

ISBN 9789052787039

Cover photo: Ulrike Riedesser, with permission

(C) Christoph Abderhalden

Printing: Datawyse | Universitaire Pers Maastricht NL 


\title{
The systematic assessment of the short-term risk for patient violence on acute psychiatric wards
}

\author{
Dissertation \\ to obtain the degree of Doctor at \\ the Maastricht University, \\ on the authority of the Rector Magnificus, \\ Prof. dr. G.P.M.F. Mols \\ in accordance with the decisions of the Board of Deans, \\ to be defended in public \\ on Thursday March 6th, 2008, at 16.00 hours \\ by
}

Christoph Abderhalden

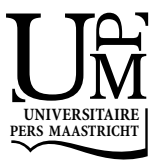




\section{Supervisors}

Prof. dr. H. Philipsen

Prof. dr. T. Dassen, Charité Universitätsmedizin Berlin, Germany

\section{Co-supervisor}

Dr. R.J.G. Halfens

\section{Assessment Committee}

Prof. dr. G. Widdershoven (chairman)

Prof. dr. R. De Bie

Prof. dr. G. Kok

Dr. H. Nijman, De Kijvelanden, Poortugaal

Prof. dr. R. De Wit

The studies presented in this thesis were financially supported by The Swiss Academy of Medical Science, the Swiss Association of Nursing Experts PES and, the Swiss National Science Foundation. 


\section{Contents}

Introduction

Part I: Patient aggression in acute psychiatry in the German speaking part of Switzerland

Chapter 1 Perception of aggression among psychiatric nurses in Switzerland

Chapter 2 The management of violence on psychiatric acute wards in the German speaking part of Switzerland: Results of a survey

Chapter 3 Nature and Frequency of aggressive incidents in acute psychiatric wards in Switzerland

Part II: Effect of the assessment of the short term risk for patient violence in acute psychiatric wards

Chapter 4 Predicting inpatient violence in acute psychiatric wards using the Brøset-Violence-Checklist: A multi-center prospective cohort study

Chapter 5 Predicting inpatient violence using an extended version of the Brøset-Violence-Checklist: Instrument development and clinical application

Chapter 6 Structured assessment of the short-time risk for violence in acute psychiatric wards: a cluster randomised controlled trial evaluating the effect on aggressive incidents and coercive measures

General Discussion

Summary: The systematic assessment of the short-term risk for patient violence on acute psychiatric wards

Samenvatting: De systematische beoordeling van het korte-termijn-risico op geweld door patiënten op acute psychiatrische opnameafdelingen 

Introduction 
The general subject of this dissertation is aggression and violence in psychiatry, particularly patient aggression and patient violence in acute psychiatric wards. The specific focus is on psychiatric nursing and nurses' contribution to the anticipation and prevention of adverse manifestations of aggression.

Studying aggression and violence in this particular setting covers a small aspect of a universal phenomenon, which is one of mankind's most fundamental problems. The World Health Organization regards violence in all its individual and collective manifestations as one of the major worldwide public health problems. Aggression and violence are amongst the most prominent causes of death, injuries, disabilities and lead to a broad range of physical, sexual, reproductive and mental health problems. Violence undermines the health and well-being of many millions of people, in addition to costing nations vast sums each year in health care, legal costs, work absenteeism and lost productivity (Krug, 2002).

As part of the human condition, aggression is inevitable and affects health care institutions and relationships between carers and clients. Aggression in healthcare settings takes various forms such as aggression of patients or their relatives against professionals, as aggression of patients against themselves, as aggression of professionals against patients, as aggression between patients or as aggression in informal care settings, e.g. aggression in patient-relatives-relationships.

\section{Defining aggression and violence}

Aggression and violence are extremely multifaceted and complex phenomena. Consequently the attempts to define them appear to be nearly countless. Commenting this situation, Bandura referred to it as a "semantic jungle" (Bandura, 1973, p. 2). Definitions depend on who is defining it and for what purpose and are based on a wide variety of theoretical approaches rooted in different disciplines and domains and focus on different aspects of the phenomenon. Additionally, definitions of the terms violence and aggression tend to overlap to some degree, and sometimes they are even used interchangeably.

The World Health Organization defines violence as: "The intentional use of physical force or power, threatened or actual, against oneself, another person, or against a group or community, that either results in or has a high likelihood of resulting in injury, death, psychological harm, maldevelopment or deprivation" (Krug, 2002, p 5). This broad definition encompasses interpersonal violence as well as suicidal behaviour and 
armed conflict, and it includes nonphysical acts such as threats and intimidation, sometimes summarized as psychological violence. On the other hand, aggression has been defined by psychologists as "any behaviour directed toward another individual that is carried out with the proximate (immediate) intent to cause harm. In addition, the perpetrator must believe that the behaviour will harm the target and that the target is motivated to avoid the behaviour" (Anderson \& Bushman, 2002). This definition excludes self-directed aggression. Within this framework, violence is a subtype of aggression and the term is used to denote extreme forms of aggression such as physical assaults (Anderson, 2000). To be elegible as aggression, the behaviour has to be intentional according to both definitions, and accidental harm is excluded. This poses some problems in "violent" and harming behaviour of mentally handicapped or cognitively disturbed persons, where the intention is unclear. There are also some conceptually alternative perceptions of violence described in the literature. Violence can be perceived as a form of communication (Rothenburg, 1971), or - from what could be termed an anti-psychiatric perspective - as a legitimate reaction to colonial oppression (Hopton, 1995). Some authors applied the concept of structural violence ("institutional violence") (Galtung, 1969) to psychiatry. Structural violence is widely defined as a systematic way in which a given regime prevents individuals from achieving their full potential; institutionalized racism and sexism are examples of this, and mental hospitals have been declared as "violent institutions" (Basaglia, 1981).

Unsurprisingly, the ambiguity of terms is mirrored in studies on the subject. In clinical research, some authors limit violence to the physical dimension (Owen, Tarantello, Jones, \& Tennant, 1998), others include verbal acts (Chambers, 1998; Gates, Fitzwater, \& Meyer, 1999; Vanderslott, 1998), and in some definitions sexual harassment (the Department of Health and Social Security as quoted by Vanderslott, 1998) or unwanted sexual acts (Flannery, Hanson, \& Penk, 1995) are included. Some authors name prerequisites as necessary to constitute violence such as the perpetrator's resulting pleasant feeling (Chambers, 1998) or the aggressors intent to harm or frighten staff (Flannery et al., 1995; Vanderslott, 1998). The ambiguity of the term aggression among health care workers is also evident in a Dutch study where psychiatric nurses were interviewed about their perception of aggression. The nurses described aggression as negative and as positive or - at least functional - depending on the form of aggression and the context. All in all the descriptions of aggression varied considerably and the authors concluded that "it was not possible to formulate a 
general definition of aggression on the basis of the results of the study" (Finnema, Dassen, \& Halfens, 1994, p. 1088).

In the present dissertation, the term "aggression" will be preferred and the following definition will be used:

Aggression is "any verbal, non-verbal, or physical behaviour that is threatening (to self, others or property), or physical behaviour that actually does harm (to self, others, or property)" (Morrison, 1990a).

This definition is rooted in works of the American Psychiatric Association (1974) and is regularly used in aggression research in psychiatry. Contrary to the definitions cited above the intention to harm is not a prerequisite to categorize behaviour as aggressive, but the distinguishing characteristic is either harm or perceived threat by others. It is an integral part of the widely used Staff Observation of Aggression Scale (SOAS-R) in its revised form (Nijman et al., 1999) and serves as description of the behaviour that should be registered when this instrument is employed. The term violence will be used to indicate physically aggressive behaviour in general, and attack and assault will stand for physical aggression against another person.

\section{Aggression in psychiatry}

Psychiatric settings are, besides emergency departments and nursing homes, among the health care environments where aggression is highly present. According to some authors violence is even an unavoidable or inherent element of psychiatric work (Cahn, 1995), and it has been called the Achilles tendon of psychiatry (Hell). Despite this, the phenomenon received little attention for many years.

In the last decades, however, this has changed and the topic gives raise to much professional and public controversies and is now perceived by many professionals and patient representatives as one of the biggest problems affecting contemporary psychiatric institutions (Whittington \& Richter, 2006b).

Factors promoting the interest in the topic include the criticism of psychiatry as societal agency of suppression as proposed by proponents of the 1968 movement (Szasz, 1970, 1987). Within this discourse, psychiatric institutions have been denounced as "violent institutions" (Basaglia, 1981). The traditional picture of psychiatric patients as dangerous and potentially violent subjects was challenged by a new view of patients being victims of social exclusion accompanied by unjustified and 
coercive treatment. Parallel to this growing criticism of traditional psychiatric theories and practices, psychiatry became object of sociological and socio-psychological studies, and violence was now investigated within organizational and interactional theoretical frameworks (e.g. Goffman, 1961). In addition, psychiatric treatment modalities came under influence of global campaigns for Human Rights and in many countries, jurisdiction was changed to ameliorate the civil rights of psychiatric patients and regulate coercive treatment. As another facet of the discourse, the situation of health care staff being assaulted by patients became a public issue, in the wider context of a growing interest in workplace related violence (Budd, 1999; Chappell \& Di Martino, 2000). Patient violence toward staff has thus been identified as a workplace hazard (Love \& Hunter, 1996; Whittington, Shuttleworth, \& Hill, 1996) with injury rates in nursing surpassing rates in industries traditionally considered high risk such as mining, lumber, and heavy construction (Love \& Hunter, 1996).

These conflicting developments stimulated an impressive amount of scientific studies on the topic of aggression, including studies on the prevalence of patient-aggression and coercion, studies on risk-factors and risk-assessment, or studies on the perception of aggression and coercion by psychiatric staff or service users. Given that staff assaults happen predominantly to nurses (Carmel \& Hunter, 1989; Carmel \& Hunter, 1993) and given the prominent involvement of nurses in coercive treatment the topic has become an important issue for nursing research.

However, until the nineties of the last century most of the scientific literature was of Anglo-American provenance, and the problem was only a marginal subject of psychiatric or nursing research in the German speaking countries including German speaking Switzerland. This lack of research in Switzerland gave rise to the studies undertaken within this dissertation.

\subsection{Prevalence}

In spite of a substantial body of research on the prevalence of aggressive behaviour considerable variation regarding study aims, study designs, settings, study populations, and data collection methods render comparisons of the results difficult and the results of these studies cannot be summarised easily due to the many disparities in the findings (Bowers, 2000; Palmstierna \& Wistedt, 2000; Steinert \& Gebhardt, 1998). Some of the factors hindering the generalisability and comparability of incidence studies are differing definitions of aggressive behaviour, the variety of registration methods, inconsistent ways of reporting incidence rates, a substantial amount of 
underreporting, and problems arising from the selection of study settings and the duration of observations. In some studies, the incidence of aggression is approached from the perspective of staff as victims with incidence expressed in terms of the assault rates among populations of nurses or doctors. Other studies focus on the proportion of patients showing assaultive behaviour or on differing types of incidencerates (e.g. per bed per year, per 100 treatment days). In the last years however, a growing number of studies were conducted that employed uniformed data collection methods. A wide-spread instrument is the Staff Observation of Aggression Scale (SOAS) (Palmstierna \& Wistedt, 1987) and its revised form SOAS-R (Nijman, 1999). The SOAS is easy to use and has been employed in numerous descriptive studies. It demonstrates good inter-rater-reliability (Nijman, 1999; Palmstierna, Lassenius, \& Wistedt, 1989; Palmstierna \& Wistedt, 1995). The scale consists of 5 separate columns to code aggressive incidents: the provocation which led to the aggressive event, the means used by the patient during the aggressive event, the target of the aggression, the consequences for the victims, and the measures taken to terminate the aggression. SOAS-R (Nijman, 1999) allows the calculation of a severity score ranging from 0 to 22. By reviewing more than 50 studies using this instrument, the authors were able to derive the annual frequency of incidents per bed per year and the percentage of patients involved in incidents as appropriative comparative figures in most of the studies. The median value was about 8 incidents per patient per year, equalling about one incident every three days on a 15 bed ward (Nijman, Bjorkly, Palmstierna, \& Almvik, 2006). However, the reported incident rates varied considerably across studies, depending on the type of ward and country involved. The highest rates were found in acute or psychiatric intensive care units (Nijman et al., 2006).

Studies on patient aggression towards staff show that all members of the multidisciplinary team can be victims, including physicians, psychologists, social workers and nurses. A study demonstrated that more than half of the non-nursing staff in four German psychiatric hospitals have been subjected to serious injury induced by patient violence during their career (Steinert, Beck, Vogel, \& Wohlfahrt, 1995) and an American study reports a rate of 35 injuries for 100 staff members per annum (Bensley et al., 1997). However, available data indicate that the nursing profession is predominantly affected (Geser, 1999) having an annual incidence rate of 16 injuries per nurse (Haller \& Deluthy, 1988; Whittington et al., 1996). In the course of their career almost $100 \%$ of nurses experience patient violence (Carmel \& Hunter, 1989) compared with a rate of $61 \%$ for other therapists (physicians, psychologists, and social workers) (Wynn \& Bratlid, 1998). Richter (1998) reported an average rate of patient 
violence towards nurses of more than $80 \%$ in western industrial societies. According to the British Crime Survey (Budd, 1999) the nursing profession is the second most vulnerable group, second only to the security and protective services.

\subsection{Consequences of patient aggression}

\section{Consequences for staff}

Physical consequences of patient assault on nurses are well documented in the literature (see for example Carmel \& Hunter, 1989; Carmel \& Hunter, 1993; Larkin, Murtagh, \& Jones, 1988; Love \& Hunter, 1996). Physical injuries include pain, lacerations, bruising (Rix \& Seymour, 1988) and head injuries (Carmel \& Hunter, 1993; Lanza, Kayne, Hicks, \& Milner, 1991). The non somatic consequences, although apparently less dramatic, are numerous and widespread as a recent literature review has revealed (Needham, Abderhalden, Halfens, Fischer, \& Dassen, 2005). Some victims of violence are reported as contracting mental distress in the form of tension, anxiousness, burnout, posttraumatic stress disorders (Hubschmid, 1996) and emotional stress (Lanza et al., 1991). Social distress to the victims of patient aggression can accrue from prejudices relating to aggression such as unconscious staff conflicts resulting in aggression and violence by patients (Morrison, 1993) or the belief that the fearful clinician is most often assaulted (Lanza et al., 1991; Morrison, 1993). Considering nurse-patient interaction one qualitative study reports that aggression can lead to the deterioration of the nurse-patient relationship with nurses disconnecting from the angry patient (Smith \& Hart, 1994) or to problematic relationships (Whittington \& Wykes, 1994). Finally violence can disrupt the functioning of the health care system as exemplified in staff illness and absenteeism (Rix, 1987) or cases of industrial compensation (Bensley et al., 1997).

Patient aggression can also have an impact on actual or perceived job stress on health care workers. It has been suggested that understanding and control over the work environment may have a moderating effect on the relationship between role stress and job satisfaction (Tetrick \& LaRocco, 1987). Thus, it is not surprising that violent attacks with no preliminary warning may lead to elevated levels of stress on staff: In a study on staff responses to violent events in closed psychiatric wards the nursing staff rated attacks perceived as random more severe than non-arbitrary incidents (Apel \& Bar-Tal, 1996). Limited capacity to predict events in the work environment leads according to a British study - to an increase in emotional exhaustion, depersonalisation, and control (Kilfedder, Power, \& Wells, 2001). It has thus been 
suggested that the understanding of events, the predictability of events, and the control of outcomes in the work environment may serve as antidotes to occupational stress (Tetrick \& LaRocco, 1987) and the ability to control the work environment seems to offer protection against adverse effects of a stressful work environment (Petterson, Arnetz, Arnetz, \& Horte, 1995). These facts are a staff related justification for the focus on risk assessment in the studies constituting the main part of this dissertation.

\section{Consequences for patients}

Impatient aggression is in many cases associated with negative consequences for patients. One issue investigated is the psychological sequelae caused by experiencing or witnessing violent incidents or being assaulted or threatened by fellow patients (Frueh et al., 2005; Kumar, Guite, \& Thornicroft, 2001). Frueh (2005) reported high rates of such events that occurred within psychiatric settings, including witnessing traumatic events ( $63 \%$ of the patients), physical assault (31\%), and sexual assault ( 8 $\%)$, and being around frightening or violent patients (54\%). Patients have underlined that the needs of the victims of aggression in the ward often remain unmet by the care system (Kumar et al., 2001). Patient aggression is in many cases answered by coercive measures as forced medication, seclusion or mechanical restraint. However, investigations conduced from the patients' stance reveal that coercive practices can be experienced as being punitive rather than therapeutical (Ray, Myers, \& Rappaport, 1996) or as having been conducted in a "brutal" fashion (Finzen, Haug, Beck, \& Lüthy, 1993). Patients describe the experience of seclusion as distressing (Hoekstra, Lendemeijer, \& Jansen, 2004). "Isolation", they report, sets off critical feelings of "going mad" or "losing control" over reality (Meehan, Vermeer, \& Windsor, 2000). Patients perceive coercive practices as used "too often" or "too long", as punitive, and as a source of unnecessary violence causing physical injury or long-lasting psychological trauma (Bonner, Lowe, Rawcliffe, \& Wellman, 2002; Eriksson \& Westrin, 1995; Greenberg, Moore-Duncan, \& Herron, 1996; Haglund, Von Knorring, \& Von Essen, 2003; Hoekstra et al., 2004). There are reports of retraumatisation among female patients with a history of sexual abuse (Bonner et al., 2002; Sequeira \& Halstead, 1997). Although surrounded by some controversies (e.g. Meyer, Taiminen, Vuori, Aijala, \& Helenius, 1999), the occurrence of Posttraumatic Stress Disorder (PTSD) caused by coercive treatment has become an area of growing interest and concern in the last years (Frueh et al., 2000). 


\section{Prevention and management}

In view of the negative consequences of aggression in psychiatric institutions, the issue of aggression has become a central concern of professional bodies and governmental agencies, and great efforts are undertaken to improve the situation. Prevention and management of aggression have become part of hospital-wide safety and security policies and programs (Cowman, 2006), and rates of coercive measures are seen as quality-indicators of psychiatric facilities (Stefan, 2006). Adapting to the requirements of evidence based practice (Sackett, Rosenberg, Gray, Haynes, \& Richardson, 1996), several professional bodies edited guidelines for the prevention and management of violence, based on the best available scientific evidence in the field. Examples are the UK-Royal College of Psychiatrists (RCP) guidelines for the Management of imminent violence (RCP, 1998), corresponding guidelines of the Psychiatric Organisations in Canada and Switzerland (Beck \& Roy, 1996; Wengle, Bitterlin, Haug, \& Schaefer, 2000), the report "The recognition, prevention and therapeutic management of violence in mental health care" edited by the United Kingdom Central Council for Nursing, Midwifery and Health Visiting (UKCC, 2002), or, most recently, the Guideline edited by the National Institute for Clinical Excellence NICE (UK) (National Institute for Clinical Excellence NICE, 2005).

All these guidelines emphasise the crucial role of a continuing comprehensive risk assessment as a conditio sine qua non for timely preventive interventions. According to an influential UKCC-report (UKCC, 2002), "the use of comprehensive risk assessment materials, followed by a properly developed plan is an absolute pre-requisite for the recognition, prevention and therapeutic management of violence" (p. 22). In line with this, one of the focal topics covered by the recent NICE-Guidelines is anticipation of risk-situation and adequate risk-assessment (National Institute for Clinical Excellence NICE, 2005). Furthermore, it has been argued that risk assessment "must be seen as an essential intervention, possibly the single most important intervention, in the therapeutic management of disturbed/violent behaviour" (National Institute for Clinical Excellence NICE, 2004, p. 44).

However, in some contrast to the ubiquitous claim of the importance of risk prediction, there is lack of scientific evidence both with regard to instruments best suitable for clinical risk-prediction as well as for the potential of systematic risk prediction to reduce aggression in psychiatric inpatient (National Institute for Clinical Excellence NICE, 2005). Additionally, and even more concerning, are reports on insufficient implementation of recommended practices. According to the results of a 
large UK-survey among acute psychiatric services (which is one of the few documents describing current practice), "... structured risk assessment is rarely used by nurses, psychiatrists or other agencies ... risk assessments (...) may not be communicated to all staff ... risk management (...) is poorly defined and practice is highly variable" (SNMAC, 1999, p. 15).

Based on such considerations, the main goal of this dissertation is to contribute to the development of accurate clinical risk prediction that will enable targeted and timely preventive measures and to extend the knowledge regarding the potential of such practice to reduce aggression.

However, working on risk prediction requires the consideration of theoretical questions regarding factors known as associated with the development and the dynamics of aggressive behaviour and of scientific evidence on approaches to assess the risk.

\section{Risk assessment}

\subsection{Theoretical frameworks relevant to risk assessment}

Theoretical conceptualizations to explain aggressive behaviours have been proposed by a wide range of disciplines including anthropology, psychology, biology, economy, political science, communication research, history, and sociology (Bjorkly, 2006; Steinert, 1995). Of particular importance to the study of interpersonal aggression in psychiatric environments are psychological and sociological theories. The aim of the theoretical work in this field is to clarify factors contributing to the occurrence of aggressive behaviour, and, eventually, to indentify factors suitable for preventive or therapeutic modification. Factors known to have an influence on the occurrence and modulation of aggression are at the same time possible risk- and/or protective factors. In the following section, three theoretical approaches will be described in brief, and the descriptions will be illustrated with empirical findings from research on aggression and violence in psychiatric contexts. The three theoretical approaches have some overlap, but each stresses specific aspects not included in the others.

The three frameworks are a) the General Aggression Model (GAM) formulated by Anderson and Bushman (2002), b) a conceptual framework specifically focusing on aggression in psychiatric wards by Nijman et al (2002), and c) a framework based on socio-psychological theories of human interactions (Whittington \& Richter, 2006a). 


\section{General Aggression Model (GAM)}

In an attempt to combine several domain-limited psychological theories Anderson and Bushman (2002) formulated the General Aggression Model (GAM). This model integrates various factors and mechanisms known to contribute to aggression. The GAM focuses on an episode of aggressive behaviour, consisting of a cycle of ongoing social interaction. The model explains personal and situational input factors, cognitive, affective and arousal routes through which these input factors have their impact, and, as outcome of these mechanisms, appraisal- and decision processes leading to either thoughtful or impulsive aggressive actions.

Figure 1: General Aggression Model GAM

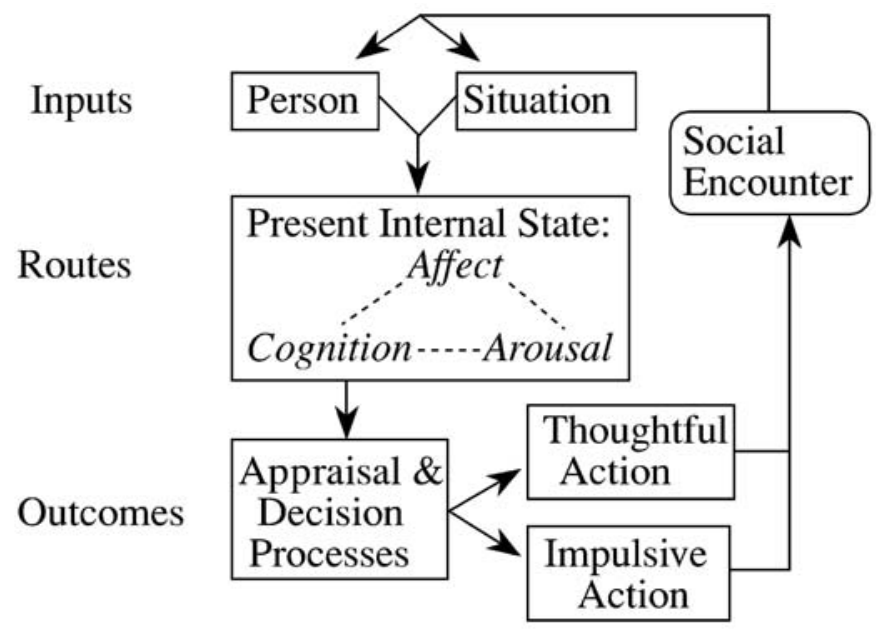

Personal factors relevant to aggression include trait-factors (e.g. hostility, suspectiveness, and self-esteem), gender, beliefs (e.g. self efficacy), attitudes, values (e.g. personal honor), interpretational and behavioural scripts. Situational factors relevant in the development of aggression are aggressive cues (e.g. presence of weapons), provocation (e.g. insults, slights and other forms of verbal aggression, perceived injustice), frustration, pain and discomfort, drugs, and incentives. Personal and situational input variables influence the resulting behaviour along three routes through the internal states they create, e.g. internal states of cognition, affect and arousal (Anderson \& Bushman, 2002, p. 38ff). Cognition related internal states are hostile thoughts and scripts, while affect states include mood and emotion, e.g. negative or aggressive affects that can set the stage for later aggressive behaviour. 
Input variables can lead to increased physiological and psychological arousal and add to the readiness for aggressive behaviour. Personal and situational inputs, mediated by cognition, affect and arousal, flow into appraisal and decision processes crucial for the behaviour someone exhibits in the situation. While the immediate appraisal is automatic, it is often followed by reappraisal processes that include searching for an alternative view of the situation, allowing a less spontaneous but more thoughtful action. As a result of these reappraisal processes a choice is made for aggressive or non-aggressive behaviours. This behaviour is the input of the individual into the social encounter. The quality of this interaction will further influence the personal and situational input.

\section{A model of aggression on inpatient psychiatric wards}

Based on results of studies on aggression in psychiatric wards, Nijman (1999; 2002) presented a model in which psychopathology and distorted cognitions of the patient are combined with environmental and communicational stressors that are specific for psychiatric wards. The basic assumption is that patient aggression in psychiatric wards is the result of the interplay of patient, staff and ward-environment-related factors.

Figure 2: A model of aggression on inpatient psychiatric wards (Nijman, 2002)

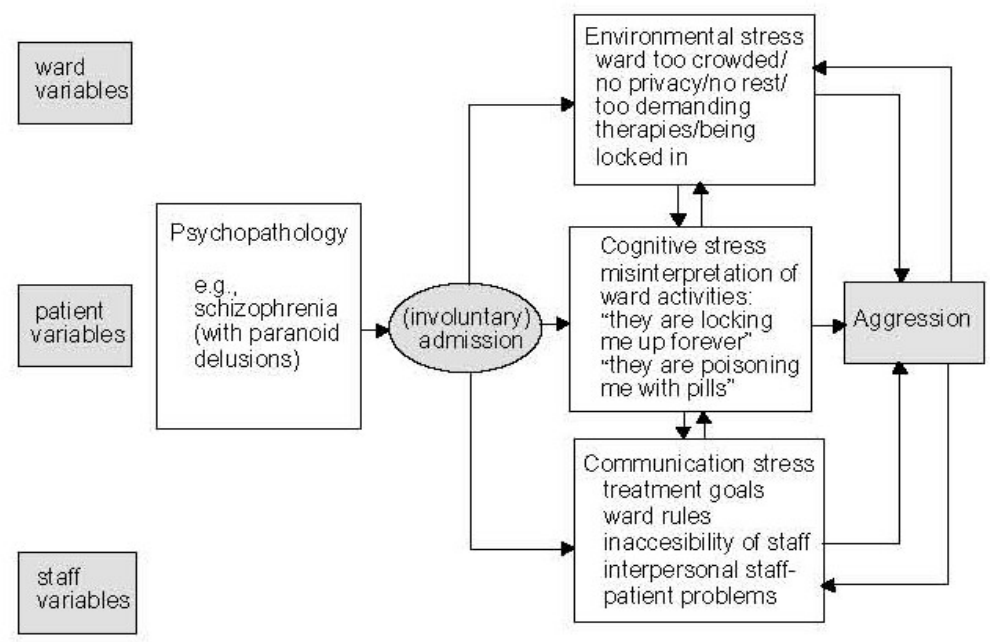

Patient factors include psychopathology, diagnosis, beliefs etc. as well as behavioural patterns. Staff related factors include staff behaviour patterns of communicating or 
limit setting as well as attitudes, professional education level and experience, anxiety, anger and other psychological states, etc. Ward variables include environmental stressors encompass ward rules, therapies, restrictions of free movement, crowding etc.

\section{Interactional theories}

Recently, interactional theories are gaining attention as a possible framework to describe and explain aggression (Whittington \& Richter, 2005, 2006a). This approach emphasises the interpersonal character of human aggression, as concisely summarised by Cox \& Leather (1994): "Human aggression is typically the product of interpersonal interactions wherein two or more persons become involved in a sequence of escalating moves and counter moves, each of which successively modifies the probability of subsequent aggression" (p. 222). This view replaces the focus on psychiatry-specific factors by an approach of "normalizing" aggression and considering it just as or similar to aggression found by healthy people (Whittington \& Richter, 2005).

Figure 3: A model of the emergence of violence in psychiatric settings (Richter 2007)

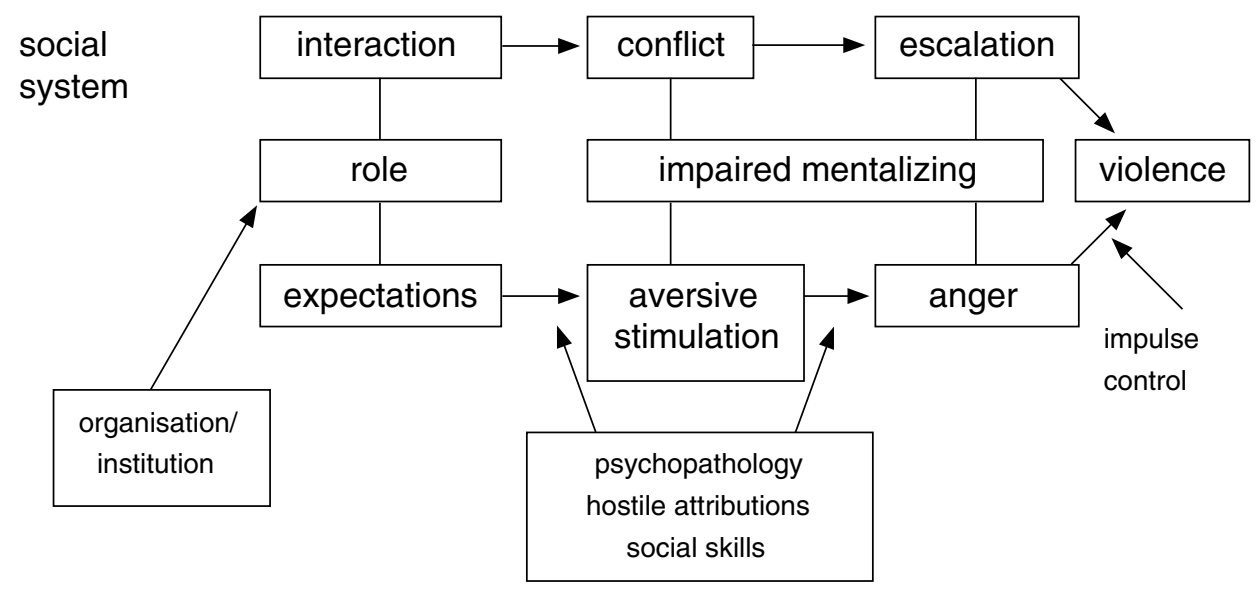

The interactional perspective on aggression takes several psychological and sociological concepts into account. These include the concept of mutual attribution, double contingency, impaired mentalizing, aversive stimulation and respective coping behaviour (Whittington \& Richter, 2006a), and, conceptualisations of phases of escalation (Breakwell, 1995), etc. The concepts of mutual attribution and double 
contingency stress the importance of reciprocal expectations as factors affecting the behaviour in conflict situations. Both staff and patients are seen as reacting towards each other based on uncertainty and assumptions about intentions of their vis-à-vis. The concept of escalation-phases put emphasis on precursors or early stages of conflicts where preventive or deescalating action remains possible (Breakwell, 1995).

\subsection{Research on factors correlated with aggression in psychiatric settings}

Based on the theoretical frameworks presented above, several factors emerge that might be relevant as factors that could be useful in considering the anticipation of aggressive incidents or in determining the likelihood of such events. Risk factors can be grouped in personal factors, environmental factors and interactional factors. Personal factors, encompassing stable (trait) or historical as well as dynamic (state) or behavioural variables, refer to characteristics of patients and staff; environmental factors refer to physical and social characteristics of the treatment setting, usually to a hospital ward, and can include stable or fluctuating aspects; interactional factors refer to the dynamics of interrelated behaviour of staff and patients when encountering each other.

Personal factors of patients: There is a plethora of studies in psychiatry investigating correlations of patient personal factors with aggressive or violent behaviour. However, summarizing a comprehensive review of studies on a large number of patient variables, Steinert (2006) points that "previous violent behaviour is the only robust predictor of violent inpatient behaviour since many studies confirmed this finding and no contra dictionary findings have been published" (p. 113). This applies to aggression in previous inpatient treatment episodes as well as to previous violent behaviour in the community, including domestic violence.

Results regarding other patient characteristics remain contradictory and vary according to different samples and types of aggression studied. For example, this is the case for age, gender and psychiatric diagnoses. Comparable numbers of studies found higher rates of aggression among men, women, or no gender related differences (Steinert, 2006). The relationship of gender to the incidence of aggression appears complex and study results vary according to different types of aggression studied (Krakowski \& Czobor, 2004). The role of age is equally inconclusive. In some studies no association of patients' age to the occurrence of aggression was observed (Barlow, Grenyer, \& IlkiwLavalle, 2000; Mellesdal, 2003), while younger age was found to be a risk factor in several others (Chou, Lu, \& Mao, 2002; Grassi, Peron, Marangoni, Zanchi, \& Vanni, 
2001; Kho, Sensky, Mortimer, \& Corcos, 1988; Nijman, Allertz, àCampo, \& Ravelli, 1997).

In some studies, psychiatric diagnoses were not related to an increased risk for aggression (Kho et al., 1988; Nijman et al., 1997; Ruesch, Miserez, \& Hell, 2003). In contrast, others found patients with distinct diagnoses more likely to be involved in aggressive incidence, e.g. patients with schizophrenia (Barlow et al., 2000; Grassi et al., 2001; Mellesdal, 2003), psychotic disorder (Chou et al., 2002), bipolar affective disorder, personality disorders, conduct disorders (Barlow et al., 2000), organic mental disorders (Mellesdal, 2003). However, the utility of diagnoses as risk factor has been questioned by several authors, pointing to the behavioural variation within diagnostic groups and the changes in symptomatology in the course of the illness (Mellesdal, 2003). In line with this, severity or acuity of illness was identified as more reliable predictors of aggression than diagnoses (Ruesch et al., 2003). In addition, there is no evidence for a consistent association of single psychopathological symptoms like hallucinations, delusions etc. with aggressive inpatient behaviour.

Personal factors in staff: While it has been suggested that "staff attitudes and behaviour may [be] the most important factors modulating aggressive behaviour" (Moldin 1984, cited in Davis, 1991, p. 587), there is little evidence from empirical studies for this proposition. This is particularly true for staff attitudes. However, there is some support for the importance of staff behaviour as trigger for aggressive behaviour of patients. Whittington (1997) found some evidence for an association between social distancing by staff and patient violence. In several studies, some forms of staff behaviour appeared as trigger for subsequent patient aggression (e.g. provocative behaviour of staff, leading to experiences of frustration or injustice, unempathic limit-setting styles) (Blair, 1991; Cooper \& Mendonca, 1989; Crowner, Peric, Stepcic, \& Ventura, 1995; Lancee, Gallop, McCay, \& Toner, 1995; Oberleitner, 2000; Richard Whittington \& Wykes, 1996).

Environmental factors: Despite of a growing interest for aggression relevant factors rooted in the ward environment, few empirical studies exist to date which have examined the role of these factors. In some studies, crowding has been identified as a factor increasing the risk of aggressive behaviour on the respective ward (Lanza, Kayne, Hicks, \& Milner, 1994; Ng, Kumar, Ranclaud, \& Robinson, 2001; Nijman \& Rector, 1999; Palmstierna, Huitfeldt, \& Wistedt, 1991). According to one German study, the concentration of the most severely ill patients into one ward in a hospital increases the incidence of aggression (Gebhardt \& Steinert, 1999). There is only weak 
evidence for the frequently discussed impact of size and staffing level of a ward on aggression (Lanza et al., 1994). In some studies, associations between aspects of organisational culture or the ward atmosphere could be established. In an observational study, Morrison (1990b) identified a "tradition of toughness" in the wards as a factor that can promote violent behaviour of patients. According to Katz (1990) and Flannery (1996), violence was more frequent and more extreme in wards with unclear structures, procedures, and leadership. Other aspects discussed are inactivity vs. over-demanding programs and flexibility/inflexibility of ward rules.

Interactional factors: Despite the convincing theoretical and anecdotal arguments in favour of this perspective, very little empirical research in psychiatric inpatient settings has focused on interactional factors contributing to aggression to date. However, sources of supportive evidence for the role of interaction in the emergence of aggressive conflicts are studies on attributions of staff and patients. According to several studies on this topic, there is a tendency of staff to stress the importance of patient-related internal causes to be mainly responsible for aggressive incidents; patients, on the other hand, tend to focus on interpersonal and environmental factors as leading cause for aggression and escalation (Abderhalden, Hahn, Bonner, \& Galeazzi, 2006; Whittington \& Richter, 2006a).

\subsection{Research on risk assessment methods}

Within the last decades, a considerable amount of research has been published on the prediction of aggression in psychiatric populations (Borum, 1996; Harris \& Rice, 1997; Mossman, 1994; Allen, 1997; Ferris et al., 1997).

Generally spoken aggression prediction falls into two categories: actuarial (or „statistical“) methods and clinical prediction models derived from acute patient observation (Dolan \& Doyle, 2000; Doyle \& Dolan, 2002; Rice, Harris, \& Quinsey, 2002). In research, the "clinical“ approach encompasses studies using clinical judgments as method for prediction, the "actuarial“ approach focuses on the identification and use of risk-factors as a basis for the assessment of risk (e.g. age, gender, diagnosis, history of violent behaviour).

Actuarial models predict risk from the presence of statistically derived risk factors like age, gender, psychopathological state, diagnosis etc. Most studies using this method found that patients who had exhibited violent behaviour in the past were substantially more likely to become aggressive during a new hospitalization than those with no history of aggressive behaviour (Ruesch et al., 2003; Steinert, 2002). 
Controversy exists on evaluating the two approaches. Some authors stress the superiority of the actuarial approach, others point to the limited value of this approach in clinical practice. Harris \& Rice (1997) summarize the findings of their review of empirical work on appraisal of the risk of violence in the following way: "Risk appraisal research indicates that violence is predictable in some populations. The factors most highly and consistently related to risk are historical, including age, sex, past antisocial and violent conduct, psychopathy, aggressive childhood behaviour, and substance abuse. Major mental disorder and psychiatric disturbance are poor predictors of violence. Actuarial methods are more accurate in predicting risk than unaided clinical judgment, which is a poor index".

However, actuarial tools predominantly used as research instruments and seem to be widely ignored in clinical practice (Allen, 1997; Steadman et al., 2000). One reason might be that the administration of existing tools is very time consuming and requires trained users (Almvik, Woods, \& Rasmussen, 2000; Monahan et al., 2000), another reason may be the fact that they have mainly been validated in forensic populations and are intended to predict into the distant future.

Of the 44 studies included in the review of Mossman (1994), only eight covered a time frame for the prediction of seven days or less. This is of special importance with regard to acute care, where most of the aggressive incidences occur shortly after admission or within the first few days of hospitalisation (Steinert, Wolfle, \& Gebhardt, 2000). The state of acute psychiatric patients often changes rapidly and calls for short-time predictions (Steinert, 2006).

Some authors question the value of the actuarial (risk-factor-based) approach for settings like acute wards in general psychiatry. Steinert (2006) points to the dynamic change of the risk in acute patients and argues that the risk in this setting "cannot be considered as a static property" of the patients (p.112). Palmstierna and Wistedt (1989) found that "risk factors associated with aggressive behaviour are of limited value in predicting aggressive behaviour among acute involuntarily admitted inpatients". In that study, only violent behaviour prior to hospitalisation and drug use, other than alcohol, were found to be weakly correlated with subsequent aggression.

The main criticisms advanced towards the utilization of actuarial methods in acute settings is a) that they discard the experience of the staff currently dealing with the patient, b) that they do not consider interactional and situational factors, c) that they perform poorer in non-forensic or acute settings (Palmstierna \& Wistedt, 1989; Steinert, 2002), d) that they ignore rapid behavioural changes during acute phases of 
illness, and e) that they require the collection of data that may not be readily available in acutely admitted patients (Allen, 1997; Steadman et al., 2000).

Only a minority of studies focuses on short-term prediction of aggression in psychiatric acute wards. In a systematic search for empirical studies on the short-term prediction of aggression in acute settings, only 17 qualitatively good studies could be identified (RCP, 1998), and the authors emphasize the heterogeneity of the studies with regard to settings, patient characteristics, periods covered, instruments used, methods of analysis, etc. In conclusion, they state that "the studies do not provide a clear consensus on items that would be clinically useful for short-term prediction across a variety of clinical settings". Nevertheless are there a number of studies employing clinical methods in the short-term prediction of aggression. A review of Mossman (1994) included 6 such studies using clinical judgment. He extracted data from the original papers and performed a receiver operating characteristic (ROC) analysis to compare the accuracy of the predictions. The average accuracy of the 6 short time period studies equals an Area under the Curve (AUC) of .6877 ( \pm 0.0333 ). Several studies place the emphasis on the staff's ability to judge the risk by integrating all available information into a formal subjective risk prediction statement. This subjective prediction is operationalised by Likert-type scales or Visual Analogue Scales (Haim, Rabinowitz, Lereya, \& Fennig, 2002; McNiel, 1991; McNiel \& Binder, 1995; H. Nijman, Merckelbach, Evers, Palmstierna, \& a Campo, 2002; Rabinowitz \& Garelik-Wyler, 1999). McNiel \& Binder (1995) found that estimates of the risk of violence on a 0-100 $\mathrm{mm}$ scale provided by staff members working on acute psychiatric admissions wards had a sensitivity of $67 \%$, a specificity of $69 \%$ and a positive predictive power of $29 \%$, and Nijman et al, applying the same approach, found correct prediction rates of $75 \%$ (2002). Similarly, the proportion of all correctly predicted cases exceeded $80 \%$ in a study of clinical prediction by Haim et al (2002). Rabinowitz (1999) used a 5-point scale $(0-25-50-75-100 \%)$ to assess the probability of violence in newly admitted patients and found a total predictive value of $61 \%$. In two studies (Haim et al., 2002; McNiel, 1991) the risk assessments of nurses and physicians were compared with the two groups performing equally. These results suggest that psychiatrists and psychiatric nurses make similarly accurate predictions of violence. However, in the majority of systematic studies on the short-term prediction of violence, the raters are physicians although risk assessment has been described as an important task of the nursing staff.

Retrospectively, nurses assess violent incidences for the most part as predictable, based on clinical observation of the patient's behaviour prior to the violent incident (Fagan-Pryor, Femea, \& Haber, 1994; Geser, 1999). In addition, in several studies 
behaviours of patients were identified that were registered within the hours preceding violent incidents, and it has been suggested to integrate them into risk-assessmenttools (Kay, Wolkenfeld, \& Murrill, 1988; Linaker, 1995; Novaco, 1994). In the study of Linaker et al (1995) the six most frequently reported changes in behaviour during a 24hour period prior to a violent incident recorded in the nursing notes were confusion, irritability, boisterousness, physical threats, verbal threats, and attacks on objects. According to logistic regression analysis, these behaviours predict a physical attack within the next 24 hours. The results of this study led to the development of the Norwegian Brøset-Violence-Checklist, which is an instrument for the short-time prediction of violence in psychiatric inpatients to be used by nurses (Almvik \& Woods, 1998; Almvik et al., 2000).

The Brøset-Violence-Checklist (BVC) is a 6 item instrument created to predict physical aggression of inpatient psychiatric patients within a 24-hour-period following rating (Almvik et al., 2000). Six behaviours are rated by nurses as being present $(=1$ ) or absent $(=0)$ : confusion, irritability, boisterousness, physical threats, verbal threats, and attacking objects (see table 1). A score of zero is interpreted as a "small risk", a score of one-two as a "moderate risk“(preventive measures should be taken). A score of three or more indicates a "very high risk" requiring immediate preventive measures and the planning of interventions for the expected attack. The rating is performed twice a day within the first three days of hospitalisation, $2 \frac{1}{2}$ hours after the beginning of a shift. The instrument was tested on 109 patients in a Norwegian study. Twelve of the patients were involved in 34 incidents with incidents defined as physical attacks on staff (Almvik \& Woods, 1998; Almvik et al., 2000). 901 ratings were taken. Interraterreliability is reported with percentages of agreement of $90 \%-100 \%$ and Kappa values of 0.48 to 1.00 (Almvik \& Woods, 1998). The behaviours represented in the BVC-items were significantly more frequently observed in patients involved in an incident compared with patients not involved (Chi-square test, $p<0.001$ ). Using a cut-off of two ore more points, the sensitivity of the instrument is reported as 0.74 and the specificity as 0.91 . The resulting positive predictive value was thus 0.11 and the negative predictive value 0.97 . With regard to these results, the BVC seems to be a promising, easy to use clinical tool to systematize and improve the short-term assessment of the risk of aggression among psychiatric inpatients. So far, the instrument has not been tested outside of Norway. It is one of the goals of this dissertation project to test the applicability and predictive capacity of this instrument in Swiss psychiatry. 


\subsection{Ethics and risk assessment}

Risk assessment and risk management have been related to several ethical questions (McGuire, 2004). The underlying dilemma stems from difficulties to reach an equilibrium between the rights and interests of the patient assessed and the safety rights and interests of potential victims, or, more generally spoken, from conflicting public and individual interests, and professionals may be confronted with conflicting loyalties (McGuire, 2004, Szmukler, 2003).

One aspect frequently discussed relates to negative implications of risk assessment in general as well as negative aspects in individual patients. The emphasis on risk in mental health services has been criticised for diverting resources towards few patients assumed risky and away from the majority of patients posing no risk (Szmukler, 2003). Overestimation of risk may led to "more custodial care that is not only useless for society but bears extremely high costs for those many patients falsely predicted to become violent" (Palmstierna, 1999, p. 1270). Some authors put the ethical question in relation to the high probability of errors and the relatively low proportion of correct predictions and question the ethical acceptability of routine application of related instruments to all patients (Palmstierna, 1999). The application of routine assessment of dangerousness to people with mental illnesses (and not to potentially dangerous non-mentally ill persons) is contrasted to their low prevalence rate of violence and seen as a discriminative and therefore violating the ethical principal of 'fairness' or 'justice' (Szmukler, 2003). Similarly, it has been criticised that 'risk assessment' in psychiatry is restricted to risk rooted in the patient, and neglecting the risks which patients face (Heyman, 2004).

The potential disadvantages for patients are false positive risk assessments (the assessment indicates a patient potentially violent patient when in fact the adverse is true), a phenomenon commonly associated with the application of structured risk assessment tools. Such assessments could result in a patient unjustifiably receiving coercive treatments and being subjected to stigmatisation (Bingley, 1997; Szmukler, 2001; Szmukler, 2003). This would contradict to the ethical norms of non-maleficence (do no harm) and beneficence (act in the best interest of the patient). In line with this, it has been argued that the ethical acceptability of an instrument depends on its predictive accuracy (McGuire, 2004). However, while most of the ethical discussions around risk assessment are concerned about threats to patient rights and potential negative impact it may have, a duty of employees to protect co-workers from injuries 
has also been ethically justified (Cowman, 2006). Following this argument, the problem would be placed in the proportion of false negative ratings.

Other ethical principles relevant to risk assessment may be 'veracity' (truthfulness, honesty), 'confidentiality', and 'fidelity' (promise keeping, loyalty) (Shinn et al., 1998). According to the principle of 'veracity', the result of the risk assessment should be openly communicated to the patient assessed. However, usual practice does not comply with this standard. 'Confidentiality' is in potential conflict with the information of third parties on results of risk assessments, while the identification of a risk for violence may interfere with promises given to a patient.

\section{Research questions}

Based on the literature findings reviewed above, the two main research issues of the present dissertation were derived.

Firstly, the lack of research on inpatient aggression and aggression management in German speaking Switzerland led to questions 1 to 4 concerning the scope of the problem in this area.

Secondly, the importance of risk assessment and management and the need for accurate and clinically useful instruments led to questions 4 to 8 , concerning the development and clinical application of structured clinical assessment of the short-tern risk for violence among acute psychiatric patents.

Specifically, the following questions will be addressed in the two parts of this dissertation:

\section{Part I:}

1. To what amount are psychiatric nurses in German speaking Switzerland exposed to aggression and violence in their work-life? (Chapter 1)

2. What is the attitude of psychiatric nurses in German speaking Switzerland towards aggression? (Chapter 1 )

3. How is the current practice of aggression management in acute psychiatric wards in German speaking Switzerland? (Chapter 2)

4. What is the nature and frequency of aggressive incidents in acute psychiatric wards in German speaking Switzerland? (Chapter 3) 
Part II:

5. What are the predictive properties of a German version of the Brøset Violence Checklist when applied in acute wards in Switzerland? (Chapter 4)

6. What are the predictive properties of an unaided subjective assessment of the risk for aggression compared to the structured assessment of the Brøset Violence Checklist? ( Chapter 5)

7. What are the predictive properties and how is the clinical applicability of a combination of a subjective assessment of the risk for physical attacks with the Brøset Violence Checklist? (Chapter 5)

8. Does the systematic assessment of the risk for violence in newly admitted psychiatric patients lead to a reduction of aggressive incidents or coercive measures? (Chapter 6).

The following research model (Figure 4) gives an overview how the aspects studied are situated within a broader perspective on aggression in in-patient psychiatry:

Figure 4: Research model

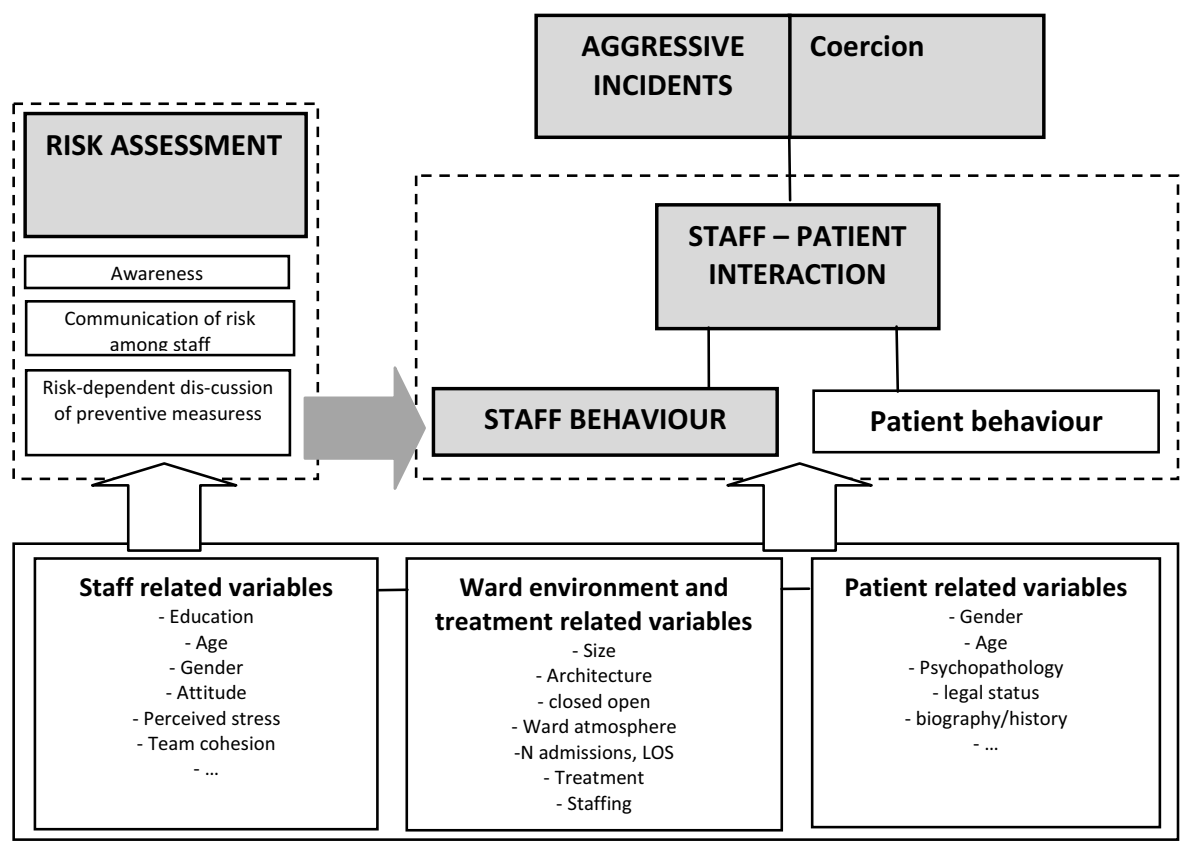


Questions 1 to 3 concern ward and staff related variables (lower end of the figure), question 4 relates to aggressive incidents (upper end of the figure).

Risk assessment (left side in the centre) is covered by questions 5, 6 und 7.

Question 8 concerns the relationship between risk-assessment and aggressive incidents. Awareness of risk, communication of risk and risk-dependent discussion of preventive measures are hypothesised ways in which risk assessment may influence staff behaviour. Staff and patient behaviour and interaction are seen as subsystem mediating the influence of risk assessment on aggression and coercion.

\section{References}

Abderhalden, C., Hahn, S., Bonner, Y. D. B., \& Galeazzi, G. (2006). Users' Perceptions and Views on Violence and Coercion in Mental Health. In R. Whittington \& D. Richter (Eds.), Violence in Mental Health Sciences (pp. 69-92). New York: Springer.

Allen, J. (1997). Assessing and managing risk of violence in the mentally disordered. J Psychiatr Ment Health Nurs, 4, 369-378.

Almvik, R., \& Woods, P. (1998). The Broset Violence Checklist (BVC) and the prediction of inpatient violence: Some preliminary results. Perspect Psychiatr Care, 5(6), 208-211.

Almvik, R., Woods, P., \& Rasmussen, K. (2000). The Broset Violence Checklist: Sensitivity, Specificity and Interrater Reliability. J Interpers Violence, 15(12), 1284-1296.

American Psychiatric Association. (1974). Task force on clinical aspects of the violent individual. Washington DC: APA.

Anderson, C. A. (2000). Violence and Aggression. In A. E. Kazdin (Ed.), Encyclopedia of psychology (pp. 162169). New York: Oxford University Press and American Psychological Association.

Anderson, C. A., \& Bushman, B. J. (2002). Human aggression. Annu Rev Psychol, 53, 27-51.

Apel, D., \& Bar-Tal, Y. (1996). Nursing staff responses to violent events in closed psychiatric wards: a comparison between attributional and cognitive-neo-associationistic analyses. Br J Soc Psychol, 35(Pt 4), 509-521.

Bandura, A. (1973). Aggression: a social learning analysis. New York: Prentice-Hall.

Barlow, K., Grenyer, B., \& Ilkiw-Lavalle, O. (2000). Prevalence and precipitants of aggression in psychiatric inpatient units. Aust N Z J Psychiatry, 34(6), 967-974.

Basaglia, F. (Ed.). (1981). Die negierte Institution oder Die Gemeinschaft der Ausgeschlossenen. Frankfurt a.M.: Suhrkamp.

Beck, P. R., \& Roy, R. (1996). Assaultive and Destructive Behaviour in a Treatment Setting: Guidelines for the Psychiatrist (Position paper, Canadian Psychiatric Association). NN: Canadian Psychiatric Association.

Bensley, L., Nelson, N., Kaufman, J., Silverstein, B., Kalat, J., \& Shields, J. (1997). Injuries due to assaults on psychiatric hospital employees in Washington State. Am J Ind Med, 1(1), 92-99.

Bingley, W. (1997). Assessing dangerousness: Protecting the interests of patients. Brit J Psychiatry, 170(suppl. 32), 28-29. 
Bjorkly, S. (2006). Psychological Theories of Aggression: Principles and Application to Practice. In R. Whittington \& D. Richter (Eds.), Violence in Mental Health Sciences (pp. 27-46). New York: Springer.

Blair, D. (1991). Assaultive behavior. Does provocation begin in the front office? J Psychosoc Nurs Ment Health Serv, 9(5), 21-26.

Bonner, G., Lowe, T., Rawcliffe, D., \& Wellman, N. (2002). Trauma for all: a pilot study of the subjective experience of physical restraint for mental health inpatients and staff in the UK. J Psychiatr Ment Health Nurs, 9(4), 465-473.

Borum, R. (1996). Improving the clinical practice of violence risk assessment. Technology, guidelines, and training. Am-Psychol., 1(9), 945-956.

Bowers, L. (2000). The expression and comparison of ward incident rates. Issues Ment Health Nurs, 21(4), 365-374.

Breakwell, G. (1995). Theories of violence. In B. Kidd \& C. Stark (Eds.), Management of violence and aggression in health care (pp. 1-11). London: Gaskell.

Budd, T. (1999). Violence at work: Findings from the British Crime Survey. London: Home Office.

Cahn, T. (1995). Gewalt - Element des psychiatrischen Berufes. Schweizer Archiv für Neurologie, Neurochirurgie und Psychiatrie, 146(3), 109-114.

Carmel, H., \& Hunter, M. (1989). Staff injuries from inpatient violence. Hosp Community Psychiatry, 40(1), 41-46.

Carmel, H., \& Hunter, M. (1993). Staff injuries from patient attack: five years' data. Am Acad Psychiatry Law, 21(4), 485-493.

Chambers, N. (1998). 'We have to put up with it--don't we?' The experience of being the registered nurse on duty, managing a violent incident involving an elderly patient: a phenomenological study. J Adv Nurs, $27(2), 429-436$.

Chappell, D., \& Di Martino, V. (2000). Violence at work (2 ed.). Geneva: ILO.

Chou, K. R., Lu, R. B., \& Mao, W. C. (2002). Factors relevant to patient assaultive behavior and assault in acute inpatient psychiatric units in Taiwan. Arch Psychiatr Nurs, 16(4), 187-195.

Cooper, A., \& Mendonca, J. (1989). A prospective study of patient assaults on nursing staff in a psychogeriatric unit. Can J Psychiatry, 34(5), 399-404.

Cowman, S. (2006). Safety and Security in Psychiatric Hospitals. In R. Whittington \& D. Richter (Eds.), Violence in Mental Health Sciences (pp. 253-271). New York: Springer.

Cox, T., \& Leather, P. (1994). The prevention of violence at work: Application of a cognitive behavioral theory. International Review of Industrial and Organizational Psychology, 9, 213-245.

Crowner, M., Peric, G., Stepcic, F., \& Ventura, F. (1995). Psychiatric patients' explanations for assaults. Psychiatr Serv, 46(6), 614-615.

Davis, S. (1991). Violence by psychiatric inpatients: a review. Hosp Community Psychiat, 2(6), 585-590.

Dolan, M., \& Doyle, M. (2000). Violence risk prediction. Clinical and actuarial measures and the role of the Psychopathy Checklist. Br J Psychiatry, 177, 303-311.

Doyle, M., \& Dolan, M. (2002). Violence risk assessment: combining actuarial and clinical information to structure clinical judgements for the formulation and management of risk. J Psychiatr Ment Health Nurs, 9(6), 649-657.

Eriksson, K. I., \& Westrin, C. G. (1995). Coercive measures in psychiatric care. Reports and reactions of patients and other people involved. Acta Psychiatr Scand, 92(3), 225-230.

Fagan-Pryor, E. C., Femea, P., \& Haber, L. C. (1994). Congruence between aggressive behavior and type of intervention as rated by nursing personnel. Issues Ment Health Nurs, 15(2), 187-199.

Ferris, L., Sandercock, J., Hoffman, B., Silverman, M., Barkun, H., Carlisle, J., et al. (1997). Risk assessments for acute violence to third parties: a review of the literature. Can-J-Psychiatry., 42(10), 1051-1060. 
Finnema, E. J., Dassen, T., \& Halfens, R. (1994). Aggression in psychiatry: A qualitative study focusing on the characterization and perception of patient aggression by nurses working on psychiatric wards. $J$ Adv Nurs, 19, 1088-1095.

Finzen, A., Haug, H. J., Beck, A., \& Lüthy, D. (1993). Hilfe wider Willen: Zwangsmassnahmen im psychiatrischen Alltag. Bonn: Psychiatrie-Verlag.

Flannery, R., Hanson, M., \& Penk, W. (1995). Patients' threats. Expanded definition of assault. Gen Hosp Psychiatry, 17(6), 451-453.

Flannery, R. B., Hanson, M. A., Penk, W. E., \& Flannery, G. J. (1996). Violence and the lax milieu?: preliminary data. Psychiatr $Q, 67(1), 47-50$.

Frueh, B. C., Dalton, M. E., Johnson, M. R., Hiers, T. G., Gold, P. B., Magruder, K. M., et al. (2000). Trauma within the psychiatric setting: conceptual framework, research directions, and policy implications. $A d m$ Policy Ment Health, 28(2), 147-154.

Frueh, B. C., Knapp, R. G., Cusack, K. J., Grubaugh, A. L., Sauvageot, J. A., Cousins, V. C., et al. (2005). Patients' reports of traumatic or harmful experiences within the psychiatric setting. Psychiatr Serv, 56(9), $1123-$ 1133.

Galtung, J. (1969). Violence, peace and peace research. Journal of Peace Research, 6(3), 167-191.

Gates, D. M., Fitzwater, E., \& Meyer, U. (1999). Violence against caregivers in nursing homes: Expected, tolerated, and accepted. J Gerontol Nurs(4), 12-22.

Gebhardt, R. P., \& Steinert, T. (1999). Should severely disturbed psychiatric patients be distributed or concentrated in specialized wards? An empirical study on the effects of hospital organization on ward atmosphere, aggressive behavior, and sexual molestation. Eur Psychiatry, 14(5), 291-297.

Geser, A. M. (1999). Aggressionen von hospitalisierten psychisch Kranken: Eine systematische Evaluation von knapp 2000 Aggressionsfällen. Unpublished Inaugural-Dissertation zur Erlangung der Doktorwürde, Universität Zürich, Zürich.

Godin, P. (2004). 'You don't tick boxes on a form': A study of how community mental health nurses assess and manage risk Health, Risk \& Society, 6(4), 347-360

Goffman, E. (1961). Asylums: Essays on the social situation of mental patients and other inmates. London: Pelican-Books.

Grassi, L., Peron, L., Marangoni, C., Zanchi, P., \& Vanni, A. (2001). Characteristics of violent behaviour in acute psychiatric in-patients: a 5-year Italian study. Acta Psychiatr Scand, 104(4), 273-279.

Greenberg, W. M., Moore-Duncan, L., \& Herron, R. (1996). Patients' attitudes toward having been forcibly medicated. Bull Am Acad Psychiatry Law, 24(4), 513-524.

Haglund, K., Von Knorring, L., \& Von Essen, L. (2003). Forced medication in psychiatric care: patient experiences and nurse perceptions. J Psychiatr Ment Health Nurs, 10(1), 65-72.

Haim, R., Rabinowitz, J., Lereya, J., \& Fennig, S. (2002). Predictions made by psychiatrists and psychiatric nurses of violence by patients. Psychiatr Serv, 53(5), 622-624.

Haller, R., \& Deluthy, R. (1988). Assaults on staff by psychiatric in-patients: A critical review. British Journal of Psychiatry, 152, 174-179.

Harris, G. T., \& Rice, M. E. (1997). Risk appraisal and management of violent behavior. Psychiatr Serv, 48(9), 1168-1176.

Hell, D. (1989). Zwang - die Achillesferse der Psychiatrie. Pro Mente Sana(3), 6-8.

Heyman, B. (2004). Risk and mental health. Health, Risk \& Society, 6(4), 297 - 301.

Hoekstra, T., Lendemeijer, H. H., \& Jansen, M. G. (2004). Seclusion: the inside story. J Psychiatr Ment Health Nurs, 11(3), 276-283.

Hopton, J. (1995). Control and restraint in contemporary psychiatric nursing some ethical considerations. Journal of Advanced Nursing, 22(1), 110-115. 
Hubschmid, T. (1996). Erfahrungen im Umgang mit Gewalttätigkeit in der psychiatrischen Klinik. PsychiatrPrax., 3(1), 26-28.

Katz, P., \& Kirkland, F. R. (1990). Violence and social structure on mental hospital wards. Psychiatry, 53(3), 262-277.

Kay, S., Wolkenfeld, F., \& Murrill, L. (1988). Profiles of aggression among psychiatric patients. II. Covariates and predictors. J Nerv Ment Dis, 176(9), 547-557.

Kho, K., Sensky, T., Mortimer, A., \& Corcos, C. (1988). Prospective study into factors associated with aggressive incidents in psychiatric acute admission wards. Br J Psychiatry, 172, 38-43.

Kilfedder, C. J., Power, K. G., \& Wells, T. J. (2001). Burnout in psychiatric nursing. J Adv Nurs, 34(3), 383-396.

Krakowski, M., \& Czobor, P. (2004). Gender differences in violent behaviors: relationship to clinical symptoms and psychosocial factors. Am J Psychiatry, 161(3), 459-465.

Krug, E. (Ed.). (2002). World report on violence and health. Geneva: World Health Organization.

Kumar, S., Guite, H., \& Thornicroft, G. (2001). Service users' experience of violence within a mental health system: A study using grounded theory approach. Journal of Mental Health, 10(6), 597-611.

Lancee, W. J., Gallop, R., McCay, E., \& Toner, B. (1995). The relationship between nurses' limit-setting styles and anger in psychiatric inpatients. Psychiatr Serv, 46(6), 609-613.

Lanza, M., Kayne, H., Hicks, C., \& Milner, J. (1991). Nursing staff characteristics related to patient assault. Issues Ment Health Nurs, 12(3), 253-265.

Lanza, M., Kayne, H., Hicks, C., \& Milner, J. (1994). Environmental characteristics related to patient assault. Issues Ment Health Nurs, 15( 3), 319-335.

Larkin, E. P., Murtagh, S., \& Jones, S. J. (1988). A preliminary study of violent incidents in a Special Hospital (Rampton). Brit J Psychiatry, 153, 226-231.

Linaker, O. M., Busch Iversen, H. (1995). Predictors of imminent violence in psychiatric inpatients. Acta Psychiatrica Scandinavica, 92(4), 250-254.

Love, C. C., \& Hunter, M. E. (1996). Violence in public sector psychiatric hospitals. Benchmarking nursing staff injury rates. J Psychosoc Nurs Ment Health Serv, 34(5), 30-34.

McGuire, J. (2004). Minimising harm in violence risk assessment: practical solutions to ethical problems? . Health, Risk \& Society, 6(4), 327-345.

McNiel, D. (1991). Clinical assessment of the risk of violence among psychiatric inpatients. Am J Psychiatry, 148(10), 1317-1321.

McNiel, D., \& Binder, R. (1995). Correlates of accuracy in the assessment of psychiatric inpatients' risk of violence. Am-J-Psychiatry., 152(6), 901-906.

Meehan, T., Vermeer, C., \& Windsor, C. (2000). Patients' perceptions of seclusion: a qualitative investigation. J Adv Nurs, 31(2), 370-377.

Mellesdal, L. (2003). Aggression on a psychiatric acute ward: a three-year prospective study. Psychol Rep, 92(3 Pt 2), 1229-1248.

Meyer, H., Taiminen, T., Vuori, T., Aijala, A., \& Helenius, H. (1999). Posttraumatic stress disorder symptoms related to psychosis and acute involuntary hospitalization in schizophrenic and delusional patients. $J$ Nerv Ment Dis, 187(6), 343-352.

Monahan, J., Steadman, H. J., Appelbaum, P. S., Robbins, P. C., Mulvey, E. P., Silver, E., et al. (2000). Developing a clinically useful actuarial tool for assessing violence risk. Br J Psychiatry 176, 312-319.

Morrison, E.F. (1990a). Violent psychiatric inpatients in a public hospital. Scholarly Inquiry for Nursing Practice, 4(1), 65-82.

Morrison, E.F (1990b) The tradition of toughness: a study of nonprofessional nursing care in psychiatric settings. Image J Nurs Sch 22(1):32-38. 
Morrison, E.F. (1993). Toward a better understanding of violence in psychiatric settings: debunking the myths. Archives of Psychiatric Nursing, 7(6), 328-325.

Mossman, D. (1994). Assessing predictions of violence: Beeing accurate about accuracy. J Consulting Clinical Psychology, 62(4), 783-792.

National Institute for Clinical Excellence NICE. (2004). Clinical Practice Guidelines for the short-erm management of disturbed/violent behaviour in in-patient psychiatric settings and emergency departmments (Draft for 2nd Consultation Period). London: National Institute for Clinical Excellence, NICE.

National Institute for Clinical Excellence NICE. (2005). Violence: The short-term management of disturbed/violent behaviour in in-patient psychiatric settings and emergency departmments (Clinical Guidline 25). London: National Institute for Clinical Excellence, NICE.

Needham, I., Abderhalden, C., Halfens, R. J., Fischer, J. E., \& Dassen, T. (2005). Non-somatic effects of patient aggression on nurses: a systematic review. J Adv Nurs, 49(3), 283-296.

Ng, B., Kumar, S., Ranclaud, M., \& Robinson, E. (2001). Ward crowding and incidents of violence on an acute psychiatric inpatient unit. Psychiatric Services, 52(4), 521-525.

Nijman, H. (1999). Aggressive behavior of psychiatric patients: Measurement, prevalence, and determinants. Unpublished Doctoral thesis, Rijksuniversiteit Limburg, Maastricht.

Nijman, H., aCampo, J., Ravelli, D., \& Merckelbach, H. (1999). A tentative model of aggression on inpatient psychiatric wards. Psychiatr Serv, 60(6), 832-834.

Nijman, H., Bjorkly, S., Palmstierna, T., \& Almvik, R. (2006). Assessing aggression of psychiatric patients: Methods of measutrement and its prevalence. In R. Whittington \& D. Richter (Eds.), Violence in Mental Health Sciences (pp. 11-23). New York: Springer.

Nijman, H., Merckelbach, H., Evers, C., Palmstierna, T., \& a Campo, J. (2002). Prediction of aggression on a locked psychiatric admissions ward. Acta Psychiatr Scand, 105(5), 390-395.

Nijman, H., \& Rector, G. (1999). Crowding and aggression on inpatient psychiatric wards. Psychiatr Serv, 50(6), 831-831.

Nijman, H. L. (2002). A model of aggression in psychiatric hospitals. Acta Psychiatr Scand Suppl(412), 142143.

Nijman, H. L., Allertz, W. W. F., àCampo, J. L. M. G., \& Ravelli, D. P. (1997). Aggressive behavior on an acute psychiatric admission ward. Eur J Psychiat, 11(1), 104-114.

Nijman, H. L. I., Muris, P., Merckelbach, H. L. G. J., Palmstierna, T., Wistedt, B., Vos, A. M., et al. (1999). The Staff Observation Aggression Scale - Revised (SOAS-R). Aggress Behav, 25, 197-209.

Novaco, R. (1994). Anger as a risk factor for violence among the mentally disturbed. In J. Monahan \& $\mathrm{H}$. Steadman (Eds.), Violence and mental disorder: Developments in risk assessment (pp. 21-59). Chicago, London: University of Chicago Press.

Oberleitner, L. L. (2000). Aversiveness of traditional psychiatric patient restriction. Arch Psychiatr Nurs, 14(2), 93-97.

Owen, C., Tarantello, C., Jones, M., \& Tennant, C. (1998). Violence and aggression in psychiatric units. Psychiatr Serv, 49(11), 1452-1457.

Palmstierna, T. (1995). Only about 1 in 30 predictions of assault by discharged psychiatric patients will be correct. BMJ, 271-272.

Palmstierna, T., Huitfeldt, B., \& Wistedt, B. (1991). The relationship of crowding and aggressive behavior on a psychiatric intensive care unit. Hosp Community Psychiatry, 42(12), 1237-1240.

Palmstierna, T., Lassenius, R., \& Wistedt, B. (1989). Evaluation of the Brief Psychopathological Rating Scale in relation to aggressive behavior by acut involuntary admitted patients. Acta Psychiatr Scand, 79 P 313 316 . 
Palmstierna, T., \& Wistedt, B. (1987). Staff observation aggression scale, SOAS: Presentation and evaluation. Acta Psychiatr Scand, 76, 657-663.

Palmstierna, T., \& Wistedt, B. (1989). Risk factors for aggressive behaviour are of limited value in predicting the violent behaviour of acute involuntarily admitted patients. Acta Psychiatr Scand., 1(2), 152-155.

Palmstierna, T., \& Wistedt, B. (1995). Changes in the pattern of aggressive behaviour among inpatients with changed ward organization. Acta Psychiatr Scand, 91, 32-35.

Palmstierna, T., \& Wistedt, B. (2000). Violence in psychiatry, view-points for standardized research. Acta Psychiatr Scand, 102(2), 79-80.

Petterson, I. L., Arnetz, B. B., Arnetz, J. E., \& Horte, L. G. (1995). Work environment, skills utilization and health of Swedish nurses-- results from a national questionnaire study. Psychother Psychosom, 64(1), 20-31.

Rabinowitz, J., \& Garelik-Wyler, R. (1999). Accuracy and confidence in clinical assessment of psychiatric inpatients risk of violence. Int J Law Psychiatry, 22(1), 99-106.

Ray, N. K., Myers, K. J., \& Rappaport, M. E. (1996). Patient perspectives on restraint and seclusion experiences: A survey of New York State psychiatric facilities. Psychiatr Rehabil J, 20(1), 11-18.

RCP, Royal College of Psychiatrists. (1998). Management of imminent violence: clinical practice guidelines to support mental health services (Occasional Paper No. OP41). London: Royal College of Psychiatrists College Research Unit.

Rice, M. E., Harris, G. T., \& Quinsey, V. L. (2002). The Appraisal of Violence Risk. Curr Opin Psychiatry, 15(6), 589-593.

Richter, D. (1998). Gewalt und Gewaltprävention in der psychiatrischen Pflege- eine Übersicht über die Literatur. In D. Sauter \& D. Richter (Eds.), Gewalt in der psychiatrischen Pflege. Bern: Huber.

Richter, D. (2007). Why do mentally ill individuals act aggressively in specific situations? Towards an integration of the individual model and the situational model. Unpublished presentation at the 27th Meeting of the European Violence in Psychiatry Research Group 19. - 21.04 2007, Istanbul

Rix, G. (1987). Staff sickness and its relationships to violent incidents on a regional secure psychiatric unit. $J$ Adv Nurs, 12(2), 223-228.

Rix, G., \& Seymour, D. (1988). Violent incidents on a regional secure unit. J Adv Nurs, 13(6), 746-751.

Rothenburg, A. (1971). On anger. American Journal of Psychiatry, 128, 454-460.

Ruesch, P., Miserez, B., \& Hell, D. (2003). Gibt es ein Täterprofil des aggressiven Psychiatriepatienten? [A risk profile of the aggressive psychiatric inpatient: can it be identified?]. Nervenarzt, 74(3), 259-265.

Sackett, D. L., Rosenberg, W. M. C., Gray, J. A. M., Haynes, R. B., \& Richardson, W. S. (1996). Evidence-based medicine: What it is and what it isn't. British Medical Journal, 312(7023), 71-72.

Sequeira, H., \& Halstead, S. (1997). Use of seclusion, restraint and emergency medication. Br J Psychiatry, $171,288-289$.

Shaw, J. (2000). Assessing the risk of violence in patients (Editorial). British Medical Journal, 320, 1088-1089.

Shinn, L. J., Cipriano, J., Britt, T., Reckling, J. B., Welsh, R., \& Sattler, B. (1998). Ethical Issues and Specific Risk Hazards Faced by Nurses in Their Practice. In L. J. Shinn (Ed.), Take Control: A Guide To Risk Management. St.Louis: American Nurses Association.

Smith, M., \& Hart, G. (1994). Nurses responses to patient anger from disconnecting to connecting. Journal of Advanced Nursing, 20, 643-651.

SNMAC, Standing Nursing and Widwifery Advisory Commitee (1999). Mental health nursing: adressing acute concerns. London: Department of Health.

Steadman, H. J., Silver, E., Monahan, J., Appelbaum, P. S., Robbins, P. C., Mulvey, E. P., et al. (2000). A classification tree approach to the development of actuarial violence risk assessment tools. Law Hum Behav, 24(1), 83-100. 
Stefan, S. (2006). Successful Seclusion and Restraint Reduction Programs as Quality Indicators for Psychiatric Services. Retrieved 20.04.2006, 2006, from http://www.medscape.com/viewprogram/5260_pnt

Steinert, T. (1995). Aggression bei psychisch Kranken. Stuttgart: Enke.

Steinert, T. (2002). Prediction of inpatient violence. Acta Psychiatr Scand Suppl(412), 133-141.

Steinert, T. (2006). Prediction of violence in inpatient settings. In R. Whittington \& D. Richter (Eds.), Violence in Mental Health Sciences (pp. 111-123). New York: Springer.

Steinert, T., Beck, M., Vogel, W., \& Wohlfahrt, A. (1995). Gewalttätige Patienten: Ein Problem für Therapeuten an psychiatrischen Kliniken? Nervenarzt., 66, 207-211.

Steinert, T., \& Gebhardt, R. P. (1998). Wer ist gefährlich? Probleme der Validitat und Reliabilitat bei der Erfassung und Dokumentation von fremdaggressivem Verhalten [Who is dangerous? Problems of validity and reliability in assessment and documentation of socially aggressive behavior]. Psychiatr Prax, 25(5), 221-226.

Steinert, T., Wolfle, M., \& Gebhardt, R. P. (2000). Measurement of violence during in-patient treatment and association with psychopathology. Acta Psychiatr Scand, 102(2), 107-112.

Szasz, T. (1970). Ideology and Insanity. Middlesex: Penguin.

Szasz, T. (1987). Insanity, the Idea and its Consequences. New York: Wiley.

Szmukler, G. (2001). Violence risk prediction in practice. Br J Psychiatry, 178(1), 84-85.

Szmukler, G. (2003). Risk assessment: 'numbers' and 'values'. Psychiatric Bulletin, 27, 205-207.

Tetrick, L. E., \& LaRocco, J. M. (1987). Understanding, prediction, and control as moderators of the relationships between perceived stress, satisfaction, and psychological well-being. J Appl Psychol, 72(4), 538-543.

UKCC, United Kingdom Central Council for Nursing, Midwifery and Health Visiting. (2002). The recognition, prevention and therapeutic management of violence in mental health care. London: UKCC, United Kingdom Central Council for Nursing, Midwifery and Health Visiting.

Vanderslott, J. (1998). A study of incidents of violence towards staff by patients in an NHS Trust hospital. J Psychiatr Ment Health Nurs, 5(4), 291-298.

Wengle, H., Bitterlin, R., Haug, H.-J., \& Schaefer, J. (2000). Qualitätsstandard für die Stationäre Psychiatrie. Aarau: Schweizerische Vereinigung psychiatrischer Chefärzte SVPC.

Whittington, R. (1997). Violence to nurses: prevalence and risk factors. Nurs Stand, 12(5), 49-54; quiz 55-46.

Whittington, R., \& Richter, D. (2005). Interactional aspects of violent behavior on acute psychiatric wards. Psychology, Crime and Law, 11, 1-12.

Whittington, R., \& Richter, D. (2006a). From the Individual to the Interpersonal: Environment and Interaction in the Escalation of Violence in Mental Health Settings. In R. Whittington \& D. Richter (Eds.), Violence in Mental Health Sciences (pp. 47-68). New York: Springer.

Whittington, R., \& Richter, D. (Eds.). (2006b). Violence in Mental Health Settings. New York: Springer.

Whittington, R., Shuttleworth, S., \& Hill, L. (1996). Violence to staff in a general hospital setting. Journal of Advanced Nursing, 24, 326-333.

Whittington, R., \& Wykes, T. (1994). Violence in psychiatric hospitals: are certain staff prone to being assaulted? J Adv Nurs., 19(2), 219-225.

Whittington, R., \& Wykes, T. (1996). Aversive stimulation by staff and violence by psychiatric patients. British Journal of Clinical Psychology, 35(1), 11-20.

Wynn, R., \& Bratlid, T. (1998). Staff's experiences with patient's assaults in a Norwegian psychiatric hospital: A pilot study. Scand J Caring Sci, 12, 89-93. 



\section{Part I:}

Patient aggression in acute psychiatry in the German speaking part of Switzerland 



\section{Chapter 1}

\section{Perception of aggression among psychiatric nurses in} Switzerland

Abderhalden C, Needham I, Friedli TK, Poelmans J, Dassen T (2002) Perception of aggression among psychiatric nurses in Switzerland. Acta Psychiatr Scand, 106 Suppl., 412: 110-117 


\section{Abstract}

Objective: To identify principal components and patterns in the perception of aggression by psychiatric nurses and to explore relationships between the perception of aggression and personal and workplace characteristics.

Method: 729 nurses working in psychiatric inpatient departments of German-speaking Switzerland completed the Perception of Aggression Scale (POAS). Data analysis included factor analysis, group comparisons and Multivariate Analysis of Covariance.

Results: Two plausible factors were identified, representing different dimensions in the perception of aggression and accounting for $35 \%$ of the variance. Firstly, aggression is perceived as dysfunctional/undesirable and, secondly, as functional/comprehensible phenomenon. Only minor differences were found in the perception of aggression with regard to personal characteristics or work environment of the nurses.

Conclusion: Nurses perceive aggression not just as negative phenomenon. The perception of aggression as measured by POAS is independent of many characteristics expected to be related to the perception of violence such as grade of education, work experience etc. 


\section{Introduction}

Aggression and violence and their negative consequences for health, safety and wellbeing of patients and personal is a major concern in inpatient psychiatric care globally. The reduction of the incidence and the negative effects of aggression and violence is thus a challenge for researchers and staff of psychiatric facilities.

According to many theoretical and empirical studies on violence in psychiatry the occurrence of violent incidents as well as their management can be regarded as a product of the interaction of various variables, including patient variables (e.g. psychopathology, gender), environmental/setting variables (e.g. ward characteristics like size of the ward, milieu, crowding), as well as interactional (e.g. aversive stimulation, provocation) and staff variables (e.g. level of professional education, special training aggression management, attitudes) $[1,2,3]$. With regard to these variables, it has been suggested that "staff attitudes and behaviour may \{be\} the most important factors modulating aggressive behaviour" [Moldin 1984, cited in 2, p. 587]. One aspect of the attitude of nurses is their perception of the concept of aggression. Previous research shows a considerable variation of different individual perceptions and definitions among psychiatric nurses: For example, Morrison [4] found great disagreements between nurses in their perception of the seriousness of various forms of aggression manifested in clinical practice and stresses the need for research on the influence of perception of violence on clinical predictions of dangerousness. Different perceptions of aggression are discussed as an explanation for the variance in the reporting of aggressive incidents $[5,6]$.

In one of the few studies on staff attitudes, Jansen, Dassen \& Moorer [6] investigated the "perception of aggression" among psychiatric nurses and developed the Perception of Aggression Scale (POAS), consisting of 30 likert-scaled statements on aggression and some questions regarding the personal and educational background and the work environment. The presented statements on aggression have the form of "definitions" ("Aggression is ..."). The selection of the statements was based on a qualitative study investigating the perception of aggression among psychiatric nurses in the Netherlands [7] and an additional literature review [6]. Jansen, Dassen \& Moorer [6] used the POAS in a survey among a sample of 274 Dutch nurses that was judged by the authors to be representative for nurses working in psychiatric settings in the Netherlands. The analysis of the responses was done using a Mokken-scale-analysis and revealed three sub-scales which were interpreted as three different perceptions of 
aggression: Firstly, aggression is perceived as a normal and acceptable reaction to feelings of anger, secondly, aggression is perceived as a form of violence, and thirdly, aggression is perceived in terms of the function it has for the patient and in terms of the effects it has on his or her treatment. Statistical analysis of the results regarding relationships between the perception of aggression and personal and environmental characteristics of the respondents revealed only a few significant relationships with $p<$ 0.05 . Variables related to one of the three factors of the perception of aggression were gender, setting (type of ward), the number of involuntary admissions, and the degree to which nurses use constraint measures. Contrary to the expectation of the authors, variables like training in aggression management, grade of education in nursing etc. yielded no relationship to the way nurses perceived aggression.

In an ongoing study supported by the European Violence in Psychiatry Research Group EViPRG [8], POAS is being used to compare the perception of aggression among nurses in different European countries. As part of this European study, a sample of nurses in psychiatric departments in the German speaking part of Switzerland representing various ward types completed a German version of the POAS developed by I.Mamier and T.Dassen (Humboldt University, Berlin D).

These Swiss data are used in the present study. The following research questions are addressed: 1) What are the dimensions in the perception of violence among psychiatric nurses in German speaking Switzerland? 2) Are there differences in the perception of aggression among nurses according to personal characteristics or characteristics of their work environment? 3) Are there patterns in the perception of aggression? 4) To what extent are personal characteristics or characteristics of the work environment predictive for the perception of aggression among the population studied?

\section{Materials and methods}

The overall design of this study was a survey approach using a written questionnaire.

\section{Subjects}

The study population consisted of 729 nurses working in psychiatric inpatient departments of German speaking Switzerland. In this convenience sample nurses from 13 from the 31 psychiatric institutions or 106 of 313 wards in the study area participated. Additionally, the sample included students of one school providing basic 
education in nursing with a focus on psychiatric nursing and participants of a postdiploma course in psychiatric nursing.

\section{Instrument}

The instrument used was a questionnaire that included questions regarding the personal and educational background, the work environment, previous experience of aggression, and a German version of the POAS [6], consisting of 32 items on a 5-point likert scale ( 1 = strongly agree $-5=$ strongly disagree).

\section{Administration}

The questionnaires were distributed through members of the Swiss Network for Nursing Research in Psychiatry in their respective work places. A total of 1009 questionnaires were administered to all nurses on duty within a 3-day-period in a convenience sample of wards accessible to the network members. Of the questionnaires distributed, 727 were returned, yielding an overall response rate of $72 \%$. The mean response rate in the wards participating was $75.3 \%$ (Median $80.0 \%$, with a range from $10 \%$ to $100 \%$.

\section{Data analysis}

In order to extract the dimensions in the perception of aggression among a principal axis factoring analysis including varimax rotation was performed on all 32 items of the German POAS, using the software package SPSS 10 for Windows. Items were included if they had a loading of $>=0.30$. Missing values were replaced by means. In order to identify relationships between respondents characteristics and the mean factor scores, independent group comparisons for single variables were made using One-WayAnalysis of Variance (ANOVA), as it's nonparametric analogon the Kruskal-Wallis H test, or Mann Whitney $U$ test, depending on the level of measurement of the independent variables and the distribution of the respective data. Pearson correlation coefficients were calculated to determine relationships between the factor scores of the continuous variables. Statistical significance was determined using the traditional cutoff level $\alpha=0.05$.

In order to investigate patterns in the perception of aggression, Pearson correlation was calculated between the mean summated scores of the items belonging to the two factors. 
Multivariate Analysis of Covariance (MANCOVA) was performed in order to examine if and how well the respondents and ward characteristics predicted the mean scores of the two different perceptions of aggression identified by the factor analysis. The factor scores of the two dimensions of aggression were treated as dependent variables. Independent variables were the variables with significantly different mean factor scores in relation to respondents characteristics identified previously in the group comparisons.

\section{Results}

\section{Sample}

$38.9 \%$ of the participants were male, $61.1 \%$ female, the mean age was 37 years (SD 10.46; Median 37). $54.7 \%$ of the respondents had a diploma degree in psychiatric nursing, $17.7 \%$ a diploma in general nursing, 3.6\% a two-year training in geriatric nursing, $15.6 \%$ were nursing students ( 3 or 4 year diploma-education), and $8.4 \%$ were nursing aids without formal professional education. $10 \%$ of the 549 trained nurses in the sample have completed a post diploma education in nursing, and $19.7 \%$ have been educated in nursing management (most of them a training as ward sister).

With regard to the setting, $42.1 \%$ of the respondents work in acute (admission) wards, $23.4 \%$ in geronto-psychiatric departments, $15.3 \%$ in rehabilitation-wards, $5.3 \%$ in longstay-psychiatry, $8.3 \%$ in forensic/addiction wards, and $5.6 \%$ in a variety of other settings, e.g. inpatient psychotherapy. About two third (63.9\%) of the participants work full time. The average working experience in psychiatry is 7.55 years (Median = 5.00 years, range $=42$ years) for the total sample and 8.89 years (Median $=7.00$ years, range $=42$ years) when students are excluded. $31.0 \%$ of the respondents (students excluded) have work experience in psychiatry of less than 1 year, and $22.3 \%$ of $2-5$ years. 515 respondents $(70.6 \%)$ are Swiss, 90 (12.3\%) come from the surrounding German speaking countries Germany, Austria or Liechtenstein, 85 (11.7\%) come from other European countries (e.g. the Netherlands, Italy, former Yugoslavia, Finland, etc.) and $24(3.4 \%)$ of the respondents are of Non-European origin (e.g. the Philippines, Korea, Brazil, Morocco, etc.). Half of the participants in the study stated that they describe themselves as a "religious person".

Participants were asked about previous experience with threatening patient behaviour and the experience of being physically attacked in their professional and their private life respectively ("Have you ever felt very seriously threatened physically in your 
professional practice?", "Have you ever felt very seriously threatened physically in your life (not in professional practice?", "Have you ever been attacked violently in your professional practice?", "Have you ever been attacked violently in your life (not in your professional practice?"; the answers offered were "never", "once" or "repeatedly"). Nearly three-quarters (72.4\%) of the respondents felt once or repeatedly seriously threatened in their professional lives and about $70 \%$ were once or repeatedly physically attacked (see tables 1 and 2). The respective figures for the experience in their private lives were $47.0 \%$ (once or repeatedly seriously threatened in their private life) and $40.5 \%$ (once or repeatedly physically attacked in their non-professional life); there were no statistically significant differences in the distribution between men and woman.

Table 1: Perceived threats in professional life

\begin{tabular}{|c|c|c|c|c|c|c|c|c|}
\hline & \multicolumn{8}{|c|}{ Felt seriously threatened in professional life } \\
\hline & \multicolumn{2}{|c|}{ Students } & \multicolumn{2}{|c|}{ Nursing Aids } & \multicolumn{2}{|c|}{ Trained Nurses } & \multicolumn{2}{|l|}{ All } \\
\hline & $\mathbf{n}$ & Percent & $\mathbf{n}$ & Percent & $\mathbf{n}$ & Percent & $\mathbf{n}$ & Percent \\
\hline Never & 59 & $51.8 \%$ & 20 & $32.8 \%$ & 108 & $19.7 \%$ & 187 & $25.8 \%$ \\
\hline Once & 24 & $21.1 \%$ & 18 & $29.5 \%$ & 138 & $25.1 \%$ & 180 & $24.7 \%$ \\
\hline Repeatedly & 30 & $26.3 \%$ & 21 & $34.4 \%$ & 300 & $54.6 \%$ & 351 & $48.7 \%$ \\
\hline Missing & 1 & $.9 \%$ & 2 & $3.3 \%$ & 3 & $.5 \%$ & 6 & $.8 \%$ \\
\hline Total & 114 & $100.0 \%$ & 61 & $100.0 \%$ & 549 & $100.0 \%$ & 724 & $100.0 \%$ \\
\hline
\end{tabular}

Table 2: Estimates of physical attacks in professional life

\begin{tabular}{lcccccccc}
\hline \multicolumn{7}{c}{ Physically attacked in professional life } \\
\hline & \multicolumn{1}{c}{ Students } & \multicolumn{2}{c}{ Nursing Aids } & Trained Nurses & All \\
\hline Never & $\mathbf{n}$ & Percent & $\mathbf{n}$ & Percent & $\mathbf{n}$ & Percent & $\mathbf{N}$ & Percent \\
Once & 69 & $60.5 \%$ & 25 & $41.0 \%$ & 116 & $21.1 \%$ & 210 & $28.9 \%$ \\
Repeatedly & 18 & $15.8 \%$ & 16 & $26.2 \%$ & 266 & $48.5 \%$ & 204 & $28.0 \%$ \\
Missing & 3 & $2.6 \%$ & 2 & $3.3 \%$ & 5 & $.9 \%$ & 300 & $41.7 \%$ \\
\hline Total & 114 & $100.0 \%$ & 61 & $100.0 \%$ & 549 & $100.0 \%$ & 10 & $1.4 \%$ \\
\hline
\end{tabular}


Of the 109 wards represented in the sample, 52 (47.7\%) have permanently or mostly open doors, 54 (49.5\%) are closed wards (information on 3 wards are missing); $55.6 \%$ of the respondents work on closed wards, $44.4 \%$ on wards with permanently or mostly open doors. The participants were asked to estimate the incidence of aggression on their ward ("How often are you confronted with aggressive behaviour of patients in your ward?"). The perceived (estimated) incidence of aggression was "daily" in $27.1 \%$ of the respondents, "weekly" in 43.9\%, and "less than once per month" in $36.8 \%$ of the respondents. Differences in these estimations between nurses working on different types of wards are shown in table 3.

Table 3: Estimates of frequency of aggression (proportions of the sample) $(n=697)$

\begin{tabular}{|c|c|c|c|c|c|c|}
\hline \multirow[t]{3}{*}{ Ward type } & \multicolumn{6}{|c|}{$\begin{array}{l}\text { Estimated frequency of aggressive behaviour on ward } \\
\text { (number of respondents) }\end{array}$} \\
\hline & \multicolumn{2}{|c|}{ Daily } & \multicolumn{2}{|c|}{ Weekly } & \multicolumn{2}{|c|}{ Less than once/month } \\
\hline & $\mathbf{n}$ & percent & $\mathbf{n}$ & percent & $\mathbf{n}$ & percent \\
\hline Acute wards & 92 & $31.5 \%$ & 154 & $52.7 \%$ & 46 & $15.8 \%$ \\
\hline Rehabilitation & 18 & $16.7 \%$ & 57 & $52.8 \%$ & 33 & $30.6 \%$ \\
\hline Geronto-psychiatry & 55 & $34.0 \%$ & 72 & $44.4 \%$ & 35 & $21.6 \%$ \\
\hline Longstay psychiatry & 9 & $23.7 \%$ & 12 & $31.6 \%$ & 17 & $44.7 \%$ \\
\hline Other (Psychotherapy, etc.) & 4 & $10.0 \%$ & 7 & $17.5 \%$ & 29 & $72.5 \%$ \\
\hline Forensic/Addict & 11 & $19.3 \%$ & 25 & $43.9 \%$ & 21 & $36.8 \%$ \\
\hline Total & 189 & $27.1 \%$ & 327 & $46.9 \%$ & 181 & $26.0 \%$ \\
\hline
\end{tabular}

$47.2 \%$ of the respondents rated the frequency of involuntary admissions to their wards as "always" or "often", $20.7 \%$ as "sometimes", and 32.1\% as "seldom" or "never".

\section{Factor Analysis}

The Kaiser-Meyer-Olkin (KMO) measure of sampling adequacy of the 32 variables was between .736 and .956, the overall value was .912, suggesting that factoring is appropriate. The criteria of examining the Scree plot suggested a 2 factor solution. The data then were subjected to Varimax rotation to obtain an initial two-factor solution. Visual inspection of the Factor plot and analysis of the factor-loadings revealed two variables that did not fit well into one of the factors and loaded on both factors. After checking other factor-solutions the two items were excluded and the final two-factor solution was calculated, using Varimax rotation. The two factors of the final solution 
cumulatively account for $35 \%$ of the variance. The Kaiser-Meyer-Olkin (KMO) measure of the 30 variables was between 0.782 and 0.956 , the overall value was .915; Bartlett's Test of Sphericity was significant with $p<.001$ (chi-square 6510.8, $435 \mathrm{df}$ ). These preliminary tests render the data set suitable for factor analysis. 19 Items load on factor 1, and 11 Items load on factor 2. The factor loadings of the items for this solution are presented in table 4 (Factor Matrix), and the respective factor plot in figure 1.

Table 4: Rotated component matrix (factor-loadings)

\begin{tabular}{|c|c|c|}
\hline \multirow[t]{2}{*}{ Item } & \multicolumn{2}{|c|}{ Component } \\
\hline & 1 & 2 \\
\hline 16 & .692 & -.359 \\
\hline 13 & .661 & -.416 \\
\hline 14 & .627 & \\
\hline 12 & .604 & \\
\hline 15 & .597 & \\
\hline 23 & .595 & -.375 \\
\hline 3 & .593 & -.381 \\
\hline 32 & .575 & -.422 \\
\hline 10 & .555 & \\
\hline 21 & .535 & \\
\hline 20 & .518 & \\
\hline 2 & .517 & \\
\hline 11 & .513 & \\
\hline 24 & .512 & \\
\hline 6 & .502 & \\
\hline 5 & .501 & \\
\hline 28 & .486 & \\
\hline 1 & .481 & \\
\hline 18 & .441 & \\
\hline 27 & & .618 \\
\hline 26 & & .598 \\
\hline 17 & & .595 \\
\hline 25 & & .585 \\
\hline 22 & & .582 \\
\hline 31 & & .578 \\
\hline 8 & & .560 \\
\hline 7 & & .558 \\
\hline 30 & & .545 \\
\hline 19 & & .511 \\
\hline 4 & & .446 \\
\hline
\end{tabular}

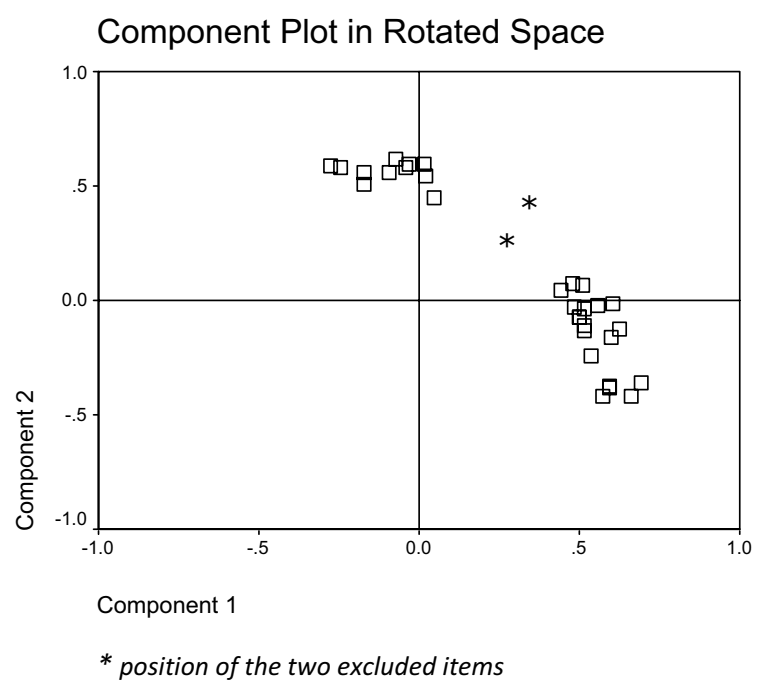


Reliability analysis of the two factors revealed satisfactory reliability-coefficients of Cronbach's Alpha $=0.88$ for factor 1 ( $\mathrm{N}$ of Cases $=649 ; \mathrm{N}$ of Items $=19$ ) and Cronbach's Alpha $=0.80$ for factor $2(\mathrm{~N}$ of Cases $=690 ; \mathrm{N}$ of Items $=11)$.

The two factors were interpreted as two different dimensions of the perception of aggression. Dimension one (factor one) was labelled "Aggression as dysfunctional/undesirable phenomenon", dimension two (factor two) "Aggression as functional/comprehensible phenomenon". The variables with the highest loading on these two dimensions are shown in table 5.

Table 5: Factors and items with highest loadings

Dimension 1: Aggression as dysfunctional/undesirable phenomenon

\begin{tabular}{lc}
\hline Item & Loading \\
\hline Aggression is an unpleasant and repulsive behaviour (Item 16) & 0.692 \\
Aggression is unnecessary and unacceptable (Item 13) & 0.661 \\
Aggression hurting others mentally or physically (Item 14) & 0.627 \\
Aggression is a disturbing intrusion to dominate others (Item 12) & 0.604 \\
Aggression is an actual action of physical violence of a patient against a nurse (Item 15) & 0.597 \\
Aggression is always negative and unacceptable; feelings should be expressed in another way \\
(Item 23)
\end{tabular}

Dimension 2: Aggression as functional/comprehensible phenomenon

\begin{tabular}{lc}
\hline Item & Loading \\
\hline Aggression is the start of a positive nurse-patient relationship(Item 27) & 0.618 \\
Aggression is the protection of one's own territory (Item 26) & 0.598 \\
Aggression is an opportunity to get a better understanding of the patient's situation (Item 17) & 0.595 \\
Aggression is a form of communication and as such not destructive (Item 25) & 0.585 \\
Aggression is a way to protect yourself (Item 22) & 0.582 \\
Aggression is a healthy reaction to feelings of anger (Item 31) & 0.578 \\
\hline
\end{tabular}

Relation between the scores of the two factors: A weak negative correlation was found between the mean summated scores of the two factors (Pearson -.315, $p<0.001$ ). Therefore, there seems to be a slight tendency that agreement on statements of dimension 1 is correlated with disagreement on statements of dimension 2. 


\section{Group comparisons}

No significant differences regarding the mean factor scores were found on the variables gender, post diploma education, percentual rate of employment, or open or closed wards. No differences were found in nurses who reported of being seriously threatened or being physically attacked in private or professional life, nor in nurses describing themselves as religious persons (see table 6, next page).

Regarding factor 1, statistically significant differences in the mean factor scores were found between age groups, nurses of different level of professional education, nurses with differing amounts of working experience in psychiatry, nurses working on different types of wards and nurses having grown up in different countries.

Significant differences in the mean scores of factor 2 were found regarding the variables level of professional education and perceived frequency of aggression on ward.

Even though these differences were statistically significant, the effects are small: For instance, between nurses in the age group of those younger or equal to 20 years of age and those over 51 years of age, the difference in the mean factor scores of factor 1 was 0.50 . On a scale of +5 to -5 , the highest and lowest scores on factor 1 were the following: age-group $\leq 20$ : mean -.177, median .271, std. .893; Group $\geq 51$ years: mean .324 , median .271, std. .893 (see figure 2). The proportions of the other betweengroups-differences were similar, e.g. between nurses with different grade/educational background.

Figure 2: Examples of differences in mean factor scores (factor 1) between groups of participants

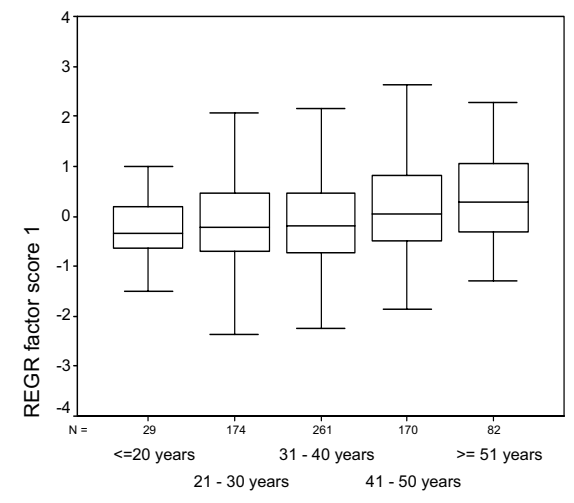

Age groups

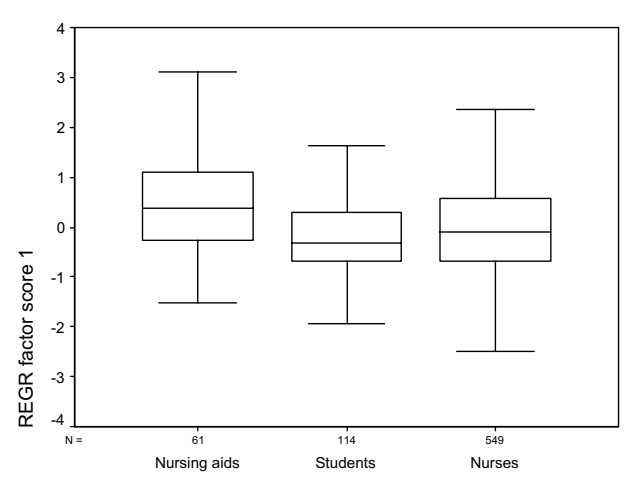

Nursing Grade 
Table 6: Relationships between mean factor scores and characteristic of participants

\begin{tabular}{lll}
\hline $\begin{array}{l}\text { Differences in mean factor scores between groups } \\
\text { p-values (Kruskall-Wallis H or Mann-Whitney U); NS = not significant, } \mathrm{P}<.05\end{array}$ & \\
\hline Variable & Factor $\mathbf{1}$ & Factor 2 \\
\hline Age Group 1) & $<.001$ & NS \\
Gender & NS & NS \\
Level of professional education 2) & $<.001$ & .024 \\
Post diploma education in nursing & NS & NS \\
Post diploma education in management & NS & NS \\
Professional experience as nurse in psychiatry 3) & .001 & NS \\
Full time/part time employment & NS & NS \\
Type of ward 4) & $<.001$ & NS \\
Ward closed / open & NS & NS \\
Number of involuntary admissions on ward & NS & NS \\
Perceived frequency of aggression on ward & NS \\
Seriously threatened in private life & NS \\
Seriously threatened in professional life & NS & NS \\
Physically attacked in private life & NS & NS \\
Physically attacked in professional life & NS & NS \\
Country of origin 5) & NS & NS \\
Religious & $<.001$ & .029 \\
\hline
\end{tabular}

1) $<=20,21-30,31-40,41-50,>=50$ years

4) Acute, Rehabilitation, Gerontopsychiatry, Longstay, Forensic/Addiction, Other

2) Nursing Aids, Students, Diploma Nurses

5) Switzerland, Germany/Austria/Liechtenstein, other

3) $0-1,>1-2,3-5,6-10,11-20$, $>20$ years European; non-European partipicants excluded due to their small number

\section{Analysis of Covariance}

For factor 1 (Aggression as dysfunctional/undesirable phenomenon), statistically significant results were obtained for three of the variables and the interaction of two of these variables with two more variables: The level of professional education, the ward type, the work experience, the interaction of work experience*age and the interaction of level of professional education*country of origin predicted slightly more than $9 \%$ of the variance of the mean factor scores (R2 .092). The contribution of the 
four predictors lie between 1.8 (ward type) and 5.4\% (work experience in psychiatry * age) (Partial Eta Squared).

For factor 2 (Aggression as functional/comprehensible phenomenon), the only significant variable was level of professional education, accounting for $1.2 \%$ of the variance.

\section{Discussion}

\section{Sample}

Questionnaires were distributed to all nurses working in a certain period of time on the wards selected, and the overall response rate of $72 \%$ was satisfactory. Therefore, it can be concluded that there was no systematic bias in the selection of participants within the respective wards and that the respondents are representative for the units included in the study. A comparison of the proportion of ward types according to a survey in 1999 and the respective proportions in the POAS-study shows a remarkable correspondence. Based on this comparison we assume that the results of the present study can be generalized to psychiatric nursing in the German speaking part of Switzerland.

\section{Research question 1: What are the dimensions in the perception of violence among psychiatric nurses in German speaking Switzerland?}

Using the factor analysis, we identified two plausible dimensions, describing two different general perceptions of the phenomenon under research. Firstly, aggression is perceived as dysfunctional/undesirable phenomenon, and secondly, aggression is perceived as functional/comprehensible phenomenon. The two dimensions represent a more positive and a more negative perception of aggression. Evidently, nurses perceive aggression not just as unwanted and not just as something that has to be prevented. We consider this result to be promising in the search for explanations for variations in the individual behaviour of nurses vis-à-vis aggressive behaviour of patients.

Our factor solution is comparable with the dimensions found in the original Dutch study of Jansen et al. [6] and nearly identical with the factors found in a recent German study [Mamier, personal communication]. However, the 2 factors explain only $35 \%$ of the variance. Several aspects of the perception of aggression are apparently not sufficiently covered by the items of the current version of POAS. The items included 
refer mainly to cognitive aspects and are mostly judgements. Possibly, emotional aspects could be of comparable importance.

\section{Research question 2: Are there differences in the perception of aggression among nurses grouped according to personal characteristics or characteristics of their work environment?}

Regarding dimension 1 ("Aggression as dysfunctional/undesirable phenomenon"), the result of the group comparisons can be summarised in the following way: Older nurses and nurses with longer working experience in psychiatry tend to score higher on dimension 1 than their younger colleagues $(p<.001)$; diploma nurses and nursing aides score higher than nursing students $(p<.001)$. Nurses working on acute wards tend to be less affirmative to dimension 1 than nurses on geronto-psychiatric wards ( $p$ $<.001$ ); nurses from German speaking countries score lower on dimension 1 than nurses from other European countries; and finally European nurses score lower on dimension 1 than nurses of non-European provenance $(p<.001)$.

Between-group-differences regarding dimension 2 ("Aggression as functional/comprehensible phenomenon") can be summarised in the following way: Diploma nurses (irrespective of the type of diploma) score lower on dimension 2 than nursing aides and students. Nurses from German speaking countries score higher on dimension 2 than nurses from other European countries.

However, as the size of the differences is very small their practical relevance is questionable.

\section{Research question 3: Are there patterns in the perception of aggression?}

In this study, no clear pattern in the perception of aggression could be found. Because of the dichotomous character of the two dimensions identified, it could be expected that respondents in favour of the items constituting the more positive perception would disagree with statements of the more negative perceptions of aggression. In contrast to such a expectation, our data showed only a very weak negative correlation of the two dimensions. An additional analysis of the data showed a very small group of nurses with a pattern of perception characterised by agreement to the "positive" dimension and disagreement with the "negative" dimension and vice versa. In our sample, nurses tended to agree to the two dimensions simultaneously. This could be interpreted as expression of a complex and non ideological perception of aggression. Furthermore, it can be assumed that the perception of aggression is strongly 
influenced by the characteristics and the context of concrete clinical situations. The items of the POAS refer to a wide range of patient behaviour and the instrument treats the topic on a quite general level. Possibly an investigation of the topic at such an abstract level is not promising without taking concrete clinical situations into consideration.

\section{Research question 4: To what extent are personal characteristics or characteristics of the work environment predictive for the perception of aggression among the population studied?}

The perception of aggression as measured by POAS is apparently relatively independent of many characteristics expected to be related to the perception of violence. This result corresponds to the results of the Dutch and German study. For example, we expected that the extent of the experience of being attacked or threatened in professional life would be predictive for the perception of aggression.

Further investigation is required to discover other factors which may render the POAS able to account for greater magnitudes of variance regarding the perception of aggression. Once established, further research should be conducted on the correlation between the perception of aggression and the actual behaviour of nurses in clinical situations.

\section{Acknowledgements}

This study was supported by the European Violence in Psychiatry Research Group EViPRG. We are indebted to G.Jansen, University Groningen NL, principal investigator of the European POAS-study. We also want to thank the members of the Swiss Network for Nursing Research in Psychiatry for the great help we received in the collection of data.

\section{Literature}

1. SHAH A, FINEBERG N, JAMES D. Violence among psychiatric inpatients. Acta Psychiatr Scand 1991: 91: 305-309.

2. DAVIS S. Violence by psychiatric inpatients: a review. Hosp Community Psychiat 1991: 2: 585-90.

3. NIJMAN H, ACAMPO J, RAVELLI D, MERCKELBACH H. A tentative model of aggression on inpatient psychiatric wards. Psychiatr Serv 1999: 60: 832-834.

4. MORRISON EF. A comparison of perceptions of aggression and violence by psychiatric nurses. Int J Nurs Stud 1993: 30: 261-268.

5. POSTER EC, RYAN JA. Nurses' attitudes toward physical assaults by patients. Arch Psychiatr Nurs 1989: 3: 315-22. 
6. JANSEN G, DASSEN T, MOORER P. The perception of aggression. Scand J Caring Sci 1997: 11: 51-55.

7. FINNEMA E, DASSEN T, HALFENS R. Aggression in psychiatry: A qualitative study focusing on the characterization and perception of patient aggression by nurses working on psychiatric wards. J Adv Nurs 1994: 19: 1088-1095.

8. BOWERS L, WHITTINGTON R, ALMVIK R, BERGMAN B, OUD N, SAVIO M. A European perspective on psychiatric nursing and violent incidents: management, education and service organisation. Int J Nurs Stud 1999: 36: 217-222. 


\section{Chapter 2}

The management of violence on psychiatric acute wards in the German speaking part of Switzerland: Results of a survey

Abderhalden C, Needham I, Dassen T, Halfens R, Fischer J.E., Haug H.-J. (2007) The management of violence on psychiatric acute wards in the German speaking part of Switzerland: Results of a survey. International Journal of Psychiatric Nursing Research (accepted for publication) 


\section{Abstract}

Background: Aggression and violence are a major concern in inpatient psychiatric care globally. In view of the negative consequences of aggression in psychiatric institutions, the issue is a central concern of user organisations, professional bodies and governmental agencies, and great efforts are undertaken to improve the situation. In order compare and improve the respective practice within health systems and between countries, data on current practice are needed.

Objective: To collect representative data on structural characteristics of aggression management on acute psychiatric admission wards in the German speaking part of Switzerland.

Method: A survey on all 86 acute psychiatric admission wards in the area regarding aggression management and the judgement thereof by staff nurses.

Results: 82 (95\%) wards participated. Approximately every third staff nurse rates violence as a serious or very serious problem. The resources of $22 \%$ of the wards were rated as inadequate. Considerable differences exist regarding resources for and practices in handling violence. The greatest deficiencies lay in practical and theoretical knowledge, recording systems, in post-incident services for victims, the lack of seclusion facilities, and the lack of systematic violence risk assessment.

Conclusions: Room for improvement exists in the areas of education, monitoring, risk assessment, post-incident help services for victims, and the reviewing process after the administration of coercive measures. 


\section{Background}

Aggression and violence and negative consequences thereof for patients and staff involved are perceived by many professionals and patient representatives as one of the biggest problems affecting contemporary psychiatric institutions (Whittington and Richter, 2006). Thus, the reduction of the incidence of aggression and violence and resultant negative effects is a challenge for researchers and staff of psychiatric facilities alike. This issue has led to a voluminous body of research on the incidence of aggression, causes, risk factors, and ways of effective management of aggression among psychiatric patients. However, until the nineties of the last century most of the scientific literature was of Anglo-American origin, and the problem was only a marginal subject of psychiatric or nursing research in the German speaking countries including German speaking Switzerland.

In view of the negative consequences of aggression in psychiatric institutions, the issue has become a central concern of mental health service users (O'Hagan, 2004), professional bodies (; (e.g. ILO, 2002; ICN, 2000) and governmental agencies, and great efforts are undertaken to improve the situation. Prevention and management of aggression have become part of hospital-wide safety and security policies and programs (Cowman, 2006). and rates of coercive measures are seen as qualityindicators of psychiatric facilities (Stefan, 2006). Adapting to the requirements of evidence based practice (Sackett, Rosenberg et al., 1996), several professional organisations edited guidelines for the prevention and management of violence, based on the best available scientific evidence in the field. Examples are the UK-Royal College of Psychiatrists (RCP) guidelines for the Management of imminent violence (RCP, 1998), corresponding Canadian and US guidelines (Beck and Roy, 1996; JCAHO, 2000), the report "The recognition, prevention and therapeutic management of violence in mental health care" edited by the United Kingdom Central Council for Nursing, Midwifery and Health Visiting (UKCC, 2002), or, most recently, the Guideline edited by the National Institute for Clinical Excellence NICE (UK) (NICE, 2005). In Germany and Switzerland, regional workgroups aim to improve prevention of violence and coercive measures (Ketelsen, Zechert et al., 2001; Steinert, Fischer-Erlewein et al., 2002), and Swiss quality standards for psychiatric inpatient treatment include recommendation for the management of dangerous situations and the application of forced treatment (Wengle, Bitterlin et al., 2000). 
In line with this, several surveys have been undertaken to explore the actual practice and/or to compare it to standards of practice. Such investigations revealed large variations within countries (Bowers, Whittington et al., 1999) or regions (Gebhardt and Steinert, 1998) or between facilities (Bowers, Crowhurst et al., 2002; Bowers, Nijman et al., 2006; Cowman and Walsh, 2004; Royal College of Psychiatrists' Research Unit, 2005; SNMAC, 1999; UKCC, 2002). However, little is known on the actual practice situation in acute wards in Switzerland.

The aims oft the present study are firstly to collect representative data on structural characteristics of aggression management on acute psychiatric admission wards in the German speaking part of Switzerland and, secondly, to evaluate how the charge nurses of the wards assess these procedures and facilities.

\section{Methods and materials}

We conducted a cross-sectional survey employing a questionnaire containing questions on ward characteristics and items on coercive practices and facilities. The questionnaire was sent to all 86 acute psychiatric admission wards in the German speaking part of Switzerland.

The wards were recruited from psychiatric hospitals lying within the German and Romansch speaking part of the country. The psychiatric hospitals in this area cater for the inpatient treatment of approximately 75\% (5'376'800 persons) of the Swiss population. Not included in this survey are psychiatric hospitals in the French and Italian speaking Cantons and a small proportion of inhabitants living in the French speaking areas of predominantly German speaking Cantons (for example psychiatric hospitals in the French speaking part of Canton Berne).

To be included in the study as an acute ward, the following criteria had to be met: The majority of the patients have an acute psychiatric disorder, they are admitted directly onto the ward, they stay less than three months on the ward, they are in general older than 18 and younger than 65 years, and the ward is not specialised in the treatment of special disorders (e.g. depression, addiction). The proportion of involuntarily admitted patients was not taken into consideration.

The questionnaires were completed by the charge nurses (the nurses leading the wards and bearing the overall responsibility for nursing). The instrument comprised of questions on ward characteristics; number of beds, locked or open status, number (full-time equivalent) and educational status of nursing staff; seclusion facilities, 
facilities for mechanical restraint, management of violent incidents, reporting systems for violent incidents, and the registration of coercive measures. In addition, we asked to which extent aggression was perceived as problem, and we requested the participating ward leaders to asses whether the resources for aggression management on their wards were sufficient.

Due to unavailability of reliable information on the prevalence of aggression and coercion on the wards, respective data could not be obtained. The data analysis was descriptive without any hypothesis testing.

\section{Results}

\section{Sample}

Eighty-two (94\%) of the 87 wards invited to the survey responded representing 30 (94\%) of the 32 institutions in the study area. The number of wards in the institutions varies from one to eight. Ten (12\%) of the wards are open, 29 (53\%) are partially open, and $43(53 \%)$ are locked. The number of beds varies between 6 and 25 (median 17, mean $16.6 \pm 3.7)$. The nursing staff / patient ratio (100\% posts / beds) lies between 0.3 and 1.8 (median 0.7 ; mean $0.7 \pm 0.2$ ).

\section{Size of the problem and overall assessment of ressources}

About one out of three ward leaders considers violence as big or very big problem (Table 1), and one fifth rated the problem as small or very small. Aggression management resources are seen as sufficient or entirely sufficient in one third wards, and slightly insufficient or insufficient in about one out of five wards (Table 2).

Table 1: Size oft he problem (numbers are wards)

\begin{tabular}{lll}
\hline Aggression assessed as.. & $\mathbf{n}$ & $\%$ \\
\hline No problem & 2 & 2.4 \\
A very small problem & 8 & 9.8 \\
A small problem & 6 & 7.3 \\
A moderate problem & 36 & 43.9 \\
A big Problem & 23 & 28.0 \\
A very big problem & 7 & 8.5 \\
\hline Total & 82 & 100.0 \\
\hline
\end{tabular}


Table 2: Assessment of resources (numbers are wards)

\begin{tabular}{lll}
\hline $\begin{array}{l}\text { Ressources for aggression mangement } \\
\text { assessed as... }\end{array}$ & $\mathbf{n}$ & $\mathbf{\%}$ \\
\hline ... entirely sufficient & 1 & 1.2 \\
Resources sufficient & 27 & 32.9 \\
Resources nearly sufficient & 36 & 43.9 \\
Resources slightly insufficient & 11 & 13.4 \\
Resources insufficient & 7 & 8.5 \\
\hline Total & 82 & 100.0 \\
\hline
\end{tabular}

Table 3 gives an overview over the main results of the survey.

48 wards (58.8 \%) have a standard (norm, guideline, protocol) for the general management of violent incidents, and 4 out of 5 wards have standards for the implementation of coercive measures. While these standards are assessed as sufficient for most wards, there were a number of remarks criticising the standards as being too theoretical, not evidence based, or as not putted in action.

$49(60 \%)$ of the wards had an educational programme on theoretic aspects of violence within the last 2 years, in 34 (41\%) of the wards accompanied by a training programmes dealing with practical aspects of violence management. These educational supports were considered as insufficient by $50 \%$ of the wards leaders. Problems mentioned were related to difficulties arising from staff turnover, lack of clinically relevant content, and lack of opportunities for practical exercise.

Special reporting forms for aggressive incidents and coercive measures were reported to be in use in $57(70 \%)$ and 69 (85\%) of the wards. However, only 5 (7.5\%) of the wards used a published standardised instrument (Staff Observation of Aggression Scale SOAS) for the registration of aggressive incidents. Data collected on aggression or coercion is rarely used for statistical descriptions or analyses and only one fifth of the wards reports on the existence of some data-feedback. $50 \%$ of the wards leaders consider the reporting system unsatisfactory, mostly with respect to lack of systematic or lack of statistical evaluation. Violence related absenteeism is monitored in only a minority of $15(19 \%)$ of the wards.

About one half of the wards assess the risk for violence in all patients, while this is done for selected patients only in the other wards, and never in two wards. Seventy 
seven (94\%) of the wards use clinical impression for risk assessment, while 3 (4\%) of the wards employ a locally developed structured risk assessment instrument. The current practice of risk assessment is judged as insufficient by 33 (40\%) of the ward leaders. Most of the critics in additional comments referred to the lack of a unified structured method or problems rooted in differing views of nursing and medical staff.

Table 3: Summary of main results (numbers are wards)

\begin{tabular}{|c|c|c|c|}
\hline \multirow[t]{2}{*}{ Item } & \multicolumn{2}{|c|}{ Reported as present } & \multirow{2}{*}{$\begin{array}{c}\begin{array}{c}\text { Assessed as } \\
\text { insufficient }\end{array} \\
\% \text { wards }\end{array}$} \\
\hline & $\mathrm{n}$ wards & $\%$ wards & \\
\hline Standard for the general management of violent incidents & 48 & $59 \%$ & $27 \%$ \\
\hline Standard coercive measures & 64 & $78 \%$ & $9 \%$ \\
\hline Educational programme on theoretic aspects aggression & 49 & $60 \%$ & $50 \%$ \\
\hline Practical training in aggression management & 34 & $41 \%$ & $52 \%$ \\
\hline Reporting systems for violent incidents & 57 & $70 \%$ & $44 \%$ \\
\hline Reporting system for coercive measures & 66 & $83 \%$ & $50 \%$ \\
\hline Risk assessment of all patients & 38 & $46 \%$ & \\
\hline Structured instrument for risk assessment & 3 & $4 \%$ & \\
\hline Lockable area (e.g. an intensive care area) & 43 & $52 \%$ & 0 \\
\hline At least one seclusion room ( $\max 6)$ & 64 & $78 \%$ & $45 \%$ \\
\hline Belts for mechanical restraint & 49 & $60 \%$ & $22 \%$ \\
\hline Alarm system (personal) & 79 & $96 \%$ & $22 \%$ \\
\hline Structured post-incident discussion among staff & 59 & $72 \%$ & $30 \%$ \\
\hline Structured discussion of coercive incidents among with pts. & 50 & $41 \%$ & $37 \%$ \\
\hline Psychological support for victims of violence & 39 & $48 \%$ & $46 \%$ \\
\hline
\end{tabular}

On just over one half of the wards $(n=43)$ there is a lockable area (e.g. an intensive care area). The majority of the wards (64 or 78\%) have at least one seclusion room, with the highest reported number of seclusion rooms being six. $45 \%$ ( $n=37$ ) of the ward nurses rate the seclusion facilities as inadequate.

Three fifths of the wards (49 or 60\%) report having straps to restrain aggressive patients at their disposal, but many respondents remarked that these facilities are employed only very rarely. 18 (22\%) assess the restraint facilities as insufficient. Seven ward leaders expressed discontent with unsuitable beds (e.g. beds on which straps can 
not be fastened), six mentioned the poor quality of straps (e.g. lack of stability, unsuitable for patients of various body size), and five respondents reported a lack of experience and/or difficulties in handling mechanical restraints.

Seventy nine wards (96\%) have at least one alarm system to call for immediate help in critical situations, mostly personal systems, and the alarm systems are deemed sufficient for three quarters of the wards. However, several participants expressed concerns with respect to technical problems like frequent false alarms or unreliable functioning.

Three out of four wards have a structured procedure for a post-incident discussion of coercive measures (seclusion, physical restraint, and forced medication) among the staff involved, and four have defined a corresponding procedure for such discussions with patients that had been subject of coercive treatment. However, several of the ward leaders pointed to problems with the implementation of these norms and criticised a lack of monitoring, especially of post-incident discussions with patients.

An institutionalised system of psychological support for victims of violence is lacking in $43(52 \%)$ of the wards.

\section{Discussion}

This survey among the admission wards in the German speaking Switzerland concerning aggression management revealed a wide variation with regard to the perceived severity of the problem as well as a regarding core practices like staff training, registration of incidents and risk assessment procedures. The greatest deficiencies were reported in practical and theoretical knowledge among staff, in recording systems, in post-incident services for victims, the lack of seclusion facilities, and the lack of a systematic violence risk assessment. These aspects show the greatest need for improvement.

Although not systematically checked, it is apparent that practices in many wards did not meet best practice standards based on the available scientific evidence (e.g. National Institute for Clinical Excellence NICE, 2005; Royal College of Psychiatrists, 1998). While a similar variation and comparable deficiencies are known from studies comparing European countries (Bowers, Whittington et al., 1999) or from surveys among UK- and Irish wards (Cowman and Walsh, 2004; Royal College of Psychiatrists' Research Unit, 2005), our study was the first to representatively depict current practice in Switzerland. The results revealed an apparent absence of overall accepted 
minimal standards in aggression management, a fact that raises some concerns in view of the current claims for evidence-based practice. However, the data provided by this study will now allow a monitoring of changes and hopefully improvements in the future.

Two main limitations hamper the validity of the results of this survey. With respect to the assessment of how big the problem of aggression was we relied on a global assessment by the ward leader alone and thus may not represent the whole picture in every ward, and we have no information on the aspects considered by the participants when judging the situation on their ward. The questionnaire employed was mainly focused on structural aspects of aggression management and thus the adequacy of drawing conclusions with regard to practice may be questionable. A serious weakness of the survey was the disregard of the view of patients and relatives, possibly leading to a one sided picture. The inclusion of the perspective of service users and relatives is becoming a standard in service-related evaluative research (Crawford, 2001), and discrepancies in the perception of aggression management by professionals and users are well known from research (Abderhalden, Hahn et al., 2006).

\section{Acknowledgments}

We thank the Nursing Directors of the hospitals in our study area, and the members of the Swiss Network for Psychiatric Nursing Research for supporting this study.

\section{Literature}

Abderhalden C., Hahn S., Bonner Y. and Galeazzi G. (2006) Users' Perceptions and Views on Violence and Coercion in Mental Health. (Ed) R. Whittington and D. Richter,Violence in Mental Health Sciences. Springer, New York, (pp) 69-92.

Beck P.R. and Roy R. (1996) Assaultive and Destructive Behaviour in a Treatment Setting: Guidelines for the Psychiatrist (Position paper, Canadian Psychiatric Association). Canadian Psychiatric Association, Ottawa.

Bowers L., Crowhurst N., Alexander J. ,Callaghan P. ,Eales, S. ,Guy S. ,McCann E. ,Ryan C. (2002) Safety and security policies on psychiatric acute admission wards: results from a London-wide survey. Journal of Psychiatric and Mental Health Nursing. 9, (pp) 427-433.

Bowers L., Nijman H., Allan T., Simpson A., Warren J., Turner L. (2006) Prevention and management of aggression training and violent incidents on U.K. Acute psychiatric wards. Psychiatric Services. 57, (pp) 1022-1026.

Bowers L., Whittington R., Almvik R., Bergman B., Oud N., Savio M. (1999) A European perspective on psychiatric nursing and violent incidents: management, education and service organisation. Intdernational Journal of Nursing Studies 36, (pp) 217-222.

Cowman S. (2006) Safety and Security in Psychiatric Hospitals. (Ed) R. Whittington and D. Richter,Violence in Mental Health Sciences. Springer, New York, (pp) 253-271. 
Cowman S. and Walsh, J. (2004) Safety and security procedures in psychiatric acute admission wards. Journal of Research in Nursing. 9, (pp) 185-193.

Crawford M. (2001) Involving users in the development of psychiatric services -- no longer an option. Psychiatric Bulletin. 25, (pp) 84-86.

Gebhardt R.P. and Steinert T. (1998) Innere Struktur der stationären psychiatrischen Krankenhausversorgung 22 Jahre nach der Psychiatrie-Enquete. Nervenarzt. 69, (pp) 791-798.

ILO International Labor Organisation (2002) Framework Guidelines for Adressing Workplace Violence in the Health Sector. ILO-ICN-WHO-PSI, Geneva.

ICN International Concil of Nurses (2000) Position Paper: Abuse and Violence Against Nursing Personnel. ICN, International Concil of Nurses, Geneva.

JCAHO Joint Commission on Accreditation of Healthcare Organizations (2000) Restraint in behavioral health care: Minimizing use, improving outcomes. Joint Commission on Accreditation of Healthcare Organizations: Joint Commission Resources, Oakbrook Terrace.

Ketelsen R., Zechert C., Klimitz H. and Rauwald C. (2001) Entwicklung eines Kooperationsmodells zwischen drei psychiatrischen Kliniken mit dem Ziel der Qualitätssicherung bei Zwangsmassnahmen am Beispiel der Fixierungsdokumentation. Psychiatrische Praxis. 28, (pp) 69-74.

NICE National Institute for Clinical Excellence (2005) Violence: The short-term management of disturbed/violent behaviour in in-patient psychiatric settings and emergency departmments (Clinical Guidline 25). National Institute for Clinical Excellence, NICE, London.

O'Hagan M. (2004) Force in mental health services: International user and survivor perspectives. Mental Health Practice. 7, (pp) 12-17.

RCP Royal College of Psychiatrists' Research Unit (2005) The National Audit of Violence 2003-2005: final report. Royal College of Psychiatrists, London.

RCP Royal College of Psychiatrists (1998) Management of imminent violence: clinical practice guidelines to support mental health services (Occasional Paper No. OP41). Royal College of Psychiatrists College Research Unit, London.

Sackett D., Rosenberg W., Gray J., Haynes, R. and Richardson W. (1996) Evidence-based medicine: What it is and what it isn't. British Medical Journal. 312, (pp) 71-72.

SNMAC, Standing Nursing and Widwifery Advisory Commitee (1999) Mental health nursing: adressing acute concerns. Department of Health, London.

Stefan S. (2006) Successful Seclusion and Restraint Reduction Programs as Quality Indicators for Psychiatric Services. Medscape (http://www.medscape.com/viewprogram/5260_pnt)

Steinert T., Fischer-Erlewein E., Kuster W., Pape C., Schwink A., Stuhlinger M., Arbeitsgemeinschaft Prävention von Gewalt in der Psychiatrie (2002) Prävention von Gewalt im psychiatrischen Krankenhaus. Krankenhauspsychiatrie. 13, (pp) 132-137.

UKCC United Kingdom Central Council for Nursing, Midwifery and Health Visiting (2002) The recognition, prevention and therapeutic management of violence in mental health care. UKCC, United Kingdom Central Council for Nursing, Midwifery and Health Visiting, London.

Wengle H., Bitterlin R., Haug H.-J. and Schaefer J. (2000) Qualitätsstandard für die Stationäre Psychiatrie. Schweizerische Vereinigung psychiatrischer Chefärzte SVPC, Aarau.

Whittington R. and Richter D. (Ed) (2006) Violence in Mental Health Settings. Springer, New York. 


\section{Chapter 3}

Nature and Frequency of aggressive incidents in acute psychiatric wards in Switzerland

Abderhalden C, Needham I, Dassen T, Halfens R, Fischer JE, Haug HJ (2007) Nature and Frequency of aggressive incidents in acute psychiatric wards in Switzerland. Clinical Practice and Epidemiology in Psychiatry 3:30 


\section{Summary}

Background: Aggression and violence and negative consequences thereof are a major concern in acute psychiatric inpatient care globally. Variations in study designs, settings, populations, and data collection methods render comparisons of the incidence of aggressive behaviour in high risk settings difficult.

Objective: To describe the frequency and severity of aggressive incidents in acute psychiatric wards in the German speaking part of Switzerland.

Methods: We conducted a prospective multicentre study on 24 acute admission wards in 12 psychiatric hospitals in the German speaking part of Switzerland. Aggressive incidents were recorded by the revised Staff Observation Aggression Scale (SOAS-R) and we checked the data collection for underreporting. Our sample comprised 2344 treatment episodes of 2017 patients and a total of 41'560 treatment days.

Results: A total of 760 aggressive incidents were registered. We found incidence rates per 100 treatment days between 0.60 (95\% $\mathrm{Cl} 0.10-1.78)$ for physical attacks and 1.83 (1.70-1.97) for all aggressive incidents (including purely verbal aggression). The mean severity was $8.80 \pm 4.88$ points on the 22 -point SOAS-R-severity measure; $46 \%$ of the purely verbally aggression was classified as severe ( $\geq 9$ pts.). $53 \%$ of the aggressive incidents were followed by a coercive measure, mostly seclusion or seclusion accompanied by medication. In $13 \%$ of the patients, one ore more incidents were registered, and $6.9 \%$ of the patients were involved in one ore more physical attack. Involuntary admission (OR 2.2; 1.6-2.9), longer length of stay (OR 2.7; 2.0-3.8), and a diagnosis of schizophrenia (ICH-10 F2) (OR 2.1; 1.5-2.9) was associated with a higher risk for aggressive incidents, but no such association was found for age and gender. 38 $\%$ of the incidents were registered within the first 7 days after admission.

Conclusion: Aggressive incidents in acute admission wards are a frequent and serious problem. Due to the study design we consider the incidence rates as robust and representative for acute wards in German speaking Switzerland, and thus useful as reference for comparative and interventional research. Implications for clinical practice include the recommendation to extend the systematic risk assessment beyond the first days after admission. The study confirms the necessity to differentiate between types of aggressive behaviour when reporting and comparing incidence-data. 


\section{Introduction}

Aggression and violence and negative consequences thereof for health, safety and wellbeing of patients and personal involved are a major concern in inpatient psychiatric care globally. Thus, the reduction of the incidence of aggression and violence and resultant negative effects is a challenge for researchers and staff of psychiatric facilities alike. This issue has led to a voluminous body of research on the incidence of aggression, causes, risk factors, and ways of effective management of aggression among psychiatric patients. In spite of a substantial body of research on the topic considerable variation regarding study aims, study designs, settings, study populations, and data collection methods render comparisons difficult and the results of these studies cannot be summarised easily due to the many disparities in the findings [1-3]. Disturbingly, this is also true for research on basic questions such as the incidence of aggressive behaviour in high risk settings (e.g. acute admission wards).

Some of the most important factors hindering the generalisability and comparability of incidence studies are differing definitions of aggressive behaviour, the variety of registration methods, inconsistent ways of reporting incidence rates, a substantial amount of underreporting, and problems arising from the selection of study settings and the duration of observations.

Due to its multidimensional nature, there is no uniform and purpose-for all-definition of aggression and it its perception is multi-facetted [4, 5]. Palmstierna suggested to look at the phenomenon using the dimensions "inner experience vs. outward behaviour; aggressor's view vs. observer's view; and persistent state vs. episodical occurrence" [1, p. 79]. Aggression may be defined as psychological state or as hostile physical or verbal act or as behaviour resulting in injuries of persons or damage to objects. In a similar display of variability conceptions of assault may range from verbal and physical behaviour to sexual harassment. Given such variability a clear cut-off for the severity of violent incidents under investigation [3] is of primary importance, and frequencies should be reported separately for different types of aggression.

Aggressive behaviour can be registered in many different ways, and there are dozens of instruments available [6]. Reviewing the literature on registration methods, Gothelf et al [7] found that almost half of the 103 studies under review did not use any structured instrument; and the remainder used a total of 52 different instruments. Such findings led to calls for the use of more standardised procedures to record violence [1]. In addition Bowers [8], reviewing some of the most frequently used instruments, pointed to some weaknesses of most of these instruments, including the 
classification of a wide variety of behaviours such as aggression directed towards self and aggression against others into the one category "aggressive incident".

Of special concern are the various ways of reporting incidence rates. As Bowers stated in a review critically appraising this topic "the expression of ward incident rates has been unclear and disorganised, resulting in incomparability between studies and lack of precision" [2, p. 365]. In some studies, the incidence of aggression is approached from the perspective of staff as victims with incidence expressed in terms of the assault rates among populations of nurses or doctors. Other studies focus on the proportion of patients showing assaultive behaviour or on differing types of incidencerates (e.g. per bed per year, per 100 treatment days etc.). As a result, in one study [9] 0.00069 violent incidents per treatment day were observed, and another study [10] reports 16 injuries per 100 staff (per annum?). Yet other authors found that $13.7 \%$ [11] or $2.7 \%$ of hospitalised patients were aggressive [12]. In a German study encompassing 162 patients among 9216 admissions aggressive incidents were registered producing an incidence rate of 0.019 equaling $2 \%$ of admissions [13], while in two single centre studies conducted at the Psychiatric University Clinic in Zurich $10 \%$ of newly admitted patients were aggressive $[14,15]$. However, in a recent overview on studies all using the same instrument, the authors were able to derive the annual frequency of incidents per bed per year and the percentage of patients involved in incidents as appropriative comparative figures in most of the studies. For acute wards, the respective figures ranged from 1.7 to 31.2 and $6.2 \%$ to $45 \%$ [16].

Another major obstacle to obtain comparable data on the incidence of aggression or violence in health care settings is underreporting [3, 17-20]. Underreporting not only distorts the statistics, but also renders some forms of aggression - especially aggression of a less severe nature - invisible. Lion et al. [18] estimated that there were five times as many assaults as formally reported in their hospital. However, it has been suggested that more severe incidents are more likely to be reported than incidents of less severe nature [21].

One repeatedly drawn conclusion from existing research is to consider specificities of certain settings and to be wary on aggregating data from different populations (e.g. ward types) and different types of aggressive behaviour for research [22, 23]. This can be illustrated by studies comparing the incidence of different forms of aggression or the incidence among different settings. Kay et al [24] found a proportion of physically aggressive patients of $26.3 \%$ in a secure care unit, compared with $8.7 \%$ in an admission ward and $1.4 \%$ in a chronic care unit, and the respective figures reported by Miller et al 
[22] were $27 \%$ for a locked short stay ward and $10 \%$ for a open short stay ward. The average monthly rate of violent behaviour (number of violent incidents divided by average census) in 13 wards ranged from 0.025 in an adult transitional program to 0.576 in a female acute admissions unit [25]. Findings that general risk factors for violence may not to be useful in acute admission settings underscore the importance of taking setting specific aspects into consideration [26, 27].

The generalisability of existing research specifically focusing on acute wards is hampered by the fact that the majority of the studies are single-centre studies, often restricted to one single ward, and - relatively to the incidence - cover a short period of observation and few treatment days. The largest sample is 7 acute wards in 4 hospitals [28], six studies comprise more than 10'000 treatment days [11, 2 wards, 1 hospital, 1.5 years , 28, 29, 1 ward, 3.5 years , 30, one ward, 5 years , 31, one ward, 3 years, 32, 1 ward, 1.5 years]. One of the findings in most studies is a small proportion of patients being responsible for a substantive proportion of incidents. These outliers make the interpretation of rates derived from single wards or short observation periods difficult.

In order to support the international collaboration in improving the management of aggressive behaviour it is imperative to obtain information which allows comparisons of services and caring approaches within health systems and between countries [1, 33].

To date only a few studies on aggression among psychiatric inpatients in Switzerland exist. These studies compare characteristics of aggressive and non-aggressive patients $[14,15,34]$ or focus on the description of incidents [35] or on costs of assaults on personnel [36]. The studies include various types of wards within one hospital [14, 15, 36] or all incidents in all wards in a group of six hospitals [34, 35], however none of them has investigated the situation of acute admission wards. Only Kaision et al [36] used an internationally widely used instrument (OAS, [37]), while the other studies employed different versions of an own instrument, though showing some similarities to the SOAS. None of these Swiss studies provides incident rates for different forms of aggressive behaviour per treatment day or per bed and year.

\section{Aim of the study}

The aim of this study is to describe the frequency and severity of aggressive incidents in acute psychiatric wards in the German speaking part of Switzerland. Secondary aims are to estimate the extent of underreporting and to explore associations of patients' 
characteristics with the occurrence of aggressive incidents. The study design aims to meet methodological problems of existing studies.

\section{Method and Materials}

We conducted a prospective multicentre study on acute admission wards in the German speaking part of Switzerland. The 32 psychiatric hospitals in this language area provide psychiatric inpatient treatment for approximately 75\% (5'376'800 persons) of the Swiss population. Of the 324 wards within these hospitals, 87 are acute wards having the following characteristics: The majority of patients have an acute psychiatric disorder, they are admitted voluntarily or against their will directly onto the ward, they stay less than three months on the ward, they are generally older than 18 and younger than 65 years, and the ward is not specialised in the treatment of special disorders (e.g. depression, addiction). Ten of these wards have a majority of private patients and few involuntarily admitted patients, 7 of them being located within private hospitals without obligation to treat patients from the region they are situated in.

\section{Setting and sample}

After approaching all 87 acute psychiatric wards in the study area 24 (27.6\%) wards from 12 hospitals agreed to participate in the study.

\section{Instruments}

Before embarking on this study a survey of all wards within the study area using a questionnaire covering data on the size of the wards, staffing, the facilities for managing aggression and violence [38] was conducted. Additionally, staff nurses were asked to rate the severity of the problem and the resources for aggression management.

Aggressive incidents were recorded by the revised Staff Observation Aggression Scale (SOAS-R) [39]. The SOAS-R covers provoking factors, the means used by the patient, the target of aggression, the consequence for the target, and the measures to terminate the aggression. The scale is to be completed by staff members witnessing aggressive behaviour of a patient whereby aggression is defined as any verbal, nonverbal, or physical behaviour that was threatening (to self, others, or property), or physical behaviour that actually did harm (to self, others, or property) [40]. The severity of the incidents was measured using the SOAS-R-scoring system which ranges 
from 0 to 22 points, and additionally by a $100 \mathrm{~mm}$-Visual Analogue Scale (VAS) with the endpoints "not severe incident" and "very severe incident".

Data on patients were taken from the hospitals data bases and included dates of admission and discharge, age, gender, and main psychiatric diagnosis according to ICD10.

In order to estimate possible underreporting visits to most of the study wards were conducted at randomly selected dates. We investigated the written shift reports of the previous three days and noted all descriptions of aggressive incidents. After termination of the study period, we controlled these incident data of the respective wards for SOAS-R-data covering these events, and estimated the severity of the incidents in cases where SOAS-R-forms were missing.

\section{Data analysis}

We included all aggressive incidents directed towards other persons or objects, but excluded purely auto-aggressive incidents. As recommended by the authors of the SOAS-R, events with a severity of 9 or more points on the SOAS-R-severity score were regarded as severe incidents (Henk Nijman, personal communication). Physical attacks were defined as recordings on the SOAS-R fulfilling the two criteria 1 ) the means of aggression = objects OR dangerous objects OR parts of the body AND 2) the target of the aggression $=$ a person other than the patient her- or himself. We calculated incidence rates for all aggressive incidents, for severe incidents, for physical attacks, physical aggression and purely verbally aggressive incidents. Incident rates were expressed as the proportion of patients involved in aggressive events, as event-rates per 100 hospitalisation days with 95\%-confidence-intervals, as event rates per bed per annum, and as the proportion of days with one or more event. In cases of multiple treatment episodes of patients in the study period, we used the first episode as index episode for the patient related analyses.

We employed binary logistic regression to test for associations between patients' characteristics and the incidence. We used the presence or absence of at least one more severe aggressive incident as binary outcome measure. We calculated crude odds ratios (OR) for each of the independent variables separately.

Statistical significance was determined using the traditional cut-off level $\alpha=0.05$. We used SPSS (Version 10.0, SPSS, Chicago, IL) and CIA (Confidence Interval Analysis, Version 2.1, University of Southampton, UK) for statistical analysis. 


\section{Results}

\section{Wards}

Information on ward characteristics were obtained from 82 of the 87 wards the study area. Twenty four wards with a total of 388 beds participated, representing 12 out of the 32 hospitals and $25 \%$ of all acute wards and $28 \%$ of all acute beds in the German speaking region of Switzerland. The number of beds per ward ranges from 9 to 19 with a mean number of beds of 16; the mean staff-patient-ratio was .77 Full Time Equivalents (FTE) per bed. Fifteen (62\%) of the wards are always closed, 9 wards part of the time, and 22 of the 24 wards have at least one seclusion room. According to the ratings of the staff nurses aggression is deemed a large or very large problem on 13 (54\%), as a small or medium problem on 11 (46\%) wards. None of the ward nurses rated aggression as very small or no problem at all. Seven (29\%) of the wards regarded their resources for managing aggression as insufficient. No significant differences were

\section{Table 1: Ward characteristics}

\begin{tabular}{|c|c|c|}
\hline & $\begin{array}{l}\text { Participating wards } \\
\qquad(\mathrm{N}=24)\end{array}$ & $\begin{array}{l}\text { Non-participating } \\
\text { wards }(\mathrm{N}=58)^{*}\end{array}$ \\
\hline Number of Beds mean (SD) & $16.1( \pm 2.4)$ & 16. $8( \pm 4.1)$ \\
\hline Nursing staff (FTE) per bed & $0.77( \pm 2.2)$ & $0.72( \pm 2.4)$ \\
\hline Proportion of wards always closed & $15(62.5 \%)$ & $28(30.4 \%)$ \\
\hline Proportion of wards with $\geq$ seclusion room & $22(95.7 \%)$ & $42(80.8 \%)$ \\
\hline \multicolumn{3}{|l|}{ Aggression rated as } \\
\hline - no/very small problem & $0(.0 \%))$ & $10(17.2 \%$ \\
\hline - small or medium problem & $11(45.8 \%)$ & $31(53.4 \%)$ \\
\hline - big/very big problem & $13(54.2 \%)$ & $17(29.3 \%)$ \\
\hline \multicolumn{3}{|l|}{ Resources for aggression-management rated as } \\
\hline - sufficient & $17(70.8 \%)$ & $47(81.0 \%)$ \\
\hline - unsufficient & $17(29.2 \%)$ & $11(19.0 \%)$ \\
\hline
\end{tabular}


problem and the rating their resources for aggression management as insufficient (table 1).

\section{Observation period}

The study period covered about 72 month (wards $x$ month) and included all seasons of the year: 13 month of observation in January-March, 5 in April-June, 16 in JulySeptember, and 38 in October - December.

\section{Patients}

During the study period 2017 patients (46.6 \% females, mean age $39.4 \pm 13.9$ years, range 12 - 96 years) accounted for 2344 treatment episodes on the 24 study wards. The hospitalisations comprised of $60.9 \%$ voluntary and $39.1 \%$ involuntary admissions giving rise to a total of 41'560 treatment days. The length of the treatment episodes ranged between one and 133 days (median 9, Mean 17.7 \pm 22.0 days). The patient's ICD-10 diagnoses comprised of schizophrenia, schizo-type and delusional disorders (ICD F2: 29.3\%), mood (affective) disorders (F3: 16.7\%), mental and behavioural disorders due to psychoactive substance use (F1: $24.9 \%$ ), neurosis (F4: $13.7 \%$ ) and personality disorders (F6: 4.1\%), and other ICD-10 categories (F0, F5, F7, F8, F9, others: $3.4 \%)$ (4.7\% missing).

\section{Aggressive incidents}

A total of 760 aggressive incidents were reported, including 396 incidents with a SOASR severity score of 9 or more and 252 physical attacks (the latter do not necessarily score 9 or more). 157 incidents were purely verbal aggression. These figures correspond to an overall incidence rate of 1.829 (95\% Cl $1.701-1.963$ ) aggressive incidents per 100 treatment days, 0.950 incidents with a severity score of $\geq 9(95 \% \mathrm{Cl}$ 0.859 - 1.049), and $0.606(95 \% \mathrm{Cl} 0.534-0.686)$ attacks against persons, respectively (table 2). The incident rates per bed per year were 7.08 for all incidents, 3.32 for more severe incidents (SOAS-R $\geq 9$ points) and 2.35 for physical attacks. On $14.2 \%$ (one in 7 days, one per week) of the calendar days within the study period at least one aggressive incident was registered, on $10.0 \%$ ( 1 in 10 days) of the days at least incident with a severity of $\geq 9$ and in $7.9 \%$ of the days at least one physical attack (one in 13 days, one every two weeks). 
Table 2: Incidence rates

\begin{tabular}{|c|c|c|c|c|c|}
\hline & $\mathbf{n}$ & $\begin{array}{c}\text { Rate per } 100 \\
\text { treatment days }\end{array}$ & $95 \% \mathrm{Cl}$ & $\begin{array}{c}\text { Rate per } \\
\text { bed per } \\
\text { year }\end{array}$ & $\begin{array}{c}\% \text { of calendar } \\
\text { days with } \geq 1 \\
\text { incident }\end{array}$ \\
\hline All incidents & 760 & 1.829 & $1.701-1.963$ & 7.08 & 14.2 \\
\hline $\begin{array}{l}\text { Incidents with SOAS-R } \\
\text { severity } \geq 9\end{array}$ & 396 & 0.950 & $0.859-1.049$ & 3.32 & 10.0 \\
\hline Physical aggression & 403 & 0.970 & $0.877-1.069$ & 3.77 & 10.3 \\
\hline Purely Verbal aggression & 357 & 0.859 & $0.772-0.953$ & 3.34 & 9.3 \\
\hline Physical attacks & 252 & 0.606 & $0.534-0.686$ & 2.35 & 7.9 \\
\hline $\begin{array}{l}\text { Incident requiring } \\
\text { treatment of the victim }\end{array}$ & 57 & 0.137 & $0.104-0.178$ & 0.53 & 2.3 \\
\hline
\end{tabular}

\section{Severity of aggressive incidents}

The severity of all 760 incidents on the SOAS-R severity scale ranged from 0 to 21 with a mean severity of $8.80 \pm 4.88$ and a median of 9 points. On the VAS, the mean severity rating was $34.40 \pm 26.26$ with a median of 28 and a range from 0 to 100 . There is a significant correlation between these two severity scores of 0.321 (Spearman Rho, $p<$ .001). The correlations were 0.352 in incidents of purely verbal aggression and 0.269 in incidents of physical aggression (table 3 ).

Table 3: SOAS-R- and VAS-Severity-Score

\begin{tabular}{lccccccc} 
& \multicolumn{2}{l}{ SOAS-R-Score } & \multicolumn{3}{c}{ VAS } & & $\begin{array}{c}\text { Corre- } \\
\text { lation }\end{array}$ \\
\cline { 2 - 7 } & $\mathrm{n}$ & Range; Med & Mean \pm SD & $\mathrm{n}$ & Range; Med & Mean \pm SD & $\mathrm{r}^{*}$ \\
\hline All incidents & 760 & $0-21 ; 9$ & $8.8 \pm 4.9$ & 669 & $0-100 ; 28$ & $34.4 \pm 26.3$ & 0.321 \\
$\begin{array}{l}\text { Physical } \\
\text { aggression }\end{array}$ & 403 & $0-21 ; 10$ & $10.0 \pm 5.1$ & 347 & $0-100 ; 30$ & $36.4 \pm 26.7$ & 0.269 \\
$\begin{array}{l}\text { Verbal } \\
\text { aggression }\end{array}$ & 357 & $0-17 ; 8$ & $7.5 \pm 4.3$ & 322 & $0-100 ; 27$ & $32.2 \pm 25.6$ & 0.352 \\
$\begin{array}{l}\text { Physical } \\
\text { attacks }\end{array}$ & 252 & $3-21 ; 11$ & $11.1 \pm 5.1$ & 212 & $0-100 ; 29$ & $36.8 \pm 27.9$ & 0.280 \\
\hline
\end{tabular}

* Spearman Rho, all correlations $p<0.001$

The mean severity of physically aggressive incidents was significantly higher than the severity of purely verbally aggression (Mann-Whitney-U Test $p<0.001$ for SOAS-R severity score and $p=0.026$ for VAS severity) (figure 1 ). However, $46 \%$ of the purely verbally aggressive incidents had a SOAS-R severity score of $\geq 9$ points and were 
classified as severe incidents, while in contrast $42 \%$ of the physically aggressive incidents scored as less severe.

Figure 1: Severity of verbally and physically aggressive incidents (VAS-score)

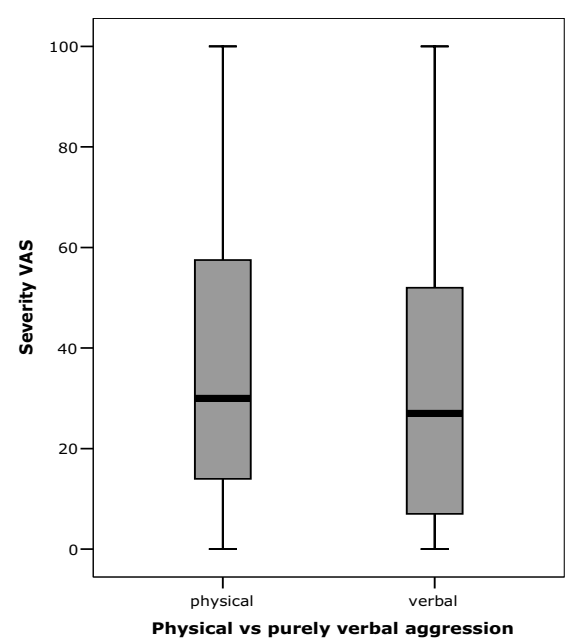

Incidents followed by a coercive measure

Dependent on their nature and severity, between 43\% (verbal aggression) and 67\% (SOAS-R-severity score of $\geq 9$ points) of the aggressive incidents were followed by a coercive measure, in most cases in form of seclusion or seclusion accompanied by per oral medication or forced injection, while physical restraint was rarely used (table 4). 
Table 4: Incidents followed by coercive measure

3 most frequently used forms of coercion in

response to the aggressive incidents

n (\%*)

\begin{tabular}{lccccc}
\hline Type of incident & $\mathbf{n}$ & $\begin{array}{c}\text { Followed by } \\
\text { coercive measure } \\
\mathbf{n}(\%)\end{array}$ & Seclusion & $\begin{array}{c}\text { Seclusion }+ \\
\text { medication } \\
\text { p.o. }\end{array}$ & $\begin{array}{c}\text { Seclusion + } \\
\text { forced injection }\end{array}$ \\
\hline All incidents & 760 & $406(53.4 \%)$ & $110(14.5 \%)$ & $96(12.6 \%)$ & $37(4.9 \%)$ \\
$\begin{array}{l}\text { Incidents with SOAS- } \\
\text { R severity } \geq 9\end{array}$ & 396 & $266(67.2 \%)$ & $72(18.2 \%)$ & $64(16.2 \%)$ & $28(7.1 \%)$ \\
$\begin{array}{l}\text { Physical aggression } \\
\text { Verbal aggression }\end{array}$ & 403 & $253(62.8 \%)$ & $7117.6 \%$ & $53(13.2 \%)$ & $28(6.9 \%)$ \\
Physical attacks & 257 & $153(42.9 \%)$ & $39(10.9 \%)$ & $43(12.0 \%)$ & $9(2.5 \%)$ \\
\hline
\end{tabular}

*\% of all incidents of the respective category

\section{Proportion of aggressive patients}

No aggressive incidents were recorded amongst 1755 (87.0\%) of the 2017 patients, while 262 (13.0\%) of the patients were responsible for one or more incident, and $6.7 \%$ were involved in one or more physical attack. $38(1.9 \%)$ of the patients accounted for $51 \%$ of all events, and $58(2.9 \%)$ of the patients accounted for $50 \%$ of all attacks (see table 5). 
Table 6: Percentage of patients involved in aggressive incidents $(n=2017) *$

\begin{tabular}{|c|c|c|c|c|c|c|c|c|}
\hline \multirow{3}{*}{$\begin{array}{l}\text { Incidents per } \\
\text { patient }\end{array}$} & \multicolumn{8}{|c|}{ Patients involved in ... } \\
\hline & \multicolumn{2}{|c|}{... all incidents } & \multicolumn{2}{|c|}{$\begin{array}{c}\text {... incidents with } \\
\text { SOAS-R-severity } \geq 9\end{array}$} & \multicolumn{2}{|c|}{... physical attacks } & \multicolumn{2}{|c|}{$\begin{array}{l}\text {... incidents } \\
\text { requiring treat- } \\
\text { ment of the } \\
\text { victim }\end{array}$} \\
\hline & $\mathrm{n}$ & $\%$ & $\mathrm{n}$ & $\%$ & $\mathrm{n}$ & $\%$ & $\mathrm{n}$ & $\%$ \\
\hline 0 & 1755 & $87.0 \%$ & 1827 & $90.6 \%$ & 1881 & $93.3 \%$ & 1977 & $98.0 \%$ \\
\hline 1 & 153 & $7.6 \%$ & 130 & $6.4 \%$ & 97 & $4.8 \%$ & 34 & $1.7 \%$ \\
\hline 2 & 52 & $2.6 \%$ & 70 & $3.5 \%$ & 26 & $1.3 \%$ & 6 & $0.3 \%$ \\
\hline $3-5$ & 34 & $1.7 \%$ & 18 & $0.9 \%$ & 10 & $0.5 \%$ & & \\
\hline $6-10$ & 16 & $0.8 \%$ & 4 & $0.2 \%$ & 2 & $0.1 \%$ & & \\
\hline $11-20$ & 4 & $0.2 \%$ & 3 & $0.1 \%$ & 1 & $0.0 \%$ & & \\
\hline$>20$ & 3 & $0.1 \%$ & & & & & & \\
\hline Total & 2017 & $100.0 \%$ & 2017 & $100.0 \%$ & 2017 & $100.0 \%$ & 2017 & $100.0 \%$ \\
\hline$\geq 1$ Incidence & 262 & $13.0 \%$ & 190 & $9.4 \%$ & 136 & $6.7 \%$ & 40 & $2.0 \%$ \\
\hline $\begin{array}{l}\text { Patients } \\
\text { accounting for } \\
50 \% \text { of } \\
\text { incidents }\end{array}$ & 38 & $1.9 \%$ & 41 & $2.0 \%$ & 58 & 2.9 & 3 & $0.1 \%$ \\
\hline
\end{tabular}

* Calculations based on index episode (one per patient); 636 incidents, 338 severe incidents, 185 physical attacks, 46 incidents requiring treatment

\section{Associations of patient characteristics with incidence of severe aggressive incidents}

The occurrence of one or more aggressive incident was significantly associated with the age of the patient, admission status of the patient, length of stay and diagnostic group (table 6). A lower risk was found in patients aged over 50 (OR 0.67), in patients with a short length of stay (OR 0.46), in patients with a diagnosis of substance abuse (F1) (OR 0.50), and, in patients with neurotic or personality disorders (F4/F6) (OR 0.56 ). $A$ higher risk was found in involuntary patients (OR 2.16), in patients with a length of stay of $\geq 17$ days (OR 2.72), in patients with a diagnosis of schizophrenia (F2) (OR 2.10) or a diagnosis out of the ICD-10 categories F0, F5, F7, F8, F9, F10 (OR 2.16). No significant association with the risk for aggression was found for gender and affective disorders (ICHD-10 F3) (table 6). 
Table 6: Odds ratios for the occurrence of severe aggressive incidents $(n=2017)$

\begin{tabular}{|c|c|c|c|c|c|c|}
\hline & & $\mathbf{n}$ & $\begin{array}{l}\text { Patients with severe } \\
\text { aggressive incident }\end{array}$ & Cru & de odds ratio & \\
\hline & Factor & & & & $\mathrm{OR}(95 \%-\mathrm{Cl})$ & $\mathrm{p}^{*}$ \\
\hline Gender & female & 940 & $8.5 \%$ & & (ref) & \\
\hline & male & 1077 & $10.2 \%$ & 1.21 & $(0.92-1.60)$ & 0.18 \\
\hline $\mathrm{Age}^{1}$ & $\leq 29$ yrs. & 537 & $10.2 \%$ & 1.04 & $(0.75-1.43)$ & 0.82 \\
\hline & $30-48$ yrs. & 986 & $10.2 \%$ & & (ref) & \\
\hline & $\geq 49$ yrs. & 493 & $6.9 \%$ & 0.67 & $(0.46-0.99)$ & 0.04 \\
\hline Admission & voluntary & 1165 & $6.6 \%$ & & (ref) & \\
\hline 2 & involuntary & 746 & $13.3 \%$ & 2.16 & $(1.63-2.90)$ & $<0.001$ \\
\hline LOS & $\leq 5$ days & 703 & $3.7 \%$ & 0.46 & $(0.29-0.73)$ & 0.002 \\
\hline & 6-16 days & 674 & $7.7 \%$ & & (ref) & \\
\hline & $\geq 17$ days & 640 & $17.5 \%$ & 2.72 & $(1.96-3.77)$ & $<0.001$ \\
\hline Diagnosis & $\mathrm{F} 1$ & 503 & $5.6 \%$ & 0.50 & $(0.33-0.76)$ & 0.001 \\
\hline (ICD-10) & $\mathrm{F} 2$ & 590 & $13.9 \%$ & 2.10 & $(1.54-2.88)$ & $<0.001$ \\
\hline+3 & F3 & 336 & $6.8 \%$ & 0.68 & $(0.43-1.08)$ & 0.101 \\
\hline & $\mathrm{F} 4 / 6$ & 358 & $5.9 \%$ & 0.56 & $(0.35-0.90)$ & 0.017 \\
\hline & Others & 136 & $16.9 \%$ & 2.16 & $(1.34-3.48)$ & 0.002 \\
\hline
\end{tabular}

\# calculated separately for each variable * wald statistic

${ }^{+}$calculated separately for each diagnostic category compared to all other diagnostic groups

${ }^{1} 1$ missing ${ }^{2} 106$ missing ${ }^{3} 94$ missing

\section{Occurrence of incidents during hospitalisation}

One in four of the incidents and $1 / 3$ of the attacks were registered within the first three days, $37.5 \%$ within the first 7 days of the hospitalisations and about half of the incidents within the first 14 days (table 7).

Most incidents occurred between 10 a.m. and 8 p.m., with peaks between 10-11 a.m. and 5 to 8 p.m., and they were nearly equally distributed among weekdays, with fewer incidents on Sundays. 
Table 9: Occurrence of incidents during hospitalisation

\begin{tabular}{lccccccccc}
\hline & \multicolumn{3}{c}{ All incidents } & \multicolumn{3}{c}{$\begin{array}{c}\text { Incidents } \\
\text { SOAS- } \geq 9\end{array}$} & & \multicolumn{2}{c}{ Physical attacks } \\
\cline { 2 - 9 } & $\mathrm{n}$ & $\%$ & Cum \% & $\mathrm{n}$ & $\%$ & Cum \% & $\mathrm{n}$ & $\%$ & Cum \% \\
\hline Day of admission & 94 & 12.4 & 12.4 & 59 & 14.9 & 14.9 & 46 & 18.3 & 18.3 \\
Day 2-3 & 107 & 14.1 & 26.4 & 56 & 14.2 & 29.1 & 37 & 14.7 & 32.9 \\
Day 4-7 & 84 & 11.1 & 37.5 & 37 & 9.4 & 38.5 & 34 & 13.5 & 46.4 \\
Day 8-14 & 97 & 12.8 & 50.3 & 46 & 11.6 & 50.1 & 27 & 10.7 & 57.1 \\
Day 15-30 & 100 & 13.2 & 63.4 & 56 & 14.2 & 64.3 & 33 & 13.1 & 70.2 \\
Day 31-90 & 146 & 19.2 & 82.6 & 80 & 20.3 & 84.6 & 41 & 16.3 & 86.5 \\
Day 91 or later & 132 & 17.4 & 100.0 & 61 & 15.4 & 100.0 & 34 & 13.5 & 100.0 \\
\hline Total & 760 & 100.0 & & 395 & 100.0 & & 252 & 100.0 \\
\hline
\end{tabular}

\section{Estimation of underreporting}

Shift reports of 191 patients covering 573 treatment days were checked by C.A. and I.N. for descriptions of aggressive incidents and then compared with the SOAS-forms from the respective time-periods and patients. We found 11 incidents not registered on the SOAS form. Two of these incidents included physical aggression (in one event, during a dispute between patients one of these threw a cup against his counterpart; in the other event a patient hit a nurse with a bedpan). Nine of the unreported incidents included only verbal aggression, but only in 2 of theses cases the verbal aggression was explicitly described as threatening and was therefore clearly covered by the definition of aggression included in the SOAS-form. According to our estimation of the severity of these incidents, the severity scores were between 1 and 5 points and none of them would have reached a severity score of 9 ore more. Therefore, calculated for the 41560 treatment days in our study, we would have about 280 unreported incidents less severe physical aggression, but no unreported incidents of a severe nature scoring 9 or more points. Considering our total of 681 reported incidents, this would equal a $30 \%$ rate of underreporting of "mild" incidents.

\section{Discussion}

The aim of this study was to describe the frequency and severity of aggressive incidents in acute psychiatric wards in the German speaking part of Switzerland and to 
explore associations of patients' characteristics with the occurrence of aggressive incidents. The study design aims to meet methodological problems of existing studies.

\section{Strengths and weaknesses}

The inclusion of 24 wards from 12 hospitals and more than $40^{\prime} 000$ treatment days makes our study to one of the largest studies addressing aggression specifically in acute wards. Given the close confidence intervals we consider our results as robust and less subject to local variations in single wards or hospitals. To our knowledge this study is the first to report data on a sample of wards representative for a larger geographic area. The strengths of our study include its prospective nature, the use of a standardized and widely used instrument, enabling us to report different incident rates and rates for different types of aggressive incidents, including confidence intervals which are rarely reported. This is one of the few studies including a systematic check of underreporting enabling us to estimate its extent. However, limitations of this study include the observed underreporting of less severe incidents and of patient-to-patient aggression, and the relatively short observation period of 3 month per ward. The participating wards are a convenience sample and therefore we cannot fully exclude the presence of a sampling bias. However, the sample included one out of four acute wards within the study area. Control for differences in the characteristics of participating and non-participating wards showed some differences. Despite of the inclusion criteria for acute admission wards, a limitation related to studies on acute wards is a possible remaining heterogeneity of the wards due to differences in service organisation (e.g. number of beds per catchment area), hospital organisation (e.g. degree of specialisation of wards) and policy (e.g. referrals from admission to other wards). This hampers the generalisability beyond the wards under study. Another limitation is the lack of more detailed information on socio-demographic, clinical and behavioural characteristics of the patients (e.g. data on the severity of psychopathology and illness). The observation periods of the study wards covered all seasons. However, they were unequally distributed and we had more months of observation in autumn and winter than in spring and summer. Thus we cannot exclude a possible seasonal bias.

\section{Implications and comparison with previous studies}

Incidence: We found incidence rates per 100 hospitalisation days of 1.8 for all aggressive incidents, of 1 for incidents with a SOAS-R severity score of $\geq 9$, and of 0.61 for attacks against persons. On $14 \%$ of the calendar days at least one aggressive 
incident was registered (one per week), on 1 in 10 days at least one more severe incident with a severity of $\geq 9$ and in one in 13 days at least one physical attack. These results confirm the findings of studies that aggression is a serious and frequent problem in acute admission wards. Compared to results of the largest studies focusing on acute wards, our overall incidence of 1.8 aggressive incidents per 100 hospitalisation was higher than the rates found in three of these studies, equal to the rate found by Barlow et al [11], but lower that the rate reported by Mellesdal [30] (see table 8). The latter can possibly be explained by the high rate of admissions and occupancy levels up to $133 \%$ reported by the authors. However, comparing the rates for physical assaults only, our rates are comparable with others. This finding underlines problems of comparing overall incidence rates. The variance in the incidence rates is lower and there is more overlap in the confidence intervals between the studies when a more narrow definition of aggression is applied. This could possibly be explained by inconsistencies in registering non-physical aggression. E.g. one third of the incidences in our study were physical assaults, compared with $80 \%$ found by Grassi et al [29], both using the same instrument (SOAS).

Table 8 Comparison of incident rates among 6 larger studies in acute wards

\begin{tabular}{lccccc}
\hline Study & Study size & $\begin{array}{c}\text { treatment } \\
\text { days }^{2}\end{array}$ & $\begin{array}{c}\text { \% patients } \\
\text { involved }\end{array}$ & \multicolumn{2}{c}{$\begin{array}{c}\text { Incident rates per } 100 \text { treatment days } \\
\text { (95\%- Cl) }\end{array}$} \\
\hline Swiss results & $12 \mathrm{~h}, 24 \mathrm{w}$ & $41^{\prime} 560$ & $13 \%$ & $1.83(1.70-1.96)$ & $0.61(0.53-0.69)$ \\
Chou et al [28] & $4 \mathrm{~h}, 7 \mathrm{w}$ & $56^{\prime} 000$ & n.a. & $1.53(1.43-1.63)$ & $0.84(0.77-0.92)$ \\
Grassi et al [30] & $1 \mathrm{w}$ & $27^{\prime} 375^{2}$ & $8 \%$ & $1.20(1.08-1.34)$ & $0.97(0.86-1.01)$ \\
Barlow et al [11] & $1 \mathrm{~h}, 2 \mathrm{w}$ & $18^{\prime} 560^{2}$ & $13 \%$ & $2.05(1.84-2.27)$ & $0.45(0.36-0.56)$ \\
Mellesdal [31] & $1 \mathrm{w}$ & $17^{\prime} 430$ & $7 \%$ & $5.63(5.28-5.99)$ & $3.15(2.90-3.43)$ \\
Omerov et al [32] & $1 \mathrm{~h}, 2 \mathrm{w}$ & $17^{\prime} 400$ & & $0.79(0.66-0.93)$ & $0.60(0.49-0.72)$ \\
\hline
\end{tabular}

${ }^{1} h=$ hospitals, $w=$ wards; ${ }^{2}$ calculated assuming 95\%-occupancy

Among other purposes, data on the incidence of aggression in psychiatry is used to investigate risk factors and as benchmark data in studies on the effectiveness of interventions or services in dealing with aggression [8]. Discrepancies as shown in table 3 add substantially to difficulties in research aimed at reducing aggression and violence.

In our study a small group of $2 \%$ of the patients accounted for $50 \%$ of all incidents, while no aggressive incidents were registered in $87 \%$ of the patients. These findings 
are consistent with other studies [11] [17] [30] [34] [39] and support the demand for a more thorough investigation of this high-risk group [40].

Severity: The mean and median severity of all incidents on the SOAS-R severity scale was 9 points. This is supportive for the cut-off of 9 points to separate more and less severe incidents. However, the correlation between the SOAS-R-severity score and the subjective VAS-data was low, lower than the correlations reported by others [16] [37] and calling for further investigation on the measurement of severity. Our SOAS-Rseverity score of physical assaults of $11.1 \pm 5.1$ points is comparable to the severity reported by Grassi et al. [29]. 46\% of the purely verbally aggressive incidents were classified as severe incidents, while $42 \%$ of the physically aggressive incidents scored as less severe. These results underscore the importance to register verbal aggression and not to rely on data restricted to aggression of physical nature.

Corresponding with other studies, we found a small proportion of very severe assaults requiring medical treatment of the victim [11] [41].

Coercion: Between 43\% (verbal aggression), 53\% (all events) and 67\% (severe incidents) of the aggressive incidents were answered by a coercive measure. This figures are equal to those reported by Nijman et al [42] and Omerov et al [31], where $49 \%$ and $46 \%$ of the incidents were followed by coercive measures (seclusion with or without restraint and forced injection or physical restraint respectively), but they appear high compared to $28 \%$ of incidents followed by parenteral medication or restraints reported by Grassi et al [29].

Patients: In our sample a higher risk for the occurrence of aggressive incidents was associated with involuntary admission (OR 2.16; 1.6-2.9), longer length of stay (OR 2.7; 2.0-3.8), F2-diagnoses (OR 2.1; 1.5-2.9) and, other diagnoses than F1, F2, F3. F4/6 (OR 2.1 ; 1.3-3.5), while this was not the case for age and gender. A higher risk for aggression in involuntary admitted patients and patients with prolonged stay on acute wards has been observed regularly [11] [30] [42]. However, this finding is not surprising given the fact that danger to others is the main reason for involuntary commitments and one frequent obstacle for discharge. No gender differences in the overall incidence of aggression were found in several studies [11] [28] [30] [42]. However, the relationship of gender to the incidence of aggression appears complex and study results vary according to different types of aggression studied [43]. E.g. findings in some studies include a higher severity of incidents caused by female inpatients [29] [30], or higher rates of verbal aggression among women [43]. This was not the case in our sample. In line with others, we found no association of patients' 
age with a higher risk for the occurrence of aggression [11] [30], while younger age was found to be a risk factor in several studies [26] [28] [29] [42]. A higher risk for aggression in patients with a diagnosis of schizophrenia [11] [29] [30] or psychotic disorder [28] was found in several studies. In contrast, other author's found no associations of diagnostic groups to an increased risk for aggression [42] [26] [34]. Based on our dataset, the higher risk in our heterogeneous rest-category of other diagnoses (F0, F5, F7, F8, F9, F 10) is difficult to interpret. It may be explained by the patients with organic conditions within this group, as organic mental disorders have been identified as risk factor for violence [30]. However, the utility of diagnoses as risk factor has been questioned by several authors, pointing to the behavioural variation within diagnostic groups and the changes in symptomatology in the course of the illness [30]. In line with this, severity or acuity of illness were identified as more reliable predictors of violence than diagnoses [34].

Time after admission: One in four of the incidents and $1 / 3$ of the attacks were registered within the first three days of the hospitalisations and about half of the incidents occurred within the first 14 days. An accumulation of aggressive incidents in the first days after admission has been reported frequently [11] [29] [30]. However, in contrast to other studies we observed a substantial proportion of incidents later in the course of the hospitalisation. This is an indication not to limit systematic risk assessment to the admission phase.

Underreporting: We found a $30 \%$ underreporting in mild incidents and no underreporting of more severe incidents scoring 9 or more points. We interpret this as clue to the validity of the SOAS-R in registering serious aggressive incidents. However, the rate of underreporting of less severe incidents including many cases of verbal aggression or aggression directed towards objects leads to an underestimation of the overall aggressivity in acute settings. Furthermore, we cannot completely exclude that some incidents were not registered in the shift reports that we used to control for underreporting on SOAS-R-forms. As shown above, the obvious variability in reporting less severe incidents makes comparisons of total incidence rates problematic. Among the unreported incidents were cases of patient-to-patient aggression, which raises some concern. As the usual reporting-systems requires that staff members are witnesses of an incident, some of the aggression between patients is inevitably undetected, as demonstrated by studies using video surveillance of day rooms [44]. However, there have been complaints of service users on neglecting the negative effects of violence in patients compared to the attention towards victimisation among staff [45]. 


\section{Conclusion}

Aggressive incidents in acute admission wards are a frequent and serious problem. Due to the large and representative sample size, the prospective study design and the use of a standardized reporting instrument this study, we consider the incidence rates as robust and representative for acute wards in German speaking Switzerland, and thus useful as reference for comparative research and studies aimed at reducing aggression and violence in acute admission wards. Implications for clinical practice include the recommendation to extend the systematic risk assessment beyond the first days after admission. More attention should be given to patient-to-patient aggression. The high rate of coercion as response to aggression underscores the need for research on preventive or less restrictive interventions vis-à-vis aggressive behaviour (see e.g. [46]).

With regard to further research this study supports the call for more in depth research on frequently aggressive patients. It confirms the necessity to differentiate between types of aggressive behaviour when reporting and comparing incidence-data.

\section{Acknowledgements}

This study was supported by grant number 3251B0-100710 of the Swiss National Science Foundation. We gratefully acknowledge the help from the members of the European Violence in Psychiatry Research Group EViPRG. We want to thank the staff of the participating wards for their patient and helpful collaboration in the collection of data.

\section{REFERENCES}

1. Palmstierna T, Wistedt B: Violence in psychiatry, view-points for standardized research. Acta Psychiatr Scand 2000, 102:79-80.

2. Bowers L: The expression and comparison of ward incident rates. Issues Ment Health Nurs 2000, 21:365-374.

3. Steinert T, Gebhardt RP: Wer ist gefährlich? Probleme der Validitat und Reliabilitat bei der Erfassung und Dokumentation von fremdaggressivem Verhalten. Psychiatr Prax 1998, 25:221-226.

4. Liu J: Concept analysis: aggression. Issues Ment Health Nurs 2004, 25:693-714.

5. Jansen G, Dassen T, Moorer P: The perception of aggression. Scand J Caring Sci 1997, 11:51-55.

6. Suris A, Lind L, Emmett G, Borman PD, Kashner M, Barratt ES: Measures of aggressive behavior: overview of clinical and research instruments. Aggression and Violent Behavior 2004, 9:165-227.

7. Gothelf D, Apter A, van Praag HM: Measurement of aggression in psychiatric patients. Psychiatry Res 1997, 71:83-95.

8. Bowers L: A critical appraisal of violent incident measures. J Mental Health 1999, 8:339-349. 
9. Cooper A, Mendonca J: A prospective study of patient assaults on nursing staff in a psychogeriatric unit. Can J Psychiatry 1989, 34:399-404.

10. Carmel H, Hunter M: Staff injuries from inpatient violence. Hosp Community Psychiatry 1989, 40:4146.

11. Barlow K, Grenyer B, Ilkiw-Lavalle O: Prevalence and precipitants of aggression in psychiatric inpatient units. Aust N Z J Psychiatry 2000, 34:967-974.

12. Spiess $\mathrm{H}$, Krischker S, Cording C: Aggressive Handlungen im psychiatrischen Krankenhaus: Eine auf die psychiatrische Basisdokumentation gestützte 6-Jahres-Studie bei 17,943 stationären Aufnahmen Psychiatr Prax 1998, 25:227-230.

13. Steinert T, Vogel W, Beck M, Kehlmann S: Aggressionen psychiatrischer Patienten in der Klinik: Eine 1Jahres-Studie an vier psychiatrischen Landeskrankenhäusern. Psychiatr Prax 1991, 18:155-161.

14. Geser AM: Aggressionen von hospitalisierten psychisch Kranken: Eine systematische Evaluation von knapp 2000 Aggressionsfällen. Zürich: Universität Zürich, Dissertation Medizinische Fakultät; 1999.

15. Gerber A: Aggressionen psychiatrischer Patienten in der Klinik: Eine 2-Jahres-Studie an der Psychiatrischen Universitätsklinik Zürich. Zürich: Universität Zürich, Dissertation Medizinische Fakultät; 1995.

16. Nijman HL, Palmstierna T, Almvik R, Stolker JJ: Fifteen years of research with the Staff Observation Aggression Scale: a review. Acta Psychiatr Scand 2005, 111:12-21.

17. Owen C, Tarantello C, Jones M, Tennant C: Violence and aggression in psychiatric units. Psychiatr Serv 1998, 49:1452-1457.

18. Lion JR, Snyder W, Merrill GL: Underreporting of assaults on staff in a state hospital. Hosp Community Psychiatry 1981, 32:497-498.

19. Bjorkly S: Report form for aggressive episodes: preliminary report. Percept Mot Skills 1996, 3:11391152.

20. Lanza ML: Nurses as patient assault victims: An update, synthesis, and recommendations. Arch Psychiatr Nurs 1992, 6:163-171.

21. Munro V: Why do nurses neglect to report violent incidents? Nurs Times 2002, 98:38-39.

22. Miller RJ, Zadolinnyj K, Hafner RJ: Profiles and predictors of assaultiveness for different psychiatric ward populations. Am J Psychiatry 1993, 150:1368-1373.

23. Cheung P, Schweitzer I, Tuckwell V, Crowley KC: A prospective study of aggression among psychiatric patients in rehabilitation wards. Aust N Z J Psychiatry 1996, 30:257-262.

24. Kay S, Wolkenfeld F, Murrill L: Profiles of aggression among psychiatric inpatients. Nature and prevalence. J Nerv Mental Disease 1988, 176:539-546.

25. Kraus JE, Sheitman BB: Characteristics of violent behavior in a large state psychiatric hospital. Psychiatr Serv 2004, 55:183-185.

26. Kho K, Sensky T, Mortimer A, Corcos C: Prospective study into factors associated with aggressive incidents in psychiatric acute admission wards. Br J Psychiatry 1998, 172:38-43.

27. Palmstierna T, Wistedt B: Risk factors for aggressive behaviour are of limited value in predicting the violent behaviour of acute involuntarily admitted patients. Acta Psychiatr Scand 1990, 1:152-155.

28. Chou KR, Lu RB, Mao WC: Factors relevant to patient assaultive behavior and assault in acute inpatient psychiatric units in Taiwan. Arch Psychiatr Nurs 2002, 16:187-195.

29. Grassi L, Peron L, Marangoni C, Zanchi P, Vanni A: Characteristics of violent behaviour in acute psychiatric in-patients: a 5-year Italian study. Acta Psychiatr Scand 2001, 104:273-279.

30. Mellesdal L: Aggression on a psychiatric acute ward: a three-year prospective study. Psychol Rep 2003, 92:1229-1248. 
31. Omerov M, Edman G, Wistedt B: Incidents of violence in psychiatric inpatient care. Nord J Psychiatry 2002, 56:207-213.

32. Miserez B: Häufigkeit und Ausmaß von Aggressionsereignissen in sechs psychiatrischen Kliniken in der Schweiz. Psych Pflege Heute 2003, 9:31-35.

33. Observation des comportements agressifs des patients hospitalisés: entre devoir d'identification précoce de l'agressivité, risques de stigmatisation et exigences thérapeutiques [www.pnel.qc.ca/violence/kaision/kaision2.htm]

34. Ruesch P, Miserez B, Hell D: Gibt es ein Täterprofil des aggressiven Psychiatriepatienten? Nervenarzt 2003, 74:259-265.

35. Yudofsky S, Silver J, Jackson W, Endicott J, Williams D: The Overt Aggression Scale for the objective rating of verbal and physical aggression. Am J Psychiatry 1986, 143:35-39.

36. Needham I, Abderhalden C, Dassen T, Haug HJ, Fischer JE: Coercive procedures and facilities in Swiss psychiatry. Swiss Med Wkly 2002, 132:253-258.

37. Nijman HL, Muris P, Merckelbach HLGJ, Palmstierna T, Wistedt B, Vos AM, van Rixtel A, Allertz WWF: The Staff Observation Aggression Scale - Revised (SOAS-R). Aggress Behav 1999, 25:197-209.

38. Morrison E: Violent psychiatric inpatients in a public hospital. Scholarly Inquiry for Nursing Practice 1990, 4:65-82.

39. Savermuttu A, Lowe T: Aggressive incidents on a psychiatric intensive care unit. Nurs Stand. 2000 May 17-23;14(35):33-6.

40. Blow FC, Barry KL, Copeland LA, McCormick RA, Lehmann LS, Ullman E: Repeated assaults by patients in VA hospital and clinic settings. Psychiatr Serv 1999, 50:390-394.

41. Raja M, Azzoni A: Hostility and violence of acute psychiatric inpatients. Clin Pract Epidemol Ment Health 2005, 1.

42. Nijman HLI, Allertz WWF, àCampo JLMG, Ravelli DP: Aggressive behavior on an acute psychiatric admission ward. Eur J Psychiat 1997, 11:104-114.

43. Krakowski M, Czobor P: Gender differences in violent behaviors: relationship to clinical symptoms and psychosocial factors. Am J Psychiatry 2004, 161:459-465.

44. Crowner ML, Stepcic F, Peric G, Czobor P: Typology of patient-patient assaults detected by videocameras. Am J Psychiatry 1994, 151:1669-1672.

45. Kumar S, Guite H, Thornicroft G: Service users' experience of violence within a mental health system: A study using grounded theory approach. J Mental Health 2001, 10:597-611.

46. Veltro F, Falloon I, Vendittelli N, Oricchio I, Scinto A, Gigantesco A, Morosini P: Effectiveness of cognitive-behavioural group therapy for inpatients. Clin Pract Epidemol Ment Health 2006, 2:16. 


\section{Part II:}

Effect of the assessment of the short term risk for patient violence in acute psychiatric wards 



\section{Chapter 4}

\section{Predicting inpatient violence in acute psychiatric wards using the Brøset-Violence-Checklist: A multi-center prospective cohort study}

Abderhalden C, Needham I., Miserez B., Dassen T., Haug HJ., Fischer JF. (2004) Predicting inpatient violence in acute psychiatric wards using the Brøset-Violence-Checklist: a multicentre prospective cohort study. Journal of Psychiatric and Mental Health Nursing 11: 422-427 


\section{Summary}

The Norwegian Brøset-Violence-Checklist (BVC) is one of the few instruments suited for short-time prediction of violence of psychiatric inpatients by nursing staff in routine care. The instrument assesses the presence or absence of six behaviours or states frequently observed prior to a violent incident. We conducted a study to elucidate whether the predictive properties of the BVC are retained in other psychiatric settings than the original North-Norwegian validation dataset. During their admission period, 219 consecutive patients admitted to 6 acute psychiatric wards were assessed as to the risk for attack using a German version of the BVC (BVC-G). Data on preventive measures were concurrently collected. Aggressive incidents were registered using an instrument equivalent to the Staff Observation of Aggression Scale (SOAS). Fourteen attacks toward staff were observed with incident severity ranging from 5 to 18 of a possible 22 points. BVC-G sensitivity was $64.3 \%$, the specificity $93.9 \%$, the positive predictive value $11.1 \%$, and the area under the receiver operating characteristic curve 0.88 . In some false positive cases intense preventive measures had been implemented. The predictive accuracy of the BVC-G proved consistent with the Norwegian original. 


\section{Introduction}

Aggression and violence and their negative consequences for health, safety and wellbeing of patients and staff are of major concern in inpatient psychiatric care. Therefore, reducing the incidence and severity of aggression and violence is of primary importance for improving the quality of care in psychiatric facilities. Accurate risk prediction would allow to plan and initiate preventive measures.

Despite of a large body of research on risk-factors, predictors, and on the accuracy of predicting violence (Steinert 2002), only few studies have focussed on the short-term prediction of violence in acute admission wards, or have systematically explored the predictive properties of risk assessment instruments in this clinical setting (Ferris et al. 1997, Harris \& Rice 1997, Mossman 1994, RCP 1998).

Recently, Norwegian researchers have developed a behavioural observation score for short-term prediction of patient violence (Almvik \& Woods 1998, Almvik et al. 2000, Woods \& Almvik 2002). The instrument is based on data by Linaker and Busch-Iverson (1995), who reported on the most frequently observed behaviours prior to a violent incident. The Norwegian Brøset-Violence-Checklist (BVC) assesses the presence or absence of six behaviours or states: confusion, irritability, boisterous behaviour, verbal threatening, physical threatening, and attacking objects. The instrument includes short definitions of the six phenomena, and each of the six items of the BVC is scored for its presence (1) or absence (0). The sum of scores is then totalled and interpreted in the following way: A sum of 0 suggests that the risk of violence is small; scores of 1 or 2 suggest that the risk is moderate, and preventive measures should be taken; and scores of 3 and more indicate that the risk of violence is very high, immediate preventive measures are required, and plans for handling an attack should be activated (Almvik \& Woods 1998, Almvik et al. 2000). Scoring can be performed in different intervals, depending on the shift system. The BVC predicts a physical attack within the next shift. One scoring per shift has been found most suitable, and therefore the usual number of ratings is 2 to 3 in 24 hours. The Norwegian BVC is easily administered by nursing staff and is one of the few instruments suited for short-time prediction of violence of psychiatric inpatients by nursing staff in routine care (Almvik et al. 2000).

The original Norwegian instrument was originally tested in 109 patients (901 predictions), amongst whom 34 of physical attacks were observed. The BVC 
demonstrated good psychometric properties and yielded a sensitivity of 0.74 with a specificity of 0.91 (Almvik et al. 2000). Presently, a number of studies are under way to assess the clinical utility of the instrument (Woods \& Almvik 2002). Since its original publication, the instrument has been widely introduced into routine practice in several countries. Despite this wide spread use, there is a paucity of studies ascertaining the predictive usefulness of the BVC. Moreover, the rate of aggressive incidents was fairly high in the specific Norwegian setting, leading to the question wheter the discriminatory properties are maintained in acute wards with lower aggression prevalence.

To address these shortcomings we conducted a multi-center prospective cohort study in acute wards in Swiss psychiatric hospitals. The aim of the present study was to validate the instrument using standard diagnostic test validation procedures. Secondary aims of the study were a) to elucidate whether more detailed assessment of the observed six behavioural categories would improve the predictive abilities of the instrument, and b) to investigate the association between scores on the German and intense preventive measures directed towards reducing the risk of aggressive incidents.

\section{Methods}

\section{Setting and subjects}

The study was conducted in six acute wards of three psychiatric hospitals within the region of Zurich, Switzerland. Each hospital provides a comprehensive psychiatric service to catchment areas of approximately 250000 citizens. Five wards are always locked, and the sixth most of the time. The number of beds ranges from 15 to 19 . Staffing levels vary between 0.7 and 0.9 full-time-equivalents (FTE) of fully qualified nurses per bed, and 0.7 to 1.0 FTE per bed for all nursing staff (including aids). The study was approved by the Ethics Committee of the Canton of Zurich, sub commission for psychiatry, neurology and neurosurgery (Project E 016-2001). Patients were informed by means of an information sheet containing general information about an ongoing study on aggressive behaviour.

The study sample consisted of 219 consecutively admitted patients 


\section{Outcomes}

The primary outcome was the occurrence of a violent act against nursing staff with physical contact. To ascertain an unbiased reporting of events, we employed a case report form, which was already implemented in the participating wards. This case report from had been tested and validated in several prior studies on the prevalence of aggressive behaviour in the participating hospitals (Gerber 1995, Geser 1999). The report records all aggressive behaviour that is damaging or threatening to objects and / or to humans. Items include date and time of the incident, possible triggers, patient behaviour prior to the incident, type of aggression, targets, consequences, and interventions to discontinue the aggression. The form contains all items of the Revised Staff Observation of Aggression Scale (SOAS-R) (Nijman et al. 1999, Palmstierna \& Wistedt 1987). We determined the severity of aggression for every event from the SOAS-R scores (Nijman et al. 1999) which range from 0 to 22. The secondary outcome of interest was the administration of intense preventive measures. These were defined as preventive injection of drugs or seclusion of the patient (see appendix).

\section{The German version}

We derived the German version of the BVC (BVC-G) in the following manner: First, we translated the original Norwegian BVC items into German and then independently retranslated the German items into Norwegian. The process was iterated until only minor differences between the re-translation and the original Norwegian version remained. These differences were deemed negligible by the authors of the original scale. A draft version of the instrument was then piloted by nurses in an admission ward of a non-participating hospital. Nurses judged this version and its item specifications as comprehensible and straightforward to use. During the pilot period four nurses rated 16 patients to obtain the interrater-reliability ( 6 pairs of raters). Interrater-reliability on the items ranged from $r=0.64$ (confusion) to $r=1.0$ (attack on objects).

For the research version, we added several items to allow for possible refinement of the scale. These items consisted of data on the rating nurses (e.g. level of experience), and visual analogue scales (VAS) to assess the severity and frequency of the six behaviours. In addition, nurses specified whether interventions to prevent aggression/violence had been implemented subsequent to the last rating. In case of preventive interventions, these were classified according to the list provided in the appendix. We also asked the participating nurses to judge the difficulty of rating 
(simple vs. difficult) and to record the time required to complete the research questionnaire.

\section{Administration of the instrument}

The primary investigator (CA) trained the participating nurses in the use of the BVC-G. Additional written information on the study and the use of the instrument was provided. To minimize confounding by risk prediction, no information was given as to the interpretation of the symptom check list. Following a run-in period of two weeks, nurses in charge of the patient completed the BVC-G instrument at the end of every shift. In this way, two ratings were obtained per 24-hour period. Patients were rated during the first four days after admission or until discharge. The „prediction period“ was defined as the interval from the first rating until 12 hours after the last rating or until discharge from the ward, whatever occurred first.

\section{Data analysis}

In a first preliminary analysis we determined the sensitivity and specificity of the BVC-G using the simple additive score (0 to 6 symptoms) as in the original Norwegian version to predict a violent attack within the 12 hours following the prediction. We calculated the sensitivity, and specificity for the cut-offs suggested by the authors of the original Norwegian BVC, as well as multilevel likelihood ratios for incremental cut-offs. We calculated the area under the Receiver Operating Characteristic (ROC) curve following the algorithm suggested by Hanley and McNeil (Hanley \& McNeil 1982). Secondary analysis comprised multivariable logistic regression models with the probability of a violent event as the dependent variable, and severity and intensity of the observed behaviour as independent covariables. The best fitting models were chosen on the basis of minimizing Akaiki's information criterion (Akaike 1974). The individual prediction and the associated outcome (event or no event during the next 12 hours) served as the unit of analysis. No correction was applied for the possible colinearity between subsequent ratings in the same patient. The limited number of events prevented a division of the data into a validation and a derivation dataset. Data were analysed using SPSS (Version 10.0, SPSS, Chicago, IL) and SAS (Version 8.1, SAS Inc, Cary, NC). 


\section{Results}

\section{Patient population and ratings}

During the study period 219 patients were admitted to the six participating wards. Of these, 133 (61 \%) were male, and 86 (39\%) were female. The median patient age was 39 years (mean 39.9 , standard deviation \pm 13 ). A total of 1263 ratings were obtained. Twenty seven percent of the patients had less than 6 ratings due to early discharge or transferral to another ward. Fifteen percent of the ratings $(n=190)$ were made on day of admission, and $32 \%(n=409), 30 \%(n=373)$, and $23 \%(n=291)$ on the second, third and fourth day of hospitalisation, respectively.

\section{Incidents}

A total of 47 aggressive incidences were reported from the six participating wards. Of these, 28 involved violence and attacks against persons, while 19 were verbal threats or aggressive acts against objects. Of the 28 attacks against persons, 4 were committed before the first rating was obtained, 14 during the prediction period, and 10 violent acts against person occurred after the prediction period. The 14 attacks against persons during the prediction period involved 10 patients ( 7 males, 3 females). Eight patients caused one incident only, while two patients were involved in three attacks each. Table 1 demonstrates the severity of incidents observed during the prediction period.

Table 1: Severity of incidents during the prediction period rated by the SOAS-score

\begin{tabular}{ccc}
\hline Severity score & $\begin{array}{c}\text { Verbal threats or attacks } \\
\text { against objects }\end{array}$ & Attacks against persons \\
\hline SOAS-R points & $\mathbf{n}(\%$ of $\mathbf{n}=\mathbf{2 5})$ & $\mathbf{n}(\%$ of $\mathbf{n}=\mathbf{2 5})$ \\
\hline 3 & $1(4 \%)$ & $2(8 \%)$ \\
5 & $1(4 \%)$ & $2(8 \%)$ \\
9 & $5(20 \%)$ & $1(4 \%)$ \\
10 & & $1(4 \%)$ \\
11 & $1(4 \%)$ & $1(4 \%)$ \\
12 & $1(4 \%)$ & $3(12 \%)$ \\
13 & $2(8 \%)$ & $1(4 \%)$ \\
15 & & $3(12 \%)$ \\
17 & & $14(56 \%)$ \\
18 & $11(44 \%)$ &
\end{tabular}




\section{BVC-G, applicability and scores}

Of the 1263 returned rating forms, 60 (4.8\%) had incomplete data and were excluded from the analysis. The nurses completed $93.2 \%$ of the forms within less than $3 \mathrm{~min}$. In $95 \%$ of the ratings, nurses judged the assessing of the patient as straightforward.

The 1203 complete ratings showed a skewed distribution of Brøset scores: Score 0, $n=$ 871 (72.4\%); Score 1, $n=174$ (14.5\%); Score 2, $n=77$ (6.4\%); Score 3, n = 38 (3.2\%); Score 4, n = 23 (1.9\%); Score 5, $n=12$ (1.0\%); Score 6, $n=8(0.7 \%)$. The Brøset scores did not differ across patient gender $(p=0.18)$.

\section{BVC-G, measures of test accuracy}

Table 2 provides the measures of test accuracy if a score of 3 or more is used as a single cut-off to define a positive or a negative test result. Based on this cut-off, we observed 77 (6.4\%) false predictions ( 5 false negatives, and 72 false positives). The likelihood ratio for a positive test result using the cut-off of 3 or more points was 10.6 $(95 \% \mathrm{Cl} 6.8-16.6)$. The likelihood ratio for a negative test result was $0.38(95 \% \mathrm{Cl}$ 0.19-0.77).

Table 2: Measures of test accuracy for the BVC-CH to predict a physical attack within the next shift $(n=1203)$

\begin{tabular}{lcccc}
\hline & \multicolumn{2}{c}{ Attack on person within next shift } & Total & \\
\cline { 2 - 5 } BVC-Score & yes & no & & Predictive values (95\% Cl) \\
\hline Positive test result $>2$ & 9 & 72 & 81 & positive 11.0\% (6.0-20.0\%) \\
Negative test result $\leq 2$ & 5 & 1117 & 1122 & negative 99.6\% (99.0-99.8\%) \\
\hline Total & 14 & 1189 & 1203 & \\
\hline Sensitivity $(95 \% \mathrm{Cl})$ & $64 \%(35-87 \%)$ & & & \\
Specificity $(95 \% \mathrm{Cl})$ & & $94 \%(92-95 \%)$ & & \\
\hline
\end{tabular}

Figure 1 displays the receiver operating characteristic curve of the BVC-G. The area under the curve as a global assessment of test performance across all possible cut-offs amounted to 0.88 (95\% $\mathrm{Cl} 0.76-0.99)$.

Multilevel likelihood ratios were $0.23(95 \% \mathrm{Cl} 0.10-0.50)$ for $\mathrm{Br} \varnothing$ set scores of 0 to 1 , 4.45 (95\% Cl 2.66-7.43) for scores of 2 to 3, and 14.3 (95\% Cl $7.74-25.7$ ) for scores of 4 to 6 . This corresponds to a risk of an attack of 1 in 208 for Brøset scores of 0 to 1, of 1 in 10.5 patients with scores of 2 to 3 , and a risk of 1 in 3.3 for Brøset scores of 4 to 6 . 
Logistic regression analysis revealed an odds ratio of $2.3(95 \% \mathrm{Cl} 1.8-3.0)$ for the occurrence of an attack per increase of one point in the Brøset score.

Figure 1: ROC-curve of the BVC-CH

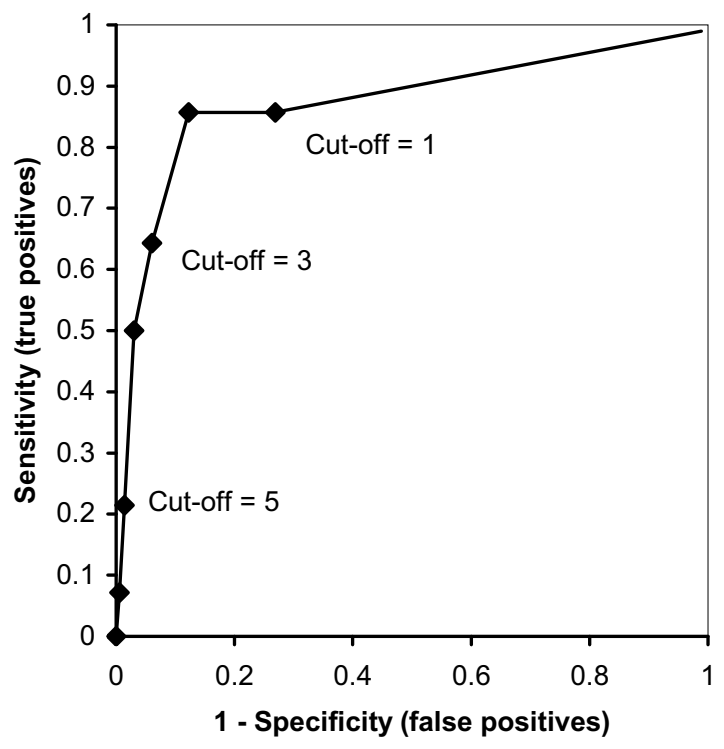

BVC-Score

\section{Association between BVC-G and preventive measures}

During the prediction period, a total of 53 intense preventive interventions (injection of psychotropic drugs, preventive seclusion) were undertaken. Using the same cut-off as for predicting violence against persons, the odds ratio for preventive interventions with BVC-G scores of 3 or more was 19.1 (95\% Cl 10.4-25). The likelihood ratio for a positive test was $10.3(95 \% \mathrm{Cl} 7.0-14.9)$, the likelihood ratio for a negative test amounted to $0.54(95 \% \mathrm{Cl} 0.4-0.7)$. The positive predictive value was $32 \%$ and the negative predictive value $98 \%$. Employing a combined outcome measure (attack or intense preventive intervention, $n=58$ ), the positive predictive value rose to $36 \%$ ( $95 \%$ $\mathrm{Cl} 26-47 \%$ ), and the negative predictive value was $97 \%$ (95\% $\mathrm{Cl} 96-98 \%$ ). According to the logistic regression model, the odds of a patient to be subjected to a preventive measure increased by $2.3(95 \% \mathrm{Cl} 1.94-2.7)$ for every point increase on the BVC-G score. 


\section{Adding additional parameters}

We calculated several models with combinations of behavioural variables and the corresponding visual analogue scales assessing frequency or intensity of the observed behaviour. None of the other models or additional information obtained from visual analogue significantly improved the predictive properties of the model (all areas under curve using ROC analysis were between 0.874 and 0.881 ).

\section{Discussion}

We conducted a multicenter prospective inception cohort study to assess the predictive accuracy of the BVC in an independent sample. Our main finding is that measures of test accuracy were consistent with the reports from the original Norwegian study. Moreover, attempts to further improve the symptom check list by introducing additional assessment of the severity or frequency of the observed behaviour did not enhance the predictive properties. Summarizing our findings, we found a sensitivity of the BVC when using a cut-off of three or more symptoms of 64.3\% (95\% Cl 35.1-87.2), and a specificity 93.9\% (95\% Cl 92.4\% - 95.2\%). The positive predictive value (PPV) of a BVC-score of more than 2 amounted to $11 \%$ (95\% Cl $6-$ $20 \%)$, and the negative predictive value (NPV) to $99.6 \%$ (95\% Cl $99-99.8 \%$ ). The sensitivity and specificity in our sample were similar to the sensitivity (74\%), specifity (91\%), PPV (11\%) and NPV (99\%) reported by Almvik and coworkers $(1998,2000)$ from the original Norwegian study population. Likewise, the area under the ROC-curve (AUC) of the BVC in our study was $0.88(95 \%-\mathrm{Cl} 0.757-0.993)$, which is similar to the data by the Norwegian investigators (AUC $=0.82,95 \%$ Cl $0.75-0.89$ ) (2000).

The self reported ease of questionnaire completion as well as the short time required to complete the extended research version indicate a general applicability of the BVC in the clinical setting of psychiatric acute wards even under periods of extreme workload, corroborating the claims advanced by the developers of the original Norwegian version (Almvik \& Woods 1998, Almvik et al. 2000).

However, we disagree with the original interpretation of the BVC-scores. The original report states: "Scores of 3 and more indicate that the risk of violence is very high, immediate preventive measures are required and plans for handling an attack should be activated" (Woods \& Almvik 2002, p. 103). Multilevel likelihood ratios obtained from our larger sample than the original suggest similar risks for patients scoring 0-1, 2-3 and 4-6 respectively. The relative risks of a violent patient attack against staff were 
$1: 208,1: 10.5$ and $1: 3$, respectively. Considering the relative high proportion of false positives when using the originally suggested cut-off, we regard the original interpretation and the suggested clinical implications of scores above 2 as potentially problematic. With respect to possible restrictions on the liberty of patients based on false positive predictions (Bingley 1997, Szmukler 2001), we suggest a more detailed interpretation of the score, based on multilevel likelihood ratios. The small number of events observed in our sample prevented to derive more specific risk enumerations for each score level.

Several limitations of the study must be acknowledged. First, the prediction using the BVC relies entirely on the behaviour of the patients although other variables are known to influence the occurrence of aggressive attacks (Steinert 2002). Models aimed to explain violent incidences include situational and staff variables (Nijman 2002, Steinert 2002). We are aware that the accuracy of the BVC could possibly be improved by including such situational factors. Second, the false positive test result rate based on occurrence of actual aggressive acts may be exaggerated due to confounding by preventive measures. It is conceivable that observed behaviour itself led to intense preventive measures such as the injection of psychotropic drugs or seclusion. This issue has repeatedly been discussed in the literature, stating that the interpretation of false positive predictions is hampered by the fact that clinicians have an obligation to intervene when patients are assessed as dangerous. Therefore, at least some of the false positive predictions may be a consequence of effective prevention (McNiel 1991, Werner et al. 1983). However, when combining an outcome as an aggressive act or an intense preventive measure, neither the area under the receiver operating characteristic curve improved (AUC $=0.83$ ), nor did the estimated odds ratio per increase in score point change (OR $=2.35,95 \% \mathrm{Cl} 2.0-2.8)$. This discussion underscores the major caveat of the present study, which lies in the small number of observed incidents This led to large confidence intervals, and by means of a low prevalence, to low positive predictive values.

In summary, we demonstrated that the BVC shows satisfactory accuracy as to the short-term prediction of violence against staff amongst newly admitted patients in acute psychiatry wards in an independent sample. The BVC appears to be a promising instrument, suitable for integration into daily clinical routine. 


\section{Acknowledgements}

This study was supported by the European Violence in Psychiatry Research Group EViPRG and by the Swiss Academy of Medical Sciences. We also want to thank the staff of the participating wards for their patient and helpful collaboration in the collection of data.

\section{References}

Akaike H. (1974) A new look at the statistical model identification. IEEE Transaction and Automatic Control AC-19, 716-723.

Almvik R. \& Woods P. (1998) The Broset Violence Checklist (BVC) and the prediction of inpatient violence: Some preliminary results. Psychiatric Care 5, 208-211.

Almvik R., Woods P. \& Rasmussen K. (2000) The Broset Violence Checklist: Sensitivity, Specificity and Interrater Reliability. Journal of Interpersonal Violence 15, 1284-1296.

Bingley W. (1997) Assessing dangerousness: Protecting the interests of patients. British Journal of Psychiatry 170, 28-29.

Ferris L., Sandercock J., Hoffman B., Silverman M., Barkun H., Carlisle J. \& Katz C. (1997) Risk assessments for acute violence to third parties: a review of the literature. Canadian Journal of Psychiatry. 42, 1051-60.

Gerber A. (1995) Aggressionen psychiatrischer Patienten in der Klinik: Eine 2-Jahres-Studie an der Psychiatrischen Universitätsklinik Zürich. Medical dissertation, University Zurich, Zurich.

Geser A.M. 1999. Aggressionen von hospitalisierten psychisch Kranken: Eine systematische Evaluation von knapp 2000 Aggressionsfällen. Medical dissertation, University Zurich, Zurich.

Hanley J.A. \& McNeil B.J. (1982) The meaning and use of the area under a receiver operating characteristic (ROC) curve. Radiology 143, 29-36.

Harris G.T. \& Rice M.E. (1997) Risk appraisal and management of violent behavior. Psychiatric Services 48, 1168-76.

Linaker O.M., Busch Iversen, H. (1995) Predictors of imminent violence in psychiatric inpatients. Acta Psychiatrica Scandinavica 92, 250-254.

McNiel D. (1991) Clinical assessment of the risk of violence among psychiatric inpatients. American Journal of Psychiatry 148, 1317-1321.

Mossman D. (1994) Assessing predictions of violence: Beeing accurate about accuracy. Journal of Consulting and Clinical Psychology 62, 783-792.

Nijman H.L. (2002) A model of aggression in psychiatric hospitals. Acta Psychiatica Scandinavica 106, Supplementum 412, 142-3.

Nijman H.L.J., Muris P., Merckelbach H.L.G.J., Palmstierna T., Wistedt B., Vos A.M., van Rixtel A. \& Allertz W.W.F. (1999) The Staff Observation Aggression Scale - Revised (SOAS-R). Aggressive Behavior 25, $197-$ 209.

Palmstierna T. \& Wistedt B. (1987) Staff observation aggression scale, SOAS: Presentation and evaluation. Acta Psychiatrica Scandinavica 76, 657-663.

RCP Royal College of Psychiatrists (1998). Management of imminent violence: clinical practice guidelines to support mental health services. Royal College of Psychiatrists Research Unit, London.

Steinert T. (2002) Prediction of inpatient violence. Acta Psychiatica Scandinavica 106, Supplementum 412, 133-41. 
Szmukler G. (2001) Violence risk prediction in practice. British Journal of Psychiatry 178, 84-5.

Werner P.D., Rose T.L. \& Yesavage J.A. (1983) Reliability, accuracy, and decision-making strategy in clinical predictions of imminent dangerousness. Journal of consulting and clinical psychology 51, 815-25.

Woods P. \& Almvik R. (2002) The Broset violence checklist (BVC). Acta Psychiatica Scandinavica 106, Supplementum 412, 103-5.

Appendix: Interventions primarily directed to prevent aggression/violence

\begin{tabular}{|l|l|}
\hline Increase of medication dosage & Preventive seclusion (closed seclusion room) \\
\hline PPR-medication per os (psychotropic drugs) & Open isolation in the patients own room \\
\hline Injection of psychotropic drugs (forced/voluntary) & Walk outdoors (directed to reduce aggression) \\
\hline Confrontation with ward rules & General conversation (directed to reduce aggression) \\
\hline Discussion of risk with patient & Relaxation exercise \\
\hline 1:1-observation for several hours & Reduction of demands (e.g. participation in activities) \\
\hline Other: & \\
\hline
\end{tabular}





\section{Chapter 5}

\section{Predicting inpatient violence using an extended version of the Brøset-Violence-Checklist: Instrument development and clinical application}

Abderhalden C, Needham I., Dassen T., Halfens R., Haug HJ., Fischer JF. (2006) Predicting inpatient violence using an extended version of the Brøset-Violence-Checklist: Instrument development and clinical application. BMC Psychiatry 6:17 


\section{Abstract}

Background: Patient aggression is a common problem in acute psychiatric wards and calls for preventive measures. The timely use of preventive measures presupposes a preceded risk assessment. The Norwegian Brøset-Violence-Checklist (BVC) is one of the few instruments suited for short-time prediction of violence of psychiatric inpatients in routine care. Aims of our study were to improve the accuracy of the short-term prediction of violence in acute inpatient settings by combining the Brøset-ViolenceChecklist (BVC) with an overall subjective clinical risk-assessment and to test the application of the combined measure in daily practice.

Method: We conducted a prospective cohort study with two samples of newly admitted psychiatric patients for instrument development (219 patients) and clinical application (300 patients). Risk of physical attacks was assessed by combining the 6item BVC and a 6-point score derived from a Visual Analog Scale. Incidents were registered with the Staff Observation of Aggression Scale-Revised SOAS-R. Test accuracy was described as the area under the receiver operating characteristic curve (AUCROC).

Results: The AUCROC of the new VAS-complemented BVC-version (BVC-VAS) was 0.95 in and 0.89 in the derivation and validation study respectively.

Conclusion: The BVC-VAS is an easy to use and accurate instrument for systematic short-term prediction of violent attacks in acute psychiatric wards. The inclusion of the VAS-derived data did not change the accuracy of the original BVC. 


\section{Background}

Patient aggression is a common problem in acute psychiatric wards. Violent outbursts threaten the health, safety and well-being of other patients and staff. Psychiatric nurses are at particularly high risk of being victimized. However, psychiatric staff is not only a passive target of potential patient violence. Violence management is a key component of clinical practice, and psychiatric staff performs a wide range of interventions to modulate the context and the interaction with potentially violent patients. Preventive measures are of special importance. The timely use of preventive measures presupposes a preceded risk assessment. Therefore, accurate risk prediction to allow targeted interventions is of paramount importance [1].

Several attempts have been made to introduce accurate measures for risk prediction [2]. Generally spoken fall into two categories: actuarial methods and prediction models derived from acute patient observation [2-4]. Actuarial models predict risk from the presence of statistically derived risk factors like age, gender, psychopathological state, diagnosis etc. Most studies using this method found that patients who had exhibited violent behavior in the past were substantially more likely to become aggressive during a new hospitalization than those with no history of aggressive behavior $[5,6]$. The main criticisms advanced towards actuarial methods is a) that they discard the experience of the staff currently dealing with the patient, b) that they perform less well in non-forensic or acute settings [5, 7] and c) that they require the collection of data that may not be readily available in acutely admitted patients $[1,8]$.

Clinical prediction models based on acute patient observation use different approaches, considering factors as e.g. psychopathological states. One approach is based on overt patient behavior. A recently published method is the Brøset Violence Checklist (BVC), which has been validated in Norwegian and German [9-11]. The BVC assesses the presence of six observable patient behaviors namely whether the patient is confused, irritable, boisterous, verbally threatening, physically threatening, and attacking objects. The reported discriminatory ability is good with a correct prediction rate around $85 \%$ [10]. Another clinical model emphasizes the staff's ability to judge the risk by integrating all available information into a formal subjective risk prediction statement. This subjective prediction is operationalized by likert-type scales or Visual Analogue Scales [12-16]. Investigators applying this approach found correct prediction rates of $75 \%$ [14]. The limitation to either approach is a considerable residual risk of false positives. 


\section{Aim of the study}

The aim of the present study was to ascertain whether combining both methods would yield improved risk prediction over either method alone. The study comprised two independent patient samples from different hospitals. The first patient sample served as a derivation dataset to identify the optimal algorithm for combining the BVC and the subjective prediction. The second patient sample served as the validation dataset, in which the prediction method was applied to clinical practice.

\section{Methods}

\section{Design}

Two independent prospective cohort studies were conducted. The first served to develop the risk assessment instrument (derivation sample). The second patient sample tested the clinical application of the method (validation sample).

The study protocols were reviewed and approved by the research ethics boards of the Cantons Zurich (E-016/2001), Appenzell AR (10/01) and Berne (24.12.2001/IH/Hz/EW).

\section{Setting and sample}

Both studies were conducted in acute psychiatric wards in the German speaking part of Switzerland. All participating wards were closed admission wards providing comprehensive psychiatric service to the respective catchment areas. The first sample (derivation dataset) consisted of 219 consecutively admitted patients to six wards within three hospitals during a two-moth period. The number of beds in each ward ranged from 15 to 19 . The second sample (validation dataset) consisted of 300 consecutively admitted patients to two wards during a six-month period. These two 12 bed wards were situated in two different hospitals in different cantons (one rural area, one urban area) to assure independence from the derivation dataset.

\section{Instrument development}

During instrument development psychiatric nurses responsible for the care of the patient provided an assessment during admission and twice daily (10 a.m. and 6 p.m.) at admission day and during the next three days or until discharge/transferral. Therefore, the maximum number of ratings per patients was 9 in the case of an admission time earlier than the regular rating at 11 a.m.. Assessment forms contained 
the German research version of the BVC and a Visual Analogue Scale (VAS) of $10 \mathrm{~cm}$ length. Nurses were asked to indicate the presence or absence of the six behaviors constituting the BVC. In addition, nurses encoded their subjective perception of risk for a physical attack within the next 12 hours on the VAS. The endpoints of the VAS were marked as "no risk" and "very high risk". The data collection form was also used to gather information about any preventive measures taken since the last rating. No clues were provided about the interpretation of the BVC or the VAS. From these data, the final instrument (BVC-VAS) was developed as described in the statistical analysis section. The objective of this instrument to be developed was to integrate the findings from the BVC and the Visual Analogue Scale to a summary score. Crafting an instrument that would be compatible with routine use required graphic refinement of the BVC as well as a simple method to translate VAS-readings into scoring points. The latter was achieved by constructing a slide rule that resembled the VAS on the front side and provided the VAS score reading on the backside. The final instrument was pretested in a different ward before application in the validation study.

\section{Instrument validation}

The new instrument (BVC-VAS) was integrated into clinical routine in two admission wards in two hospitals. To test the instrument during practical application, staff was aware about the interpretation of the obtained scores. Like in the derivation sample, nurses assessed the risk of newly admitted patients on the day of admission and the following three days twice daily.

\section{Outcome measurements}

The main outcome measure was the occurrence of physical attacks on persons during the next shift following assessment. The severity of the aggressive event was recorded using the Staff Observation of Aggression Scale Revised (SOAS-R) [17-19]. Test accuracy was described as the area under the receiver operating characteristic curve [20]. A secondary outcome was the implementation of intense preventive measures such as seclusion or forced injection of psychotropic drugs. While this outcome may not be regarded as independent from the prediction, it allows the evaluation of false positive cases, i. e. to examine whether patients were unable to perpetrate violent attacks because of intense preventive measures. Thus, some of the false positive predictions may in fact be a consequence of effective prevention $[13,21]$. 


\section{Statistical analysis}

The derivation of the BVC-VAS was carried out using the following procedures: First, we employed logistic regression analysis on the number of positive BVC items. To account for possible non-linear relation between risk and individual BVC items, we performed additional analyses by entering each item as individual variable and by recoding numbers of BVC items into dummy variables. Second, we explored the relation between the VAS-distance measured in $\mathrm{mm}$ and the occurrence of physical attacks by independent logistic regression analyses. Several transformations of the raw VAS score (logarithmic, quadratic) were carried out, of which the logarithmic transformation yielded the highest discriminatory power. In the next step, we checked which combination of BVC scores and VAS scores would yield the best performing model. This was achieved by testing different weights of the two scores. Models in the derivation dataset revealed the best performance at equal weights. Thus, the final scale consisted of 12 score points, of which up to 6 were contributed from the BVC and up to 6 from a logarithmic transformation of the VAS. Finally, we calculated multilevel likelihood ratios for ranges of the revised BVC score, to be able to enumerate risk rather than expressing risk with ambiguous wordings. For practicability we chose four risk segments, corresponding to very low risk, low risk, moderate risk and high risk. In the validation dataset we elucidated the discriminatory performance of the total score and each subscore by logistic regression analyses. Analyses were carried out in SPSS version 10 (SPSS inc, Chicago, Illinois) for obtaining confidence intervals for area under the receiver operating characteristic curves and in SAS (version 8.2, SAS institute, Cary, North Carolina) for model development.

\section{Results}

\section{Patient sample}

The derivation sample consisted of 219 patients; the validation sample of 300 patients. Patients in both samples were similar regarding gender, lengths of stay, the proportion of involuntary admission and the proportion of patients having a ICD-10 F1, F2 and F3 diagnosis. The validation sample comprised a lower proportion of patients having ICD10 F4/F6 diagnoses (Neurotic, stress-related or somatoform disorder / personality disorder), and the mean age was lower (Table 1). 
Table 1: Patient characteristics

\begin{tabular}{|c|c|c|c|}
\hline & $\begin{array}{l}\text { Derivation } \\
\text { sample }\end{array}$ & $\begin{array}{l}\text { Validation } \\
\text { sample }\end{array}$ & \\
\hline Number & 219 & 300 & \\
\hline Male (\%) & $60.3 \%$ & $61.0 \%$ & ns \\
\hline Age (mean $\pm S D)$ & $39.8 \pm 12.9$ & $36.4 \pm 13.3$ & $p=0.002^{*}$ \\
\hline ICD-10 F1 (Alcohol and drug use disorders) & $23.9 \%$ & $22.8 \%$ & ns \\
\hline $\begin{array}{l}\text { ICD-10 F2 (Schizophrenic or delusional } \\
\text { disorder) }\end{array}$ & $34.9 \%$ & $40.1 \%$ & ns \\
\hline ICD-10 F3 (Affective disorder) & $14.8 \%$ & $16.5 \%$ & ns \\
\hline $\begin{array}{l}\text { ICD-10 F4/6 (Neurotic, stress-related or } \\
\text { somatoform disorder / personality disorder) }\end{array}$ & $20.6 \%$ & $13.6 \% \%$ & $p=0.042^{* *}$ \\
\hline ICD-10 (Other diagnoses) & $5.8 \%$ & $7.0 \%$ & ns \\
\hline Involuntary admissions & $58 \%$ & $64 \%$ & ns \\
\hline Median length of stay (days) & 23 & 22 & ns \\
\hline Physical attacks & 14 & 37 & \\
\hline Patients involved in $\geq 1$ attack & $10(4.6 \%)$ & $27(9.0 \%)$ & ns \\
\hline Severity of attacks (SOAS-R) (mean; range) & $12.7(5-18)$ & $13.4(4-20)$ & ns \\
\hline Intense preventive measures & 52 & 94 & \\
\hline $\begin{array}{l}\text { Patients with } \geq 1 \geq \text { intense preventive } \\
\text { measure }\end{array}$ & $28(12.8 \%)$ & $41(13.7 \%)$ & n.s. \\
\hline
\end{tabular}

* Mann-Whitney U-Test ** Pearson chi ${ }^{2}$

\section{Instrument development phase}

During the derivation study we obtained 1203 ratings for each of the two measures for the 219 patients (5.5 ratings per patient). During the study period 14 physical attacks toward staff occurred involving 10 patients. The severity of the incidents on the 22point SOAS-severity scale ranged from 5 to 18 . Fifty-three of the ratings were followed by implementation of intense preventive measures (injection of drugs or seclusion). The sensitivity of the original BVC (cut-off > 2 points) was $64.3 \%$ (95\%-Cl 35.1-87.2), the specificity was $93.9 \%(95 \%-\mathrm{Cl} 92.4-95.2 \%)$, yielding a positive predictive value in this low-prevalence sample of $11.1 \%(95 \%-\mathrm{Cl} 6 \%-20 \%)$. The area under the receiver operating characteristic curve (AUCROC) amounted to AUCROC $=0.88(95 \%-\mathrm{Cl} 0.76-$ $0.99)$. In $1 / 3$ of the cases with a false positive result intense preventive measures were 
implemented following the rating. The subjective VAS based risk assessment yielded a slightly higher discriminatory ability than the BVC-rating with an AUCROC $=0.93$ (95\%$\mathrm{Cl} 0.88$ to 0.98). As explained in the methods section, a non-linear transformation of the VAS-distances to scoring points provided the best fit of the model. The final scoring solution is presented in Table 2.

Table 2: Transformation of VAS-data into 6-point-scale

\begin{tabular}{cc}
\hline VAS (mm) & Score (Points) \\
\hline 0 & 0 \\
\hline $1-5$ & 1 \\
\hline $6-10$ & 2 \\
\hline $11-20$ & 3 \\
\hline $21-40$ & 4 \\
\hline $41-80$ & 5 \\
\hline $81-100$ & 6 \\
\hline
\end{tabular}

Adding these scores to the summed BVC resulted in a new scale ranging from 0 to 12 . Due to the small number of observations, logistic regression analyses did not allow to ascertain with statistical significance whether non-balanced weighing would have yielded improved diagnostic performance over giving equal weights to the subjective assessment and the BVC. The test accuracy of the prediction for the equally weighted combined score (BVC-VAS) amounted to an AUCROC of 0.94 (95\%-Cl 0.90 to 0.98) (figure 1).

For the clinical application study, we developed a slide rule style VAS to capture the subjective assessment of risk and to implement the logarithmic transformation of VAS distances into scores (see figure 2).

The front side shows the VAS scale, while the rear provides a window from which the log transformed score can be obtained. We also included a multilevel-likelihood based interpretation of the BVC-VAS score, in order to prevent the danger of overestimation of the potential aggressiveness of patients [22, 23], aiming to avoid unjustified interventions. We specifically employed natural number frequency wordings instead of percentages to ease interpretation. Table 3 displays the wording of the resulting risk assessment. 


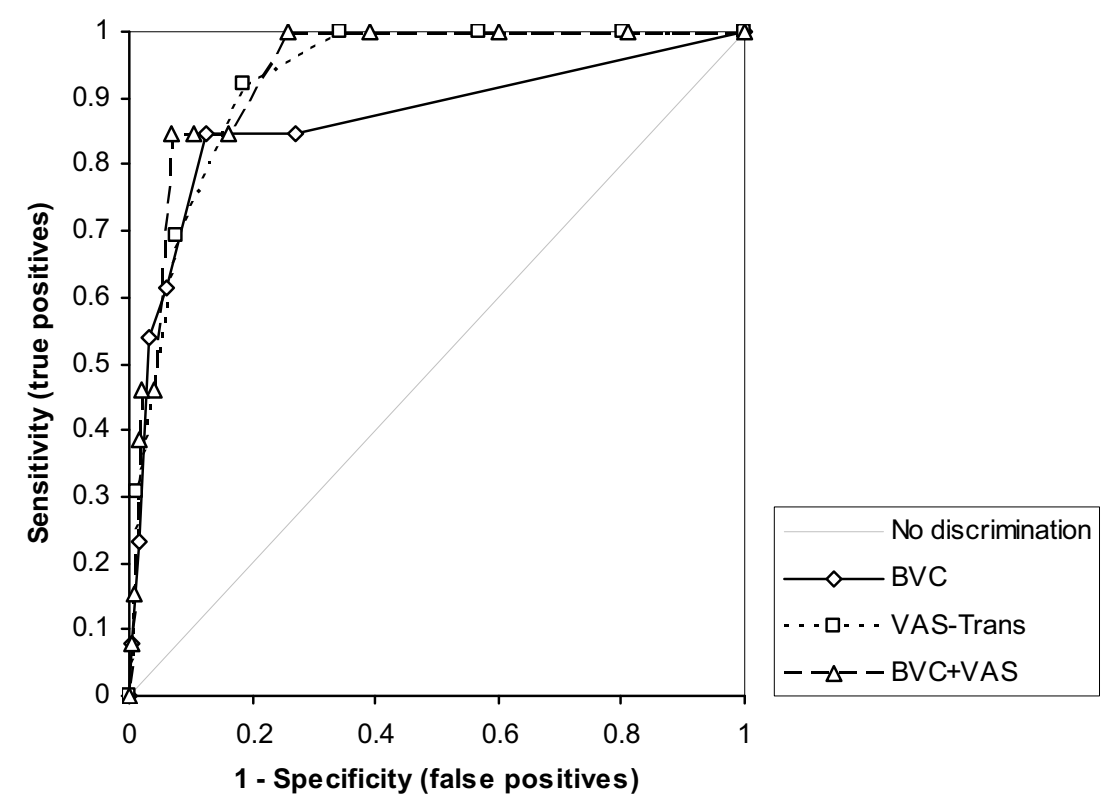

Figure 2: Slide rule

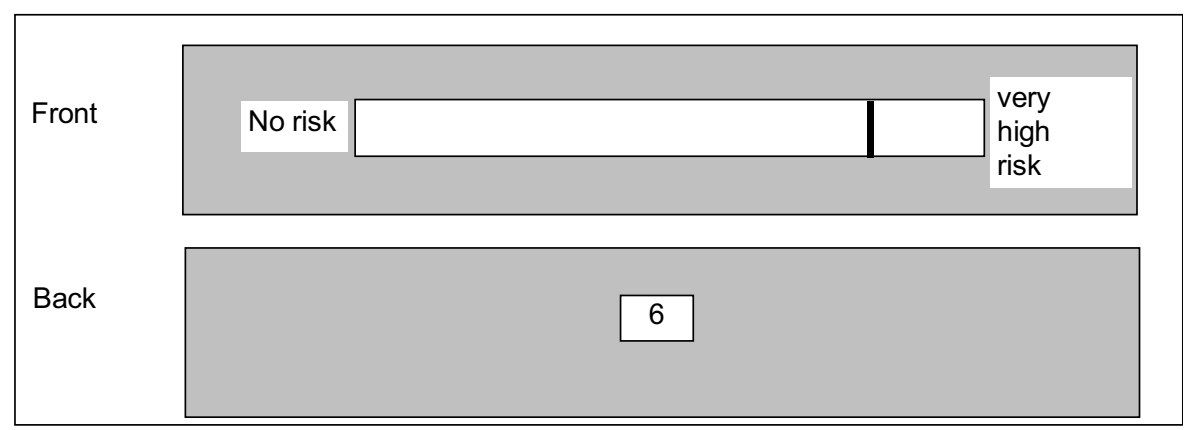

Because we were interested in testing the performance of the instrument in routine application we provided recommendations in addition to the risk enumeration. The 
scoring form suggested discussing the risk within the nursing team for patients scoring between 7 and 9 (moderate risk) and to consider the implementation of preventive measures from a list provided with the instrument. A score of 10 or more (high risk) constituted the obligation to discuss the risk AND to plan and implement preventive measures from the same list of possible preventive measures (see appendix).

Table 3: Interpretation of the extended version of the BVC, obtained from the derivation data-set

\begin{tabular}{ll}
\hline 0 - 3 Points & Very low risk (<1 of 300 patients with these scores will attack a person) \\
\hline $4-6$ Points & Low risk (about 1 out of 100 patients having this risk will attack a person) \\
\hline 7 - 9 Points & Moderate risk (about 1 out of 10 patients having this risk will attack a person) \\
\hline 10-12 Points & High risk (about 1 out of 4 to 5 patients having this risk will attack a person) \\
\hline
\end{tabular}

\section{Validation phase}

The validation phase comprised the clinical application of the BVS-VAS and involved 300 consecutive patients for whom 2084 ratings for each of the two measures were observed. Twenty seven percent of the patients had less than 6 ratings due to early discharge or transferral to another ward.During this period 37 attacks were registered, involving 27 patients. The instrument was well accepted by the nurses and was easily integrated into daily routine. The AUCROC for the combined BVC-VAS amounted to 0.83 (95\% Cl: 0.75 - 0.90). While the original BVC alone showed a similar discriminatory performance as in the derivation dataset AUCROC $=0.86(95 \% \mathrm{Cl}: 0.79$ 0.92 ), the ruler-based visual analogue scale yielded a considerably lower accuracy with an AUCROC $=0.74(95 \% \mathrm{Cl}: 0.65-0.83)$. Because the staff was provided with an interpretation and recommendation of action in cases of moderate and high risk, we also determined the test accuracy for a composite endpoint combining the primary outcome (attack) and the secondary outcome (intense preventive measures). Using this event definition, the combined instrument yielded an AUCROC $=0.90(95 \% \mathrm{Cl}$ : 0.86-0.93), with an AUCROC $=0.89$ (95\% Cl: 0.86-0.92) for the original BVC, and an AUCROC $=0.85$ (95\% Cl: $0.81-0.89)$ for the ruler based VAS (see tables 4 and 5 ). 
Table 4: Summary of the areas under the receiver operating characteristic curves $(95 \%$ Confidence interval)

\begin{tabular}{lll}
\hline Physical attack within next shift & Derivation sample & Validation sample \\
\hline Original BVC & $0.87(0.74-0.99)$ & $0.86(0.80-0.93)$ \\
VAS (Transformed) & $0.94(0.89-0.97)$ & $0.74(0.65-0.83)$ \\
BVC-CH & $0.95(0.90-0.98)$ & $0.83(0.75-0.90)$ \\
\hline & & \\
\hline Physical attack OR intense preventive measure & Derivation sample & Validation sample \\
within next shift & & \\
\hline Original BVC & $0.82(0.75-0.89)$ & $0.88(0.86-0.92)$ \\
VAS (Transformed) & $0.87(0.82-0.91)$ & $0.85(0.81-0.89)$ \\
BVC-CH & $0.89(0.84-0.94)$ & $0.90(0.86-0.93)$ \\
\hline
\end{tabular}

Table 5: Ratings and accuracy of predictions

\begin{tabular}{|c|c|c|c|c|c|c|}
\hline \multirow{3}{*}{$\begin{array}{l}\text { Outcome within the } \\
\text { next shift } \\
\text { Prediction method } \\
\text { and cut-off points }\end{array}$} & \multicolumn{2}{|c|}{ Derivation-Sample } & \multicolumn{2}{|c|}{ Validation-Sample } & \multirow{2}{*}{\multicolumn{2}{|c|}{$\begin{array}{c}\text { Validation-Sample } \\
\text { physical attack OR } \\
\text { intense preventive } \\
\text { measure } * *\end{array}$}} \\
\hline & \multicolumn{2}{|c|}{ physical attack } & \multicolumn{2}{|c|}{ physical attack } & & \\
\hline & $\begin{array}{l}\text { BVC } \\
>=3\end{array}$ & $\begin{array}{c}\text { BVC-VAS } \\
>=7\end{array}$ & $\begin{array}{l}\text { BVC } \\
>=3\end{array}$ & $\begin{array}{c}\text { BVC-VAS } \\
>=7\end{array}$ & $\begin{array}{l}\text { BVC } \\
>=3\end{array}$ & $\begin{array}{c}\text { BVC-VAS } \\
>=7\end{array}$ \\
\hline Ratings & 1203 & $1189 *$ & 2084 & 2084 & 2084 & 2084 \\
\hline True Positives & 9 & 11 & 25 & 20 & 74 & 82 \\
\hline False Negatives & 5 & 2 & 12 & 17 & 47 & 39 \\
\hline True Negatives & 1117 & 1095 & 1852 & 1884 & 1817 & 1862 \\
\hline False Positives & 72 & 81 & 195 & 163 & 146 & 101 \\
\hline $\begin{array}{l}\text { Sensitivity/ } \\
\text { Specificity }\end{array}$ & $64 \% / 94 \%$ & $85 \% / 93 \%$ & $68 \% / 91 \%$ & $54 \% / 92 \%$ & $61 \% / 93 \%$ & $68 \% / 95 \%$ \\
\hline
\end{tabular}

* 4 VAS-ratings missing

** seclusion and/or mechanical restraint and/or forced injection

In the validation dataset, the Spearman's Rho correlation coefficient between the VAS and the BVC was $r=0.59$ (explained variance $r 2=0.35$ ), as compared to $r=0.50$ in the derivation dataset (explained variance $r 2=0.19$ ). 


\section{Discussion}

The first aim of the study was to develop an extended version of the Brøset-ViolenceChecklist that includes both the structured clinical assessment of observable patient behavior as well as the unaided subjective clinical assessment of psychiatric nurses on the patient's risk of perpetrating a violent attack. The second aim of the study was to test the instruments test accuracy and application in clinical practice. To this end, we conducted a prospective cohort study involving separate samples for instrument development (derivation sample) and clinical application (validation sample). The main findings of the study were that the visual analogue scale slightly improved the diagnostic accuracy in the derivation dataset (where no interpretation was provided), but that this effect was not retained in the validation dataset (where interpretation of the score was available). In contrast, the performance of the BVC was identical in both samples.

What are the clinical implications of these findings? The original BVC checklist proved to be remarkably stable in the independent dataset. Apparently, the BVC checklist combines the virtues of a structured clinical method by inquiring about specific patient behaviors. While it is still left to the discretion of the rater to decide, whether a specific behavior is actually present or not (e.g. being boisterous). Such subjective decisions may be more reliable than the subjective overall assessment provided in a Visual Analogue Scale. Moreover, we cannot rule out that providing the interpretation of the score affected the ratings. Of the two assessment methods, the BVC score is closer to resembling the practice of actuarial scores. The replication of almost identical test accuracy to the original Norwegian study in two independent samples underscores the possible generalizability of the instrument. Notwithstanding these encouraging findings, a relevant issue remains the limited positive predictive value in our settings with a low prevalence of physical attacks. This underscores the need for cautious interpretation of positive results and reporting of multilevel likelihood ratios. The satisfactory test accuracy ( $A U C R O C=0.90$ ) of the combined instrument when using the composite endpoint emphasizes the applicability in daily routine. Our data do not support the presumption that the test accuracy improved to a relevant extent by including the subjective element of the visual analogue scale. Despite the observation of a comparable accuracy of the VAS compared to the BVC, we hesitate to recommend to solely using the VAS, mainly from three reasons: Firstly, we assume that the accuracy of the VAS could be influenced by the amount of clinical experience in acute psychiatry. We assume that a checklist of observable behaviour is extremely helpful 
especially for less experienced staff. Secondly, the VAS-results have to be regarded as product of a hidden process of clinical reasoning (black-box); we prefer the combination of the VAS with the BVC because of the transparency of the results obtained by the latter. Thirdly, nurses' feedback on the user friendliness of the combined instrument suggested an increased compliance and acceptance of the instrument as compared to the BVC alone. Therefore, we have opted for using the combined instrument in the ongoing randomized controlled trial evaluating the efficacy of systematic prediction on occurrence rates of violent attacks and intense coercive measures.

Several caveats of the study must be acknowledged. A purist approach to the validation study would have mandated employing exactly the same presentation and forms as used for the derivation set in the validation dataset. Instead we skipped this step and moved directly to the clinical application of a practicable and user-friendly form along with recommendations as to the consequences of the ratings to be considered. This design feature inhibits clearer delineation, whether the observed differences in the VAS performance were due to the different sample, differing professional experience amongst staff, the alteration of the design (scale versus ruler), the immediate feedback of the result on the score or the provided recommendations. A related problem is the lack of information on the factors considered by the nurses when rating the VAS. A second limitation is the small number of events that prevented the calculation of more elaborate statistical models accounting for other patient covariates such as diagnosis or demographic variables. We are currently addressing the first problem by means of a qualitative research project, in which nursing staff is interrogated about the thoughts and considerations leading to a specific subjective risk assessment. This project will reveal whether subjective risk assessment is actually incorporating actuarial data such as knowledge about prior patient behavior. Finally, providing an interpretation and suggestion for action with the score result partially violates the condition of independence between outcome and prediction. If only the occurrence of attacks is considered as an outcome event, cases of attacks prevented by interventions initiated as a consequence of the rating may inflate the false positive rate. In contrast, the composite outcome (attacks and interventions initiated following the rating) overestimates the true positive rate. It is reassuring that the area under the Receiver Operating Characteristic curve using either outcome definition differed only by a small margin $(0.90$ versus 0.86$)$. It should also be noted that the performance of the VAS in the validation dataset was similar to that of earlier reports from other investigations [14]. 
In summary, we ascertained satisfactory performance of the BVC in an independent dataset where multilevel likelihood ratio based interpretations and action plans were provided. Adding a visual analogue scale for subjective risk assessment appeared to improve the compliance of the staff with systematic risk prediction but did not result in improved test accuracy in the validation dataset. The considerable difference in test performance for the visual analogue scale between the application within a research framework (derivation dataset) and the use in daily practice warrant further scrutiny. The combined instrument is currently been tested in a multi-center randomized controlled trial to assess the efficacy of systematic risk assessment. Until these data are available the recommendation for routine use cannot be extended from the BVC risk assessment to the combined BVC-VAS instrument.

\section{Acknowledgements}

This study was supported by the European Violence in Psychiatry Research Group EViPRG and by the Swiss Academy of Medical Sciences. We also want to thank the staff of the participating wards for their patient and helpful collaboration in the collection of data.

\section{References}

1. Allen J: Assessing and managing risk of violence in the mentally disordered. J Psychiatr Ment Health Nurs 1997, 4:369-378.

2. Rice ME, Harris GT, Quinsey VL: The Appraisal of Violence Risk. Curr Opin Psychiatry 2002, 15:589-593.

3. Dolan M, Doyle M: Violence risk prediction. Clinical and actuarial measures and the role of the Psychopathy Checklist. Br J Psychiatry 2000, 177:303-311.

4. Doyle $\mathrm{M}$, Dolan $\mathrm{M}$ : Violence risk assessment: combining actuarial and clinical information to structure clinical judgements for the formulation and management of risk. J Psychiatr Ment Health Nurs 2002, 9:649-657.

5. Steinert T: Prediction of inpatient violence. Acta Psychiatr Scand Supp/ 2002:133-141.

6. Ruesch P, Miserez B, Hell D: Gibt es ein Täterprofil des aggressiven Psychiatriepatienten? [A risk profile of the aggressive psychiatric inpatient: can it be identified?]. Nervenarzt 2003, 74:259-265.

7. Palmstierna T, Wistedt B: Risk factors for aggressive behaviour are of limited value in predicting the violent behaviour of acute involuntarily admitted patients. Acta Psychiatr Scand 1989, 1:152-155.

8. Steadman HJ, Silver E, Monahan J, Appelbaum PS, Robbins PC, Mulvey EP, Grisso T, Roth LH, Banks S: A classification tree approach to the development of actuarial violence risk assessment tools. Law Hum Behav 2000, 24:83-100.

9. Abderhalden C, Needham I, Almvik R, Miserez B, Dassen T, Haug H, Fischer J: Predicting inpatient violence in acute psychiatric wards using the Brøset-Violence-Checklist: A multi-centre prospective cohort study. J Psychiatr Ment Health Nurs 2004, 11:422-427. 
10. Almvik R, Woods P, Rasmussen K: The Broset Violence Checklist: Sensitivity, Specificity and Interrater Reliability. J Interpersonal Violence 2000, 15:1284-1296.

11. Almvik R, Woods P: Short-term risk prediction: the Broset Violence Checklist. J Psychiatr Ment Health Nurs 2003, 10:236-238.

12. McNiel D, Binder R: Correlates of accuracy in the assessment of psychiatric inpatients' risk of violence. Am J Psychiatry 1995, 152:901-906.

13. McNiel D: Clinical assessment of the risk of violence among psychiatric inpatients. Am J Psychiatry 1991, 148:1317-1321.

14. Nijman H, Merckelbach H, Evers C, Palmstierna T, a Campo J: Prediction of aggression on a locked psychiatric admissions ward. Acta Psychiatr Scand 2002, 105:390-395.

15. Rabinowitz J, Garelik-Wyler R: Accuracy and confidence in clinical assessment of psychiatric inpatients risk of violence. Int J Law Psychiatry 1999, 22:99-106.

16. Haim R, Rabinowitz J, Lereya J, Fennig S: Predictions made by psychiatrists and psychiatric nurses of violence by patients. Psychiatr Serv 2002, 53:622-624.

17. Nijman HLI, Muris P, Merckelbach HLGJ, Palmstierna T, Wistedt B, Vos AM, van Rixtel A, Allertz WWF: The Staff Observation Aggression Scale - Revised (SOAS-R). Aggress Behav 1999, 25:197-209.

18. Nijman $\mathrm{H}$, Palmstierna $\mathrm{T}$ : Measuring aggression with the staff observation aggression scale - revised. Acta Psychiatr Scand Suppl 2002:101-102.

19. Palmstierna T, Wistedt B: Staff observation aggression scale, SOAS: Presentation and evaluation. Acta Psychiatr Scand 1987, 76:657-663.

20. Swets JA: Measuring the accuracy of diagnostic systems. Science 1988, 240:1285-1293.

21. Werner PD, Rose TL, Yesavage JA: Reliability, accuracy, and decision-making strategy in clinical predictions of imminent dangerousness. J Consult Clin Psychol 1983, 51:815-825.

22. Szmukler G: Violence risk prediction in practice. Br J Psychiatry 2001, 178:84-85.

23. Bingley W: Assessing dangerousness: Protecting the interests of patients. Brit J Psychiatry 1997, 170:28-29. 


\section{Appendix:}

\section{Preventive Measures to consider:}

No specific measures to prevent an attack

Careful observation

General conversation (directed to reduce aggression)

Walk outdoors 1:1 (directed to reduce aggression)

Walk outdoors in a group (directed to reduce aggression)

Reduction of demands (e.g. participation in activities)

Relaxation exercise

Confrontation with ward rules

Discussion of risk with patient

Talk-down (to deescalate)

Transfer to intensive area within ward

1:1-observation for several hours

Increase of medication dosage

PRN-medication per os (psychotropic drugs)

Open isolation in the patients own room (time out)

Preventive seclusion (closed seclusion room)

Injection of psychotropic drugs (forced/voluntary)

Physical restraint (indicate $\mathrm{nr}$. of points) 


\section{Chapter 6}

Structured assessment of the short-time risk for violence in acute psychiatric wards: a cluster randomised controlled trial evaluating the effect on aggressive incidents and coercive measures

Abderhalden C, Needham I., Dassen T., Halfens R, Haug HJ., Fischer JF. (2008) Systematic prediction of the short-time risk for violence in acute psychiatric wards: a cluster randomised controlled trial evaluating the effect on aggressive incidents and coercive measures (British Journal of Psychiatry, accepted for publication) 


\section{Summary}

Background: There is a lack of research on the possible contribution of a systematic risk prediction to reduce aggression in psychiatric inpatient care.

Aims: To assess whether risk assessments decrease the incidence of violence and coercion.

Method: A randomised controlled trial with 14 acute psychiatric admission wards as units of randomisation, including a preference arm. The intervention comprised a standardized risk assessment during the first treatment days with mandatory evaluation of prevention in high-risk patients.

Results: Incidence rates decreased substantially in the intervention wards, while little change occurred in the control wards. The adjusted risk ratios suggest a $41 \%$ reduction in severe aggressive incidents, and a decline in the rate of coercive measures of $27 \%$. The severity of aggressive incidents did not decrease.

Conclusion: Systematic risk assessment within the first treatment days may contribute to reduced violence and coercion in acute psychiatric wards. 


\section{Introduction}

Aggression and violence is a major problem in acute psychiatric wards $[1,2]$ with career prevalences of being assaulted approximating $100 \%$ for mental health-care staff [3]. Manifest or impending violence is frequently managed by coercive measures such as seclusion, restraint, or forced medication. Reducing the perceived need for coercion and the rate of aggressive incidents would advance the quality of psychiatric care. A prerequisite for adequate prevention is the assessment of high risk situations (National Institute for Clinical Excellence NICE, 2005). Previous research has related specific aspects of acute patient behaviour to subsequent violent outbursts [4,5]. Building on this research, we developed a modified risk-prediction scale [6]. The current study evaluates the effect of the routine use of this scale on the frequency and severity of patient aggression and the use of coercive measures in a multi-centre trial.

\section{Methods}

We conducted a prospective multi-centre randomised waiting-list controlled trial with wards as the unit of randomisation and including a preference arm to assess the impact of a structured risk assessment on the incidence rate of severe patient aggression and coercive measures. Data collection and data verification procedures were pilot tested in an independent study involving two wards [7]. The study was approved by six regional research ethics committees.

\section{Study area and eligibility of wards}

In German speaking part of Switzerland, 32 psychiatric hospitals provide psychiatric inpatient treatment for approximately 75\% (5'376'800 persons) of the Swiss population on 324 wards. To be eligible for participation, a psychiatric ward had to meet the following criteria: a) the majority of patients have an acute psychiatric disorder, b) patients are admitted voluntarily or against their will directly onto the ward, c) usually, patients stay less than three months on the ward, d) patients are older than 18 and younger than 65 years, and e) the ward admits all potential patients and is not specialised for the treatment of specific disorders (e.g. depression, addiction). Eighty-six wards satisfied these criteria for acute admission wards. 


\section{Recruitment and design}

These 86 acute wards were invited to partake in a large intervention trial, of which one arm was a structured risk assessment. Sixty-two wards declined participation, including 10 wards predominantly treating private patients with very few involuntarily admissions. Nineteen wards consented to be randomised within the trial, while 5 wards preferred to introduce the study protocol of structured risk assessment without randomisation. Randomization was carried out prior to inclusion on the basis of a computer generated random number list. Here, we report on the four wards randomized to structured risk assessment, the five wards randomized to the waiting control arm, and the five wards of the preference group (Figure 1). After enrolment, wards collected baseline data during a three-month period (phase 1), followed by the three-month intervention period (phase 2, Figure 1). The first ward was enrolled in June 2002; the last ward completed the study in April 2004. 


\section{Figure 1: Recruitment and follow-up}

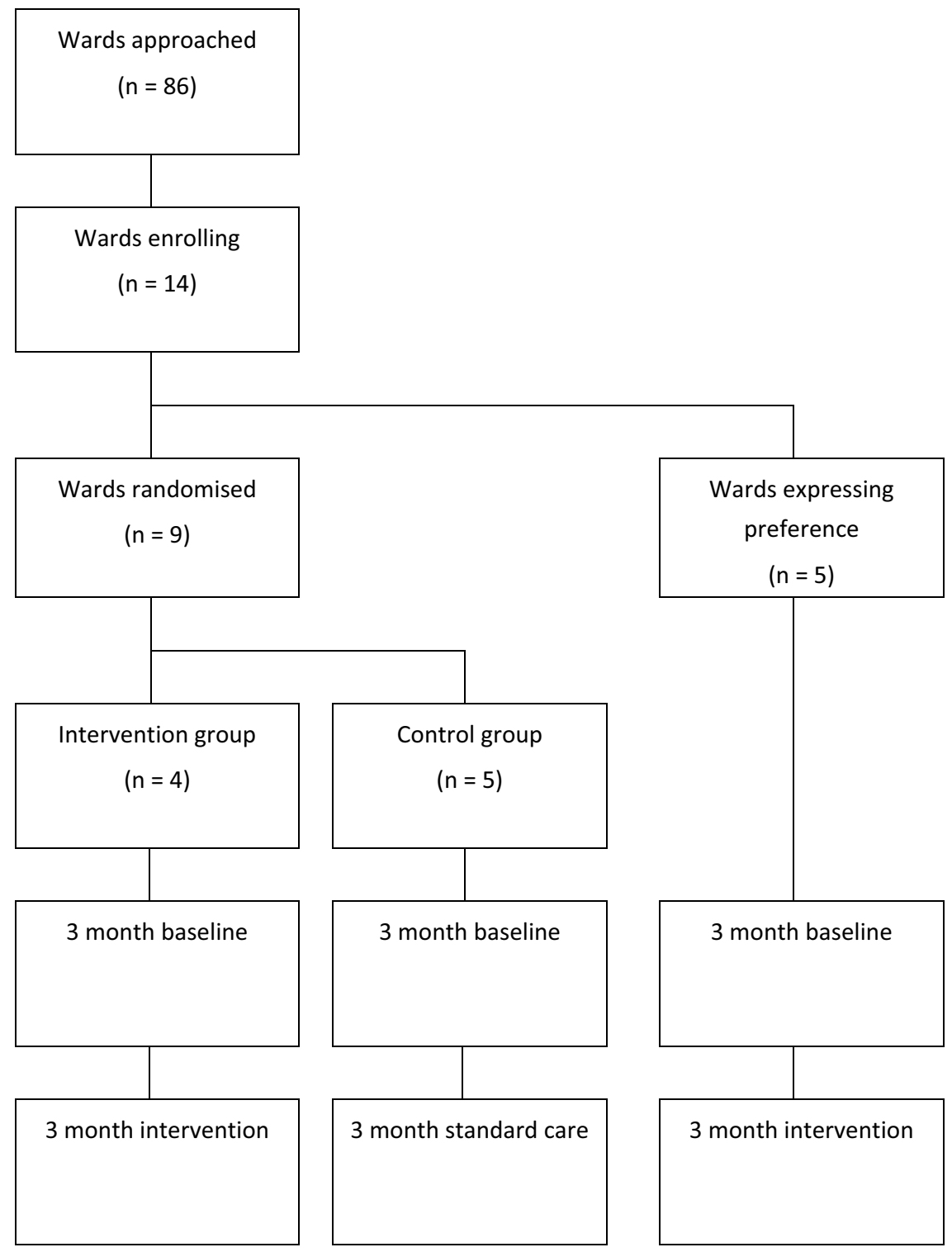




\section{Intervention}

The intervention consisted of a structured short-time risk assessment for every new patient during the first three days of hospitalization. The instrument was the previously validated extended version of the Brøset-Violence-Checklist (BVC-CH) [5, 6, 8]. In principle, the BVC-CH requires nurses to rate six patient behaviours (confused, irritable, boisterous, verbally threatening, physically threatening and attacking objects) and to perform an overall subjective assessment of the risk of imminent violence using a slide-rule-VAS. These combined ratings produce a score between 0 (very low risk) and 12 (high risk). The inter-rater reliability of the instrument evaluated in a separate study on three wards yielded intraclass correlation coefficients ranging from 0.85 to 0.93 for the 0-12 point risk score [9].

Based on empirical data from the instrument validation study, raw scores of 0 to 12 have been translated to four risk levels $[5,6,8]$. In order to facilitate interpretation and communication of the risk level, the risk is expressed as natural frequencies based on empirical data: (score 0-3) < 1 in 100 patients with this score will physically attack another person during the next shift; (score 4-6) about 1 in 100; (score 7-9) 1 in 10; and (score 10-12) 1 in 4 patients, respectively.

Ratings were carried out twice daily. We assisted the clinical application of the scores by explicit recommendations. For patients obtaining scores from 7 to 9 we suggested to staff that they discuss possible prevention measures from a list provided on the risk assessment form (Figure 2). For patients with scores of 10 or above we recommended a multidisciplinary team consultation to discuss the need for immediate measures. The organisational implementation and compliance with these recommendations was left to the discretion of wards without systematic data collection.

\section{Outcome measures}

The main outcome measures were the changes in incidence rates of severe aggressive events and coercive measures comparing the baseline period with the intervention period. Aggressive incidents were recorded by the revised Staff Observation Aggression Scale (SOAS-R) $[10,11]$. The SOAS-R records provoking factors, means used by the patient, target of the aggression, consequences for the target, and measures taken to terminate the aggression. The scale is completed by staff members witnessing aggressive behaviour of a patient. Aggression is defined as any verbal, non- 
Figure 2: Preventive measures for consideration in high-risk situations

Preventive Measures

- No specific measures to prevent an attack

- Careful observation

- General conversation (directed to reduce aggression)

- Walk outdoors 1:1 (directed to reduce aggression)

- Walk outdoors in a group (directed to reduce aggression)

- Reduction of demands (e.g. participation in activities)

- Relaxation exercise

- Confrontation with ward rules

- Discussion of risk with patient

- Talk-down (to deescalate)

- Transfer to intensive area within ward

- 1:1-observation for several hours

- Increase of medication dosage

- $\quad$ PRN-medication per os (psychotropic drugs)

- Open seclusion in the patients own room (time out)

- Preventive seclusion (closed seclusion room)

- Injection of psychotropic drugs (forced/voluntary)

- $\quad$ Physical restraint (indicate nr. of points)

verbal, or physical behaviour that was threatening (to self, others, or property), or physical behaviour that actually caused harm (to self, others, or property). The severity of the incidents is measured using the SOAS-R-scoring system ranging from 0 to 22 points. Following the recommendation of the authors of the SOAS-R, incidents with a score of 9 or more points were regarded as severe [12]. Coercive measures were recorded on a standardized form developed and pretested on the basis of existing formats in general use in the area [7]. The form covers a wide range of measures from forced injection of psychotropic medication to seclusion and mechanical restraint. For this study coercive measures were recoded into dichotomous data (present/absent). 


\section{Data collection}

In order to control for possible recruitment bias, we conducted a survey of all wards within the study area prior to our investigation using a questionnaire including the size of the wards, staffing, and the facilities for managing aggression and violence [13]. In addition, we asked the ward leaders to rate the severity of the problem and the resources for aggression management (see Table 1).

During both study periods, all aggressive incidents were registered using the SOAS-R form. Coercive measures were recorded on the purpose designed study form. Physical attacks were considered if the SOAS-R description of the incident met the following two criteria, namely 1) means of aggression = objects $O R$ dangerous objects $O R$ parts of the body AND 2) target of aggression = a person other than the patient her- or himself.

To estimate possible underreporting of aggressive incidents, two investigators (C.A. and I.N.) regularly visited the study wards on randomly selected dates. During these site visits, all patient records were hand reviewed for the preceding three days to detect any evidence of an aggressive incident. After termination of the study, each incident as abstracted from the patient records was compared with the available SOAS-R-report forms. This made it possible to estimate the extent of underreporting and to assess the severity of those incidents for which no corresponding SOAS-R-form was available. The same investigators abstracted additional patient data in a standardized format from the hospitals' databases. These data included admission and discharge dates, age, gender, admission modality (voluntary vs. involuntary) and main ICD-10 psychiatric diagnosis.

\section{Data analysis}

For each study period and ward, we calculated the incidence rate of events per 100 hospitalization days. For this analysis, we included all aggressive incidents directed towards other persons or objects, but excluded pure aggression to self. The primary outcome was the rate of severe incidents with a SOAS-R score of 9 or more. Secondary outcomes were the rate of physical attacks and the rate of coercive measures. Ninetyfive percent confidence intervals for rates were calculated assuming independence of the probability of an incident for individual hospitalization days (no correction for autocorrelation). From these raw incidence rates we calculated the risk ratios for an event for each of the three study arms. The change in incidence rates between the 
intervention and control groups was tested using a test for the difference between two proportions (Statistica Version 6). We used the number of patients not the number of treatment days for the calculation of the degrees of freedom. This is equivalent to the Geisser-Greenhouse lower bound test for repeated measures designs to control for sphericity [14].

Due to the non-normal distribution of data, comparisons between participating and non-participating wards were conducted using the Mann-Whitney-U-test for independent samples and the $\mathrm{Chi}^{2}$-test or Fishers exact test. Unless otherwise stated, data are reported as means \pm standard deviation. For all analyses, statistical significance was determined as a two-sided error probability of $\alpha=0.05$.

Data were analysed using SPSS (Version 10.0, SPSS, Chicago, IL) and CIA (Confidence Interval Analysis, Version 2.1, University of Southampton, UK).

\section{Results}

\section{Study population}

During both study periods, the 14 participating wards admitted a total of 2364 patients accounting for 45913 hospitalization days. The study wards had a mean number of beds of 16.9 (SD 1.9, range 13 to 19 beds) and a mean number of staff (in full time equivalents) of 0.71 (SD 0.2) per patient. Table 1 compares patient and ward characteristics including information available for the non-participating wards. The data indicate similar ward characteristics excluding ward managers' perception of aggression as a greater problem on the intervention wards. Also the distribution of patient diagnoses across the intervention and the control arm of the study at baseline were comparable. In contrast, the preference arm had significantly fewer patients with ICD10 F2 diagnoses (schizophrenia, schizo-type and delusional disorders, $26.5 \%$ vs. $33.4 \%$ in the intervention wards and $35.7 \%$ in the control wards, Table 1 ). 
Table 1: Ward characteristics

\begin{tabular}{|c|c|c|c|c|c|}
\hline & $\begin{array}{l}\text { Inter- } \\
\text { vention } \\
\text { wards } \\
(\mathrm{N}=4)\end{array}$ & $\begin{array}{l}\text { Preference } \\
\text { wards } \\
(n=5)\end{array}$ & $\begin{array}{l}\text { Control } \\
\text { wards } \\
(n=5)\end{array}$ & $\begin{array}{l}\text { Non-Partici- } \\
\text { pating } \\
\text { wards } \\
(n=68)^{*}\end{array}$ & \\
\hline Number of Beds mean (SD) & $17.5 \pm 1.29$ & $15.4 \pm 2.19$ & $18.0 \pm 1.23$ & $16.5 \pm 4.0$ & $p=0.301^{a}$ \\
\hline Nursing staff (FTE) per bed & $0.67 \pm 0.24$ & $0.75 \pm 0.23$ & $0.73 \pm 0.08$ & $0.74 \pm 0.25$ & $p=0.977^{a}$ \\
\hline $\begin{array}{l}\text { Proportion of wards } \\
\text { always open }\end{array}$ & $0 \%$ & $0 \%$ & $0 \%$ & $14.7 \%$ & $p=0.151^{b}$ \\
\hline $\begin{array}{l}\text { Proportion of wards with } \geq \\
\text { seclusion room }\end{array}$ & $100 \%$ & $100 \%$ & $100 \%$ & $82.3 \%$ & $p=0.894^{b}$ \\
\hline \multicolumn{6}{|l|}{ Aggression rated as } \\
\hline - no/very small problem & $0.0 \%$ & $0.0 \%$ & $0.0 \%$ & $14.7 \%$ & \\
\hline - small or medium problem & $0.0 \%$ & $60.0 \%$ & $60.0 \%$ & $52.9 \%$ & $p=0.254^{b}$ \\
\hline - big/very big problem & $100.0 \%$ & $40.0 \%$ & $40.0 \%$ & $36.6 \%$ & \\
\hline \multicolumn{6}{|l|}{$\begin{array}{l}\text { Resources for aggression- } \\
\text { management rated as }\end{array}$} \\
\hline - sufficient & $75.0 \%$ & $80.0 \%$ & $60.0 \%$ & & $p=0.760^{b}$ \\
\hline - insufficient & $25.0 \%$ & $20.0 \%$ & $40.0 \%$ & $20.6 \%$ & \\
\hline \multicolumn{6}{|l|}{ Baseline } \\
\hline Men & $54.4 \%$ & $47.5 \%$ & $55.2 \%$ & & $p=\underset{c}{0.048}$ \\
\hline Age & $39.0 \pm 13.1$ & $41.7 \pm 15.9$ & $38.0 \pm 14.3$ & & $p=0.321^{a}$ \\
\hline LOS & $20.7 \pm 29.9$ & $16.9 \pm 25.8$ & $18.1 \pm 26.5$ & & $p=0.468^{a}$ \\
\hline Involuntary admissions & $41.4 \%$ & $36.9 \%$ & $38.4 \%$ & & $p=0.433^{c}$ \\
\hline \multicolumn{6}{|l|}{ Main diagnosis at discharge } \\
\hline FO & $3.8 \%$ & $1.7 \%$ & $4.3 \%$ & & \\
\hline F1 & $26.2 \%$ & $27.0 \%$ & $24.2 \%$ & & \\
\hline F2 & $33.4 \%$ & $26.5 \%$ & $35.7 \%$ & & \\
\hline F3 & $15.5 \%$ & $21.4 \%$ & $15.3 \%$ & & $P<0.001^{c}$ \\
\hline $\mathrm{F} 4$ & $14.3 \%$ & $21.9 \%$ & $11.5 \%$ & & \\
\hline F6 & $4.0 \%$ & & $5.0 \%$ & & \\
\hline Others & $2.7 \%$ & $1.4 \%$ & $4.1 \%$ & & \\
\hline
\end{tabular}


Of the 2364 patients ( $46.6 \%$ females, mean age 39.5 years, SD $=14.2$, range $14-95$ years), $56 \%$ were admitted on a voluntary basis. The involuntary admission rate of $44 \%$ is typical for wards within German speaking Switzerland. The median length of stay (LOS) was 9 days with an average of 19 days (SD $=26.8$, range $1-265$ days). The ICD10 diagnoses of the patients were FO organic, including symptomatic, mental disorders $(78=3.3 \%), F 1$ disorders due to psychoactive substance use $(574=24.3 \%), F 2$ schizophrenia, schizo-type and delusional disorders (734 = 31.0\%), F3 mood (affective) disorders $(382=16.2 \%)$, F4 neurotic, stress-related and somatoform disorders, behavioural syndromes associated with physiological disturbances and physical factors $(339=14.3 \%), F 6$ personality disorders of adult personality and behaviour $(76=3.2 \%)$, others (e.g. mental retardation, disorders of psychological development, behavioural and emotional disorders with onset occurring in childhood and adolescence; $66=$ $2.8 \%)$, and missing $(115=4.9 \%)$.

\section{Aggressive incidents and coercive measures}

Over both phases of the study, 770 aggressive incidents were reported involving 314 patients (13.3\% of all patients) and 632 coercive measures were recorded. The difference between these numbers is attributable the fact that not all aggressive incidents are followed by coercive measures. Additionally, coercive measures are sometimes employed to prevent aggression. Of the 770 aggressive incidents 418 (54\%) had a SOAS-R score of 9 or above and 258 (34\%) incidents were physical attacks. The overall incidence rate of severe aggressive events during the baseline period was 1.09 (95\% Cl: 0.96 - 1.24) per 100 hospitalization days. The overall incidence rate of coercion during baseline was 1.57 (95\% Cl: 1.41-175) per 100 hospitalization days. Further rates are provided in Table 2.

\section{Intervention}

From baseline to the intervention period, the rate of severe aggressive events with a SOAS-R $\geq 9$ declined both in the control arm and in the intervention arm. The decline in the intervention wards (risk ratio $=0.59,95 \% \mathrm{Cl} 0.41-83$ ) was significantly larger $(\mathrm{p}<$ 0.001 ) than the decline in the control arms (risk ratio $=0.85,95 \% \mathrm{Cl} 0.64-1.13$ ). Raw and calculated data are presented in Table 2. Likewise, all rates declined more in the intervention wards as compared to the control wards for all secondary outcomes: attacks $(41 \%$ vs. $7 \%, p<0.001)$, and coercive measures $(27 \%$ vs. increase by $10 \%, p<$ 
0.001), respectively. Finally, Figure 3 illustrates that for all outcomes the effects were larger in the preference wards as compared to the wards randomized to intervention or control. Similar results were obtained when analyzing the data as to the occurrence of days with any aggressive incident on the ward versus incident-free days (data not shown).

\section{Figure 3: Main outcome measures}
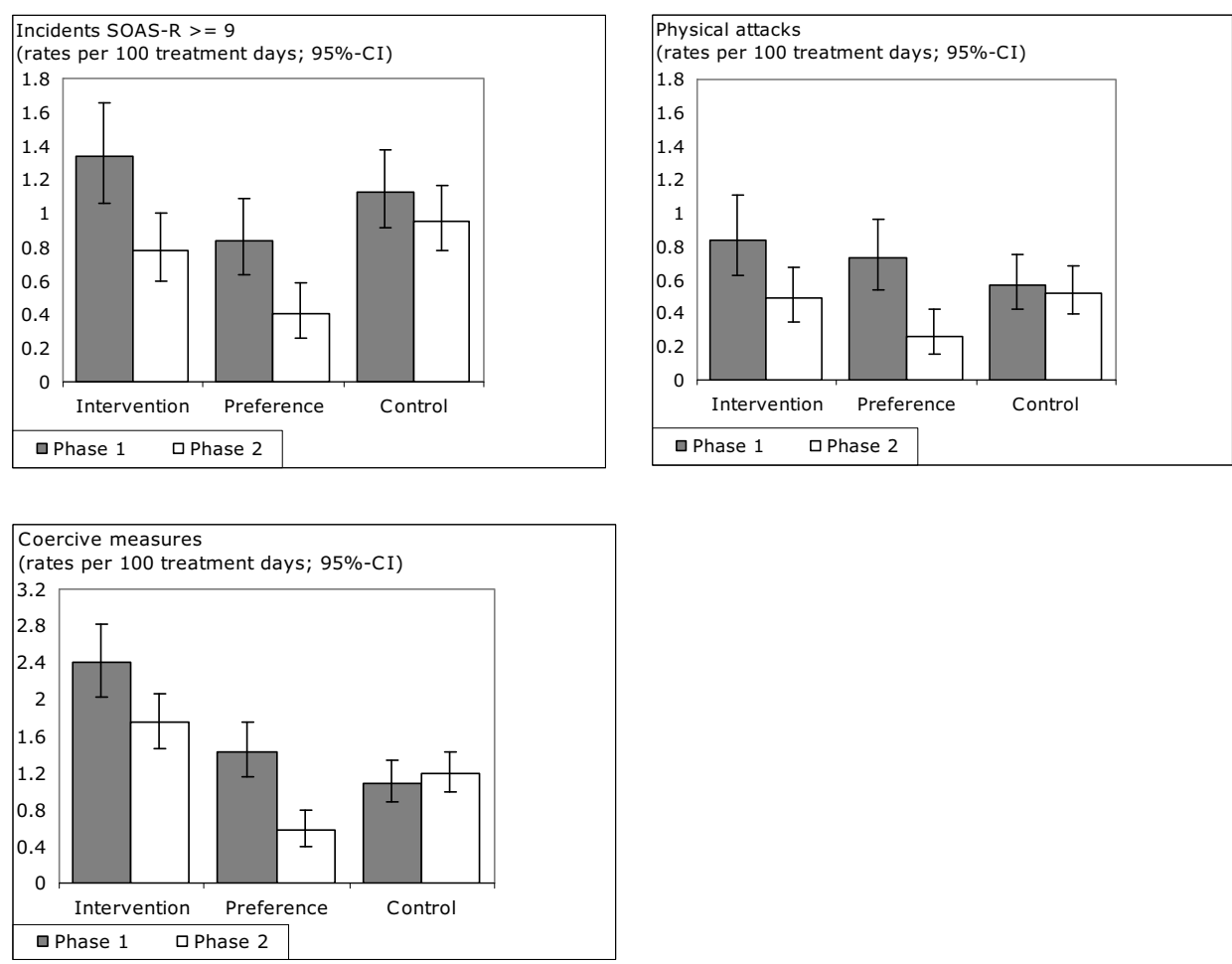


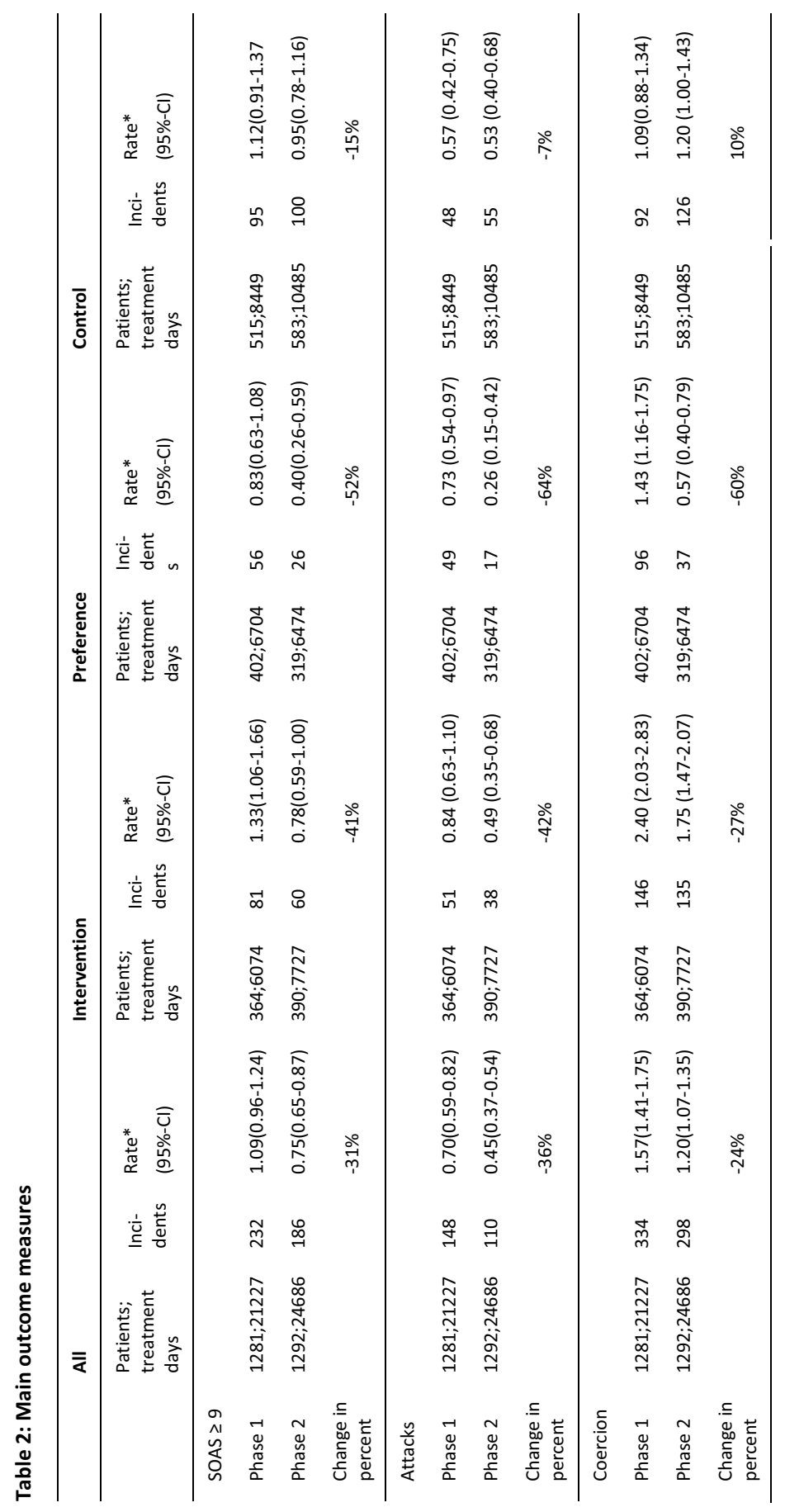




\section{Estimation of underreporting}

In contrast to the reduction in the rates of incidents and coercive measures, the mean severity of all recorded incidents increased in the intervention group and in the control group (table 3). We had anticipated the possibility of an increasing underreporting of less severe events as the study progressed. Therefore, two investigators (C.A. and I.N) manually searched on randomly assigned dates the entire patient documentation and shift reports of 115 patients covering 460 treatment days. The search identified five incidents not registered with a corresponding SOAS-R form, with an estimated severity of the non-reported incidents ranging from 1 to 5 points. This may infer that predominantly minor incidents (<9 points) escaped reporting, while only very few of the severe incidents ( $\geq 9$ points) remained unreported. Figure 4 (next page) compares the frequency of events stratified by score for each study period between the intervention and the control group.

Table 3: Severity of aggressive incidents

\begin{tabular}{|c|c|c|c|c|c|c|c|c|c|}
\hline & \multicolumn{3}{|c|}{ Intervention } & \multicolumn{3}{|c|}{ Preference } & \multicolumn{3}{|c|}{ Control } \\
\hline & $\mathrm{n}$ & Mean (s.d.) & $95 \%-\mathrm{Cl}$ & $\mathrm{n}$ & Mean (s.d.) & $95 \%-\mathrm{Cl}$ & $\mathrm{n}$ & Mean (s.d.) & $95 \%-\mathrm{Cl}$ \\
\hline Phase 1 & 180 & 7.85 (4.5) & $7.2-8.5$ & 97 & $9.85(4.8)$ & $8.9-10.8$ & 185 & $8.14(4.7)$ & $7.5-8.8$ \\
\hline Phase 2 & 103 & 9.69 (4.9) & $8.7-10.6$ & 33 & $12.79(4.8)$ & $11.1-14.5$ & 172 & 9.65 (4.7) & 8.9-10.4 \\
\hline
\end{tabular}

\section{Discussion}

\section{Main findings and clinical relevance}

In this randomized controlled multi-centre trial we tested the effect of a structured assessment of the short-time risk of violence in acute psychiatric wards. The intervention substantially reduced severe events of patient aggression (adjusted risk reduction 41\%) and also reduced the need for coercive measures (adjusted risk reduction $27 \%$ ). An even larger effect was observed in those wards not consenting to randomization but partaking in the study as a preference group. We consider a reduction in the incidence rates of aggression and coercion of the magnitude found in this study as clinically relevant for patients and staff alike. The results are particularly encouraging because the intervention is relatively simple to implement, inexpensive 
Figure 4: Event severity across study periods

The figure compares the intervention and the control group. Each histogram shows the frequency of aggressive events standardized to the number of hospitalization days during the intervention period. The black shaded areas in the background denote the frequency during the intervention period. The gray shaded areas in the foreground denote the frequency during the baseline period. The comparison of the histograms reveals that the intervention predominantly affected mild to moderately severe incidents. No reduction was seen for the most severe events (SOAS-R > 16).
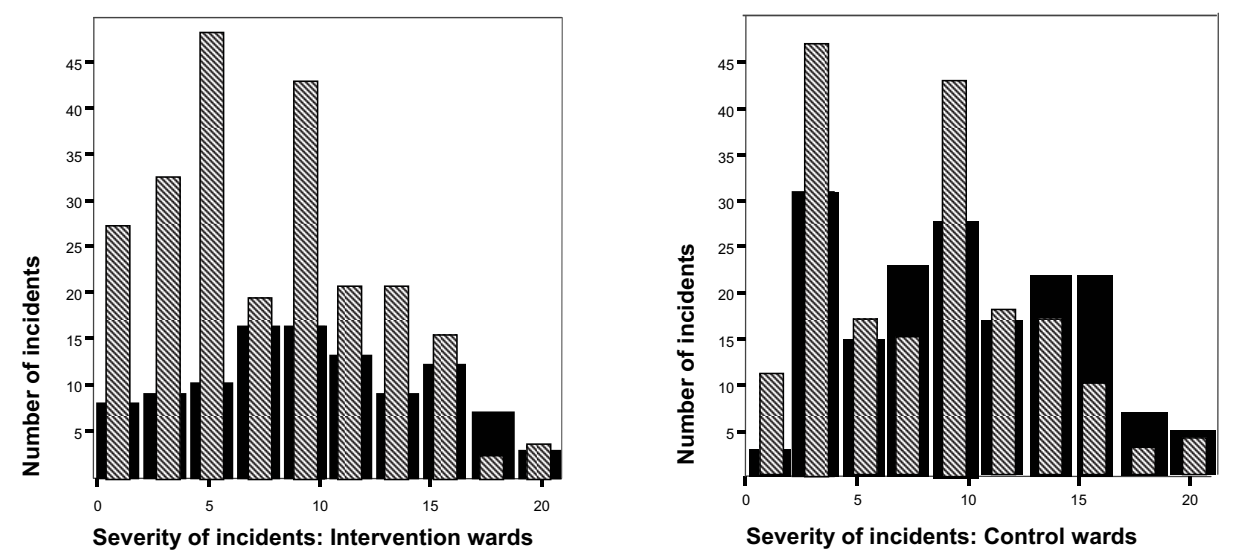

and easy to integrate into daily practice. The study results reflect the importance of continuing structured risk assessment and support recommendations put forward in recent guidelines [2].

\section{Mechanisms of effectiveness}

Strictly speaking, the intervention in this study consisted of three elements: First, there was the repeated structured determination of the risk in the first three days of the hospital stay of all patients. Second, in cases of a high or very high risk, staff were encouraged to discuss preventive measures from a list provided on the risk assessment form. Third, in cases of a very high risk, the teams were prompted to plan and implement preventive measures. Although related to each other, each of these elements might have been independently effective. For example, identification of patients with a high risk score allows allocating staff time spent during group meetings for discussion of preventive measures to a small subgroup of high risk patients. Thus, there are several possible explanations for the observed overall effects. The obligation to assess all patients twice a day might have increased the general awareness for potential dangers. This awareness may itself have fostered a more cautious approach 
and deescalating staff behaviour. The risk assessment form may also have facilitated the intra- and interprofessional communication of risk. These factors, in combination with the obligatory discussion of high risk situations, may have resulted in a more consistent team response to potentially dangerous patients. It is conceivable that the crucial factor might have been an improved intra- and interprofessional collaboration and unité de doctrine. Finally, part of the risk assessment form was a list of simple practical prevention measures. The visibility of these measures might have acted as a constant reminder of possibilities to prevent escalation of aggressive situations or as a source of inspiration for aggression related care planning. Taken together, the current intervention appears to be an example of a simple strategy to influence complex staffpatient interactions, in particular where patients are responsive to intervention. This is underscored by the finding that the intervention did not reduce the incidence rate of the severest aggressive events which are probably not as amenable to staff-patient intervention (e.g. de-escalation).

Although the systematic registering of aggression using the SOAS-R has been reported to be per se an effective mechanism to reduce aggression [15], we exclude this explanation given the stable aggression rates in the control wards.

Several design features of the study warrant discussion. In line with the literature we designed the study to combine risk assessment with elements of risk management, forgoing the possibility of delineating the effect of "pure" risk assessment alone. We purposely included a preference arm in the study to simulate a patient preference RCT paradigm or the comprehensive cohort design [16]. In the present study, the effect in the preference arm exceeded the effect observed in the group randomized to intervention. We offer several possible explanations: The patient population in the preference wards included a smaller proportion of patients with F2 diagnoses (schizophrenic disorders). This raises the possibility that, beyond a preference effect [17], wards with fewer schizophrenic patients may particularly benefit from the intervention. Alternatively, the more favourable results in the preference wards could also be seen as manifestation of staff characteristics and their preference to introduce risk assessment. This finding would then be independent of the patient population.

\section{Limitations}

In interpreting the findings of our study, several limitations must be considered. We relied on randomisation of wards to minimise bias. However, while the intervention and control wards were comparable with respect to most of the characteristics considered, we still had baseline differences in important aspects. All 4 intervention 
wards rated patient aggression as big or very big problem, in contrast to 2 out of 5 control wards. Correspondingly, the baseline rates of aggression were higher on the intervention wards compared to the controls. This may have led to a higher sensitivity and perceived need to improve the situation, which may have increased the effect of the intervention. Due to the small number of wards, randomisation might not be fully adequate to determine equality of the study groups. Additionally, a larger number of participating wards would have allowed to employ more sophisticated statistical models that simultaneously control for clustering and autocorrelation, i. e. a threelevel multilevel model with days / events nested within patients nested within wards. Moreover, the nature of the intervention rendered blinding impossible. A further limitation is the absence of data on the interventions actually implemented as a consequence of the risk assessment. Finally, data on the frequency of aggression or patient characteristics from the non-participating wards were unavailable. Caution is therefore warranted in generalizing our data beyond the present study population. However, the aggression rates found in this study are comparable to rates found in other studies on psychiatric acute wards [11].

\section{Clinical and practical implications}

In this study in acute psychiatric wards in German speaking Switzerland a simple and low-cost intervention reduced the incidence rate of coercive measures and severe aggressive incidents. The intervention consists of a risk assessment twice daily for the first three days of hospitalisation in acutely admitted psychiatric patients combined with a communication of risk scores as natural frequency numbers (e. g. one out of 10 patients instead of $10 \%$, one out of 1000 patients instead of $0.1 \%$ ) [18] and a recommendation for action tailored to the risk level.

\section{References}

1. Whittington R, Richter D. (ed) Violence in Mental Health Settings. New York: Springer, 2006.

2. National Institute for Clinical Excellence NICE. Violence: The short-term management of disturbed/violent behaviour in in-patient psychiatric settings and emergency departments (Clinical Guidline 25). London: National Institute for Clinical Excellence NICE, 2005.

3. Menckel E, Viitasara E. Threats and violence in Swedish care and welfare magnitude of the problem and impact on municipal personnel. Scand J Caring Sci 2002;16: 376-85.

4. Linaker OM, Busch Iversen, $\mathrm{H}$. Predictors of imminent violence in psychiatric inpatients. Acta Psychiatr Scand 1995;92: 250-4. 
5. Almvik R, Woods P. The Brøset Violence Checklist (BVC) and the prediction of inpatient violence: Some preliminary results. Perspect Psychiatr Care 1998;5: 208-11.

6. Abderhalden C, Needham I, Dassen T, Halfens R, Haug H, Fischer J. Predicting inpatient violence using an extended version of the Brøset-Violence-Checklist: Instrument development and clinical application. BMC Psychiatry. 2006;6: 17.

7. Needham I, Abderhalden C, Meer R, Dassen T, Haug HJ, Halfens RJG, et al. The effectiveness of two interventions in the management of patient violence in acute mental inpatient settings: Report on a pilot study. J Psychiatr Ment Health Nurs 2004;11: 595-601.

8. Almvik R, Woods P, Rasmussen K. The Brøset Violence Checklist: Sensitivity, Specificity and Interrater Reliability. J Interpers Violence 2000;15: 1284-96.

9. Abderhalden C, Gurtner C. Wie reliabel ist die Brøset-Gewalt-Checkliste (BVC) zur Einschätzung des kurzfristigen Gewaltrisikos? In Kompetenz - zwischen Qualifikation und Verantwortung (ed M Schulz, C Abderhalden, I Needham, S Schoppmann, H Stefan): 105-9. Unterostendorf: Ibicura, 2007

10. Nijman HL, Muris P, Merckelbach HLGJ, Palmstierna T, Wistedt B, Vos AM, et al. The Staff Observation Aggression Scale - Revised (SOAS-R). Aggress Behav 1999;25: 197-209.

11. Nijman HL, Palmstierna T, Almvik R, Stolker JJ. Fifteen years of research with the Staff Observation Aggression Scale: a review. Acta psychiatr Scand 2005;111: 12-21.

12. Palmstierna T. Cut-off point of SOAS-R. Personal Communication. 2003.

13. Needham I, Abderhalden C, Dassen T, Haug HJ, Fischer JE. Coercive procedures and facilities in Swiss psychiatry. Swiss Med Wkly. 2002;132: 253-8.

14. Turner JRA, J.F. T. Introduction to Analysis of Variance: Design, Analysis, and Interpretation. Newbury Park: Sage, 2001.

15. Nijman $\mathrm{H}$, Merckelbach $\mathrm{H}$, Evers $\mathrm{C}$, Palmstierna $\mathrm{T}$, a Campo J. Prediction of aggression on a locked psychiatric admissions ward. Acta psychiatr Scand 2002;105: 390-5.

16. Brewin $\mathrm{CR}$, Bradley $\mathrm{C}$. Patient preferences and randomised clinical trials. BMJ 1989;299: 13-5.

17. Howard L, Thornicroft G. Patient preference randomised controlled trials in mental health research. Br J Psychiatry 2006;188: 303-4.

18. Hoffrage U, Lindsey S, Hertwig R, Gigerenzer G. Medicine. Communicating statistical information. Science 2000;290: 2261-2. 
General Discussion 
In this chapter the main findings of the presented studies are summarised and discussed. After addressing the strengths and limitations of the research, the chapter ends with concluding suggestions for future research.

In the following, the studies results will be arranged in two thematic sections. The first section concerns investigations on the scope of the problem in acute inpatient psychiatry in German speaking Switzerland, the second relates to the development and clinical application of a structured clinical assessment of the short-tern risk for violence among acute psychiatric patents. Before discussing the results in detail, a brief summary of the overall findings is presented.

\section{Summary of the results}

Summing up, the studies yielded the following findings:

\section{Scope of the problem}

Three out of four psychiatric nurses in the German speaking part of Switzerland reported experiences of serious threats and $70 \%$ reported physical attacks in their work-life, while $47 \%$ and $40 \%$ respectively reported such experiences in their private life.

They perceive aggression not only as a negative phenomenon, but also as functional/comprehensible phenomenon. Only minor differences were found in the perception of aggression with regard to personal characteristics or work environment of the nurses.

Violence is rated as a serious or very serious problem in one third of the acute wards in the study area. Considerable differences exist regarding resources for and practices in handling patient aggression. The greatest deficiencies were reported in practical and theoretical knowledge among staff, in recording systems, in post-incident services for victims, the lack of seclusion facilities, and the lack of a systematic violence risk assessment.

In acute wards in the area, the incident rates per 100 treatment days were 0.60 for physical attacks and 1.83 for all aggressive incidents (including purely verbal aggression). Per ward, one severe incident every ten days and a physical attack every two weeks was registered. Nearly half of the purely verbally aggression was classified as severe, and $53 \%$ of the aggressive incidents were followed by a coercive measure, 
mostly seclusion or seclusion accompanied by medication. $13 \%$ of the patients were responsible for one ore more incident, and $6.9 \%$ were involved in one ore more physical attack. $38 \%$ of the incidents were registered within the first 7 days after admission.

\section{Systematic risk assessment}

In a clinical validation study the German version of the Norwegian Brøset - Violence Checklist BVC retained its predictive properties in the short-term prediction of physical attacks in Swiss acute wards. A subjective assessment of risk covering other risk factors than the 6 behaviours of the original instrument (e.g. situative factors) could be integrated into an enhanced version of the checklist (BVC-CH), complemented with recommendations for preventive action to be considered in high risk patients.

In a clinical application study, the new instrument was well accepted and proved to be applicable in daily care in acute admission wards. The predictive properties remained stable, while, due to a considerable proportion of false positive ratings, overestimating the risk to some degree.

In a prospective randomised waiting-list controlled trial with 9 acute admission wards as units of randomisation, the BVC-CH was tested for its potential to reduce violent. The study included a preference arm of 5 additional wards which declined randomisation. The reduction in severe aggressive events, attacks and coercion during the intervention period suggests that systematic risk assessment within the first days of hospitalisations may contribute to reduced violence and coercion in acute psychiatric wards.

\section{Discussion of the results, strengths and limitations}

\section{Scope of the problem}

Our survey among psychiatric nurses in German speaking Switzerland was the first multicentre study of this kind in the area and, due to the large dataset, delivered data that will be useful as Swiss reference for international comparisons and as reference for smaller studies in this area. The results were comparable to results from other international studies. However, one interesting result was the high proportion of nurses reporting prior exposure to threats (47\%) and physical violence $(40 \%)$ in their private life. Comparable results could not be found in the literature and deserve further attention. Experiences of violence of health personnel in their private life 
should be considered as potential confounder in studies on associations between work-related violence and psychosocial impairment (e.g. PTSD). Furthermore the results support the argument of a tight interconnection between aggression and violence in psychiatry and the respective phenomena in society as a whole and stress the notion that aggression should not be seen as a specific problem of psychiatry or psychiatric patients. The latter argument has some importance for the efforts currently taken to fight stigmatisation of psychiatric patients (Rusch, Angermeyer, \& Corrigan, 2005), as perceived dangerousness remains to be a main source of stigmatisation e.g. vis-a-vis of patients suffering from schizophrenia (Thompson et al., 2002).

However, some limitations have to be considered when interpreting the results. Due to the snow-ball-type of data collection, we had only very limited control over the sampling procedures. Despite the representativeness with respect to ward-types, the generalisability to the population of psychiatric nurses is not fully guaranteed. To obtain this, a random sampling procedure would have been appropriate. However, a precondition to such a sampling procedure would be a list of all psychiatric nurses, which is not obtainable at this time. A problem relating to all research on experiences with violence at work is a possible bias by an unknown number of nurses that may have left the profession as consequence of their exposure to aggression. This could lead to a possible underrepresentation of the most affected persons. Another weakness of this study was the quite global nature of questions regarding past experiences with aggression.

The results on perceptions of aggression among nurses, drawn from the same sample, are again useful as Swiss reference data for other studies, and indeed have already contributed to comparative European studies (Jansen, Middel, \& Dassen, 2005; Jansen, Middel, Dassen, \& Reijneveld, 2006) as well as to the further development of the Perception of Aggression Scale (POAS) (Needham, Abderhalden, Dassen, Haug, \& Fischer, 2004). To change the attitude of nurses has repeatedly been suggested as potential way to reduce patient aggression and to improve aggression management. However, the apparent independence found of the perception of aggression with regard to personal or work environment characteristics of the nurses stresses the hypothesis of the complex nature of attitudes towards aggression and prevents from simplistic expectations with respect to their influencability.

In addition to the sampling-related limitations mentioned above, the main problem in interpreting the results regarding the perception of aggression is the global character of the questionnaire. While it appears plausible that nurses perceive the phenomenon as well as negative and positive, it would be interesting to know to what kind of 
behaviour the respective perception refers to. A second problem is the lack of information on the actual behaviour and the actual prevalence of work-related violence of nurses with differing attitudes towards aggression. Therefore, the answer to the question of more or less helpful attitudes it is left to speculation.

The survey among the admission wards in the area revealed differences with regard to the perceived severity of the problem as well as a wide variation regarding core practices like staff training, registration of incidents and risk assessment procedures. Although not systematically checked, it is apparent that practices in most wards did not meet best practice standards based on the available scientific evidence (e.g. (National Institute for Clinical Excellence NICE, 2005; Royal College of Psychiatrists, 1998). While a similar variation and comparable deficiencies were known from studies comparing European countries (Bowers et al., 1999) or from surveys among UK- and Irish wards (Cowman \& Walsh, 2004; Royal College of Psychiatrists' Research Unit, 2005), our study was the first to representatively depict current practice in Switzerland. This data will now allow a monitoring of changes and hopefully improvements in the future. Thanks to a replication of our study in a sample of wards in Germany, it was possible to compare the current practice in Switzerland with its immediate neighbour (Steinert, Schmid, Abderhalden, \& Needham, 2004). The results revealed an apparent absence of overall accepted minimal standards in aggression management, a fact that raises some concerns in view of the current claims for evidence-based practice. Last but not least the results showed the need to develop risk assessment practices towards a more systematic approach.

There are two main limitations hampering the validity of the results of this survey. With respect to the assessment of how big the problem of aggression was we relied on a global assessment just by the ward leader. However, this appraisal may not represent the whole picture in every ward, and we have no information on the aspects considered by the participants when judging the situation on their ward. The questionnaire employed was mainly focused on structural aspects of aggression management and it may be arguable if drawing conclusions with regard to practice was adequate. A serious weakness of the survey was the fact that the view of patients and relatives was not included, possibly leading to a one sided picture. The inclusion of the perspective of service users and relatives is becoming a standard in service-related evaluative research (Crawford, 2001), and discrepancies in the perception of aggression management by professionals and users are well known from research (Abderhalden, Hahn, Bonner, \& Galeazzi, 2006). 
The study presented here was the first investigation of aggressive incidents focusing on the specific setting of acute admission wards in German speaking Switzerland and the first Swiss prevalence study employing an internationally widespread instrument (Staff Observation of Aggression Scale Revised - SOAS-R, Nijman et al., 1999; Nijman, Palmstierna, Almvik, \& Stolker, 2005), thus allowing direct comparisons across regions and country borders. We found rates of aggression in a medium range compared to results of other large sample studies in acute wards. However, the interpretation of the prevalence rates found in our study remains difficult when it comes to judging the numbers as too high, high or low. Beyond dispute, it is an important goal to reduce aggression on the wards. However, it is likewise indisputable that it is impossible to completely reach that goal. It is therefore difficult to decide under what circumstances which rates would be acceptable or "optimal". To add to this difficulty, there is no clear consensus on the suitability of different types of rates (Bowers, 2000). With respect to this, consensual recommendations would be very helpful. This would also be the case with regard to the problem of outlier, i.e. patients involved in a high number of aggressive incidents and possibly inflating figures. Another problem related to the interpretation is the difficult question of an adequate measure for the severity of incidents (Bowers, 1999). The cut-off of 9 points on the SOAS-R-severity score remains arbitrary, although often used, and more efforts should be undertaken to clarify this matter.

\section{Systematic risk assessment}

The studies describing the first clinical validation of the German version of the Brøset Violence Checklist (BVC) and the development of an enhanced version resulted in a short and easy to use instrument that was well accepted by the practitioners. To our knowledge, it is the first instrument for such purposes available in German that has been tested with respect to its accuracy and clinical applicability. The integration of a Visual Analog Scale (VAS) to include the experience of the staff currently dealing with the patient allows the consideration of fluctuating situational, environmental and interactional risk factors, thus contributing to the shift away from a simplistic exclusive focus on patient related variables when assessing the risk in a given situation, the latter being congruent with current theoretical positions. However, the improvement of the predictive accuracy by the inclusion of the VAS found in the course of instrument development could not be replicated in the clinical application study. The interpretation of this result is hindered by the lack of information on the factors considered by the staff members when applying the tool in daily practice. 
Thus, the lack of concrete information on the practical use of the instrument is one of the limitations of the study. The integration of the VAS relies to some extent on the application of intuition and clinical experience. Therefore, the quality of its application might depend on the educational level and the amount of clinical experience of the users. The absence of such data on the staff constitutes another limitation.

To our knowledge, our study on the effectiveness of a systematic assessment of the short time risk for violence to reduce patient aggression is the first randomised controlled trial concerning this intervention. We consider the reduction in the incidence rates of aggression and coercion of the magnitude found in the clinical trial as clinically relevant for patients and staff alike. The results are particularly encouraging because the intervention is relatively simple to implement, inexpensive and easy to integrate into daily practice. The study results reflect the claimed preventive potential of continuing risk assessment and support recommendations forwarded by recent guidelines (National Institute for Clinical Excellence NICE, 2005). However, due to several limitations, the results have to be interpreted with some caution.

Despite randomisation, there remain some questions regarding the comparability of the wards. Due to the package nature of the intervention, i.e. the combination of risk assessment with subsequent review of the risk by the team, and the list of possible preventive measures, an estimation of the effectiveness of each of these components was impossible. In addition, there was no formal control of the concrete modalities of the implementation on the study wards. A problem inherent in the cluster randomisation study design is the lack of independence of discrete observations, leading to uncertainty with respect to the relative influence of patient- and ward characteristics in one risk situation.

\section{Ethics of risk assessment}

The ethical problem of overestimation of the risk (relatively high proportion of false positives) and the related possibility of unjustified interventions was addressed by two characteristics of the risk assessment instrument used in the intervention study. Firstly, the instrument includes an interpretation of the risk-scores employing natural number frequency wordings (e.g. "Moderate risk = about 1 out of 10 patients having this risk will attack a person"). Secondly, in cases of increased risk, the recommendation given was to discuss preventive measures, thus avoiding the unreflected automatisms in the application of restrictive interventions. However, according to the principle of 'veracity', the result of a risk assessment should be openly communicated to the 
patient assessed. This obligation was not included in the instrument and has to be regarded as an ethical weakness of the approach chosen.

\section{Suggestions for future research}

Considering the results of the studies discussed above, the following recommendations for further research are made:

\section{Epidemiology}

Within the last decade, a growing number of epidemiological studies have been published that offer data that are comparable, one among them is the prevalence study that is part of this dissertation. One factor contributing to more comparable data is the spread of the Staff Observation of Aggression Scale (SOAS-R) which has become a standard instrument to describe aggressive incidents, especially in Europe. However, comparability is in many cases still restricted on pure frequency, on some characteristics of the incidents, and the most frequently studied factors are patient related factors. Based on current theoretical approaches and study results stressing the important role of staff, environmental and interactional variables, it is recommended to include more staff and environmental data into studies on the prevalence of inpatient aggression. Such data could include measurements of the organisational culture, ward atmosphere, ward rules, safety and security policies, staffing including staff attitudes, evaluation of treatment opportunities and ward environment by patients and relatives, etc. Such contextual data are urgently needed in order to advance the understanding and explanation of the variation in the prevalence of aggression.

With respect to a further standardisation of reporting, consensus processes (e.g. Delphi surveys) are recommended in order to develop a set of recommendations for data collection and reporting (e.g. recommendations for different prevalence rates, minimal information to be provided when reporting prevalence rates, etc.).

Another area where research is needed is measures for the severity of incidents.

\section{Risk assessment}

With respect to the further refinement of the extended version of the Brøset Violence Checklist (BVC-CH), the existing studies should be completed with systematic tests of the instrument with regard to interrater reliability. Further studies are needed in order to understand the processes that lead to the subjective risk assessment. Such studies 
on the implicit clinical knowledge of nurses and their practical application of the VAS may reveal deficiencies in its use, and/or provide new aspects of risk not considered yet. Results of such studies could contribute to improvements of the instructions of the BVC-CH.

Previous research, the studies in this dissertation included, had its focus in the identification of factors suitable for risk prediction. In extension of this, it is recommended to focus on the practical application of existing tools and the degree of observance of existing guidelines in daily practice. In addition to this, future research should focus on risk management as consequence of risk assessment. To date, research on the professional answers to different degrees of risk is all but inexistent. Data drawn from the list of preventive measures included in the BVC-CH could be suitable for this purpose. Another issue that waits to be explored relates to the question of how risk assessments are communicated, among staff and vis-a-vis of relatives and patients. Linked with this, future research should also address the practical implication of falsely positive risk estimations and the possible role of selffulfilling prophecy.

\section{Patient involvement}

The involvement of experienced service users could be one of the most promising approaches to improve risk assessment and prevention of aggression patients (Langan \& Lindow, 2004). On the one side, user involvement in research projects could be crucial to integrate ward-, staff and interaction-related risk factors into risk assessment procedures, and, on the other hand, could contribute to development risk assessment and prevention into a matter of collaboration.

\section{References}

Abderhalden, C., Hahn, S., Bonner, Y. D. B., \& Galeazzi, G. (2006). Users' Perceptions and Views on Violence and Coercion in Mental Health. In R. Whittington \& D. Richter (Eds.), Violence in Mental Health Sciences (pp. 69-92). New York: Springer.

Bowers, L. (1999). A critical appraisal of violent incident measures. Journal of Mental Health, 8(4), 339-349.

Bowers, L. (2000). The expression and comparison of ward incident rates. Issues Ment Health Nurs, 21(4), 365-374.

Bowers, L., Whittington, R., Almvik, R., Bergman, B., Oud, N., \& Savio, M. (1999). A European perspective on psychiatric nursing and violent incidents: management, education and service organisation. Int J Nurs Stud, 36, 217-222.

Cowman, S., \& Walsh, J. (2004). Safety and security procedures in psychiatric acute admission wards. Journal of Research in Nursing, 9, 185-193. 
Crawford, M. (2001). Involving users in the development of psychiatric services -- no longer an option. Psychiatr Bull, 25(3), 84-86.

Jansen, G. J., Middel, B., \& Dassen, T. W. (2005). An international comparative study on the reliability and validity of the attitudes towards aggression scale. Int J Nurs Stud, 42(4), 467-477.

Jansen, G. J., Middel, B., Dassen, T. W., \& Reijneveld, M. S. (2006). Cross-cultural differences in psychiatric nurses' attitudes to inpatient aggression. Arch Psychiatr Nurs, 20(2), 82-93.

Langan, J., \& Lindow, V. (2004). Living with risk: Mental health service user involvement in risk assessment and management. Bristol: The Policy Press.

National Institute for Clinical Excellence NICE. (2005). Violence: The short-term management of disturbed/violent behaviour in in-patient psychiatric settings and emergency departmments (Clinical Guidline 25). London: National Institute for Clinical Excellence, NICE.

Needham, I., Abderhalden, C., Dassen, T., Haug, H. J., \& Fischer, J. E. (2004). The perception of aggression by nurses: Psychometric scale testing and derivation of a short instrument. J Psychiatr Ment Health Nurs, 11(1), 36-42.

Nijman, H. L., Muris, P., Merckelbach, H. L. G. J., Palmstierna, T., Wistedt, B., Vos, A. M., et al. (1999). The Staff Observation Aggression Scale - Revised (SOAS-R). Aggress Behav, 25, 197-209.

Nijman, H. L., Palmstierna, T., Almvik, R., \& Stolker, J. J. (2005). Fifteen years of research with the Staff Observation Aggression Scale: a review. Acta Psychiatr Scand, 111(1), 12-21.

Royal College of Psychiatrists' Research Unit. (2005). The National Audit of Violence 2003-2005: final report. London: Royal College of Psychiatrists.

Royal College of Psychiatrists. (1998). Management of imminent violence: clinical practice guidelines to support mental health services (Occasional Paper No. OP41). London: Royal College of Psychiatrists College Research Unit.

Rusch, N., Angermeyer, M. C., \& Corrigan, P. W. (2005). Mental illness stigma: concepts, consequences, and initiatives to reduce stigma. Eur Psychiatry, 20(8), 529-539.

Steinert, T., Schmid, P., Abderhalden, C., \& Needham, I. (2004). Management von Aggression und Gewalt in psychiatrischen Krankenhäusern. Krankenhauspsychiatrie, 15:, 146-150.

Thompson, A. H., Stuart, H., Bland, R. C., Arboleda-Florez, J., Warner, R., Dickson, R. A., et al. (2002). Attitudes about schizophrenia from the pilot site of the WPA worldwide campaign against the stigma of schizophrenia. Soc Psychiatry Psychiatr Epidemiol, 37(10), 475-482. 
Summary

The systematic assessment of the short-term risk for patient violence on acute psychiatric wards 
As component of the human condition, aggression inevitably affects health care institutions and relationships between carers and clients. Aggression in healthcare settings takes various forms. It exists as aggression of patients or patients relatives against professionals, as aggression of professionals against patients, as aggression between patients or as aggression in informal care settings, e.g. aggression in patientrelatives-relationships. Due to its negative consequences for all parties involved, the prevention of aggression is a challenge for health care practitioners and for researchers alike. Research in this area should lead to a better understanding and explanation of the phenomenon and, on the other hand, contribute to the development of effective prevention.

The general subject of this dissertation is patient aggression against others and violence in psychiatry, particularly aggression and violence in acute psychiatric wards. More specifically, the studies comprising this dissertation relate to two thematic areas, namely (1) to the scope of the problem in acute inpatient psychiatry in German speaking Switzerland, and (2) to the development and clinical application of a structured clinical assessment of the short-tern risk for violence among acute psychiatric patents.

The overall aim of the work included in this dissertation intends to contribute to the improvement of nursing practice related to the anticipation and prevention of adverse manifestations of aggression.

The introduction to this thesis provides an overview on problems related to the definition of aggression, followed by summaries of scientific evidence on the prevalence aggression in psychiatry and consequences for staff and patients. Risk prediction is discussed with respect to relevant theoretical positions, research on risk factors, methods of risk prediction and, ethical questions related to risk assessment. Based on this background information, the research questions to be addressed in the thesis are derived.

Part I (Chapters 1 to 3 ) includes investigations into the scope of the problem in acute inpatient psychiatry in German speaking Switzerland.

In Chapter 1, a study is presented aimed at exploring the experiences and perception of aggression among psychiatric nurses. 729 nurses working in psychiatric inpatient departments of German-speaking Switzerland completed the 32-item Perception of Aggression Scale (POAS). Data analysis included factor analysis, group comparisons and multivariate analysis of covariance. Nearly three-quarters (72.4\%) of the respondents felt once or repeatedly seriously threatened in their professional lives and about $70 \%$ 
were once or repeatedly physically attacked. The respective figures for the experience in their private lives were $47.0 \%$ (once or repeatedly seriously threatened in their private life) and $40.5 \%$ (once or repeatedly physically attacked in their nonprofessional life). With respect to the perception of aggression, factor analysis revealed two plausible factors, representing different dimensions in the perception of aggression and accounting for $35 \%$ of the variance. Firstly, aggression is perceived as dysfunctional/undesirable and, secondly, as functional/comprehensible phenomenon. Only minor differences were found in the perception of aggression with regard to personal characteristics or work environment of the nurses. The results of the study confirmed the high work-life prevalence on being victimized by aggression among psychiatric nurses. The independence of the perception of violence of many characteristics expected to be related to the perception of violence such as grade of education, work experience etc., and the prevalence of exposure to violence in the private life support the argument of a tight interconnection between aggression in psychiatry and the respective phenomena in society as a whole and stress the notion that aggression should not be seen as a specific problem of psychiatry or psychiatric patients.

Chapter 2 reports on the results of a survey in which representative data on structural characteristics of aggression management on acute psychiatric admission wards in the German speaking part of Switzerland were collected. All acute psychiatric admission wards in the area were questioned regarding aggression management and the judgment thereof by staff nurses. Eighty-two (94\%) of the 87 wards invited to the survey responded representing 30 (94\%) of the 32 institutions in the study area. Approximately every third staff nurse rated violence as a serious or very serious problem. The resources of $22 \%$ of the wards were rated as inadequate. Considerable differences existed regarding resources for and practices in handling violence. The greatest deficiencies lay in practical and theoretical knowledge, recording systems, in post-incident services for victims, the lack of seclusion facilities, and the lack of systematic violence risk assessment. About one half of the wards assess the risk for violence in all patients, while this is done for selected patients only in the other wards, and never in two wards. Seventy seven (94\%) of the wards use clinical impression for risk assessment, while 3 (4\%) of the wards employ a locally developed structured risk assessment instrument. The current practice of risk assessment is judged as insufficient by $33(40 \%)$ of the ward leaders. Most of the critics in additional comments referred to the lack of a unified structured method or problems rooted in differing views of nursing and medical staff. The results revealed an apparent absence of overall accepted minimal standards in aggression management, a fact that raises some 
concerns in view of the current claims for evidence-based practice and, the results showed the need to develop risk assessment practices towards a more systematic approach.

Chapter 3 contains a prospective multicentre study on the frequency and severity of aggressive incidents in 24 acute psychiatric wards in the German speaking part of Switzerland. The background of the study was a lack of research on aggression among psychiatric inpatients in Switzerland and, in order to support the international collaboration in improving the management of aggressive behavior, the need to obtain information which allows comparisons of services and caring approaches within health systems and between countries. To date, variations in study designs, settings, populations, and data collection methods render comparisons of the incidence of aggressive behaviour in high risk settings difficult. Therefore, the objective of the study was to establish robust and comparable data on the prevalence of aggressive incidents in acute psychiatric wards in the study area, meeting methodological problems of existing studies. Aggressive incidents were recorded by the revised Staff Observation Aggression Scale (SOAS-R) and we checked the data collection for underreporting. The study sample comprised 2344 treatment episodes of 2017 patients and a total of 41 '560 treatment days. A total of 760 aggressive incidents were registered. Incidence rates per 100 treatment days were between 0.60 (95\% Cl 0.10-1.78) for physical attacks and 1.83 (1.70-1.97) for all aggressive incidents (including purely verbal aggression). The mean severity was $8.80 \pm 4.88$ points on the 22 -point SOAS-R-severity measure; $46 \%$ of the purely verbally aggression was classified as severe ( $\geq 9$ pts.). $53 \%$ of the aggressive incidents were followed by a coercive measure, mostly seclusion or seclusion accompanied by medication. $13 \%$ of the patients were responsible for one ore more incident, and $6.9 \%$ were involved in one ore more physical attack. Involuntary admission (OR 2.2; 1.6-2.9), longer length of stay (OR 2.7; 2.0-3.8), and a diagnosis of schizophrenia (ICH-10 F2) (OR 2.1; 1.5-2.9) was associated with a higher risk for aggressive incidents, but no such association was found for age and gender. These results led to the conclusion that aggressive incidents in acute admission wards are a frequent and serious problem. Due to the study design the incidence rates were considered as robust and representative for acute wards in German speaking Switzerland, and thus useful as reference data for comparative and interventional research in acute admission wards. The study confirmed the necessity to differentiate between types of aggressive behavior when reporting and comparing incidence-data. 
Part II (Chapters 4 to 6) focus on the development, testing and clinical application of an instrument for a systematic assessment of the short term risk for violence in acute wards.

Chapter 4 is a study on the validation of a German Version of an instrument to assess the risk for physical attacks in psychiatric wards. The Norwegian Brøset-ViolenceChecklist (BVC) is one of the few instruments suited for short-time prediction of violence of psychiatric inpatients by nursing staff in routine care. The instrument assesses the presence or absence of six behaviours or states frequently ob-served prior to a violent incident. Aim of the study was to elucidate whether the predictive properties of the BVC are retained in other psychiatric settings than the original Norwegian validation dataset. During their admission period, 219 consecutive patients ad-mitted to 6 acute psychiatric wards were assessed as to the risk for attack using a German version of the BVC (BVC-G). Data on preventive measures were concurrently collected. Aggressive incidents were registered using an instrument equivalent to the Staff Observation of Aggression Scale (SOAS-R). Fourteen attacks toward staff were observed with incident severity ranging from 5 to 18 from a possible maximum of 22 points. BVC-G sensitivity was $64.3 \%$, the specificity $93.9 \%$, the positive predictive value $11.1 \%$, and the area under the receiver operating characteristic curve 0.88 . In some false positive cases intense preventive measures had been implemented. The predictive accuracy of the BVC-G proved consistent with the Norwegian original. These promising results gave rise to further development and evaluation of this instrument.

Chapter 5 describes a study carried out in order to improve the accuracy of the shortterm prediction of violence in acute inpatient settings by combining the BrøsetViolence-Checklist (BVC) with an overall subjective clinical risk-assessment and to test the application of the combined measure in daily practice. The study was designed as a prospective cohort study with two samples of newly admitted psychiatric patients for instrument development (219 patients) and clinical application (300 patients). Risk of physical attacks was assessed by combining the 6-item BVC and a 6-point score derived from a Visual Analog Scale. Incidents were registered with the Staff Observation of Aggression Scale-Revised SOAS-R. Test accuracy was described as the area under the receiver operating characteristic curve (AUCROC). The AUCROC of the new VAScomplemented BVC-version (BVC-CH) was 0.95 in and 0.89 in the derivation and validation study respectively. The satisfactory test accuracy of the combined instrument and its acceptance by practitioners emphasizes the applicability in daily routine. Adding a visual analogue scale for subjective risk assessment appeared to improve the compliance of the staff with systematic risk prediction and offers the 
opportunity to consider additional risk factors (e.g. historical factors, dynamic and environmental factors). Overall, the study results suggested that the BVC-CH is an easy to use and accurate instrument for systematic short-term prediction of violent attacks in acute psychiatric wards.

Chapter 6 describes a randomised controlled intervention study aimed at assessing whether a systematic risk assessments using the newly developed BVC-CH-instrument decreases the incidence of violence and coercion. The trial included 9 acute psychiatric admission wards as units of randomisation, and 5 additional wards which declined randomisation (preference arm of the study). The intervention comprised a standardized risk assessment during the first treatment days with mandatory discussion of preventive measures in high-risk patients. The incidence rates decreased substantially in the intervention wards, while little change occurred in the control wards. The intervention substantially reduced severe events of patient aggression (adjusted risk reduction 41\%) and also reduced the need for coercive measures (adjusted risk reduction 27\%). An even larger effect was observed in those wards not consenting to randomization but partaking in the study as a preference group. A reduction in the incidence rates of aggression and coercion of the magnitude found in this study was considered as clinically relevant for patients and staff alike. The results are particularly encouraging because the intervention is relatively simple to implement, inexpensive and easy to integrate into daily practice. The study results reflect the importance of continuing risk assessment and support recommendations forwarded by recent guidelines.

Finally, in the general discussion chapter, the main findings of the thesis are summarised and critically discussed with respect to methodological limitations of the studies described. Considering the results and limitations of the studies presented, several recommendations for further research are made. These recommendations relate to the nature of data to be included in epidemiological research on aggression in psychiatry; to the further refinement of the BVC-CH-instrument; to research on the effectiveness of preventive measures and, finally, to the involvement of experienced service users as promising approach to improve risk assessment and prevention of aggression. 
Samenvatting

De systematische beoordeling van het korte-termijn-risico op geweld door patiënten op acute psychiatrische opnameafdelingen 
Als onderdeel van het menselijk bestaan, is het onvermijdelijk dat agressie invloed heeft op gezondheidszorginstellingen en op de relatie tussen zorgverleners en cliënten. Agressie in zorginstellingen komt in verschillende vormen voor. Vanwege de negatieve gevolgen voor alle betrokken partijen, vormt de preventie van agressie een uitdaging voor zowel medewerkers als onderzoekers. Onderzoek op dit gebied zou moeten leiden tot een beter begrip van en verklaring voor het verschijnsel agressie en bovendien moeten bijdragen aan de ontwikkeling van een effectieve preventie.

Het hoofdthema van dit proefschrift is agressie van patiënten tegenover anderen en geweld in de psychiatrie, met name agressie en geweld op acute psychiatrische opnameafdelingen. Dit proefschrift gaat specifiek over twee thematische gebieden, namelijk (1) de omvang van het probleem op acute psychiatrische opnameafdelingen in Duits-sprekend Zwitserland, en (2) de ontwikkeling en klinische toepassing van een instrument voor gestructureerde klinische inschatting van het korte-termijn risico op geweld bij psychiatrische patiënten.

Het hoofddoel van het onderzoek waarvan in dit proefschrift verslag wordt gedaan, is het leveren van een bijdrage aan de verbetering van de kwaliteit van de zorg met betrekking tot de anticipatie op, en de preventie van, ongewenste uitingen van agressie.

De inleiding van dit proefschrift biedt een overzicht van problemen met betrekking tot de definitie van agressie, gevolgd door een samenvatting van de huidige stand van wetenschappelijke kennis op het gebied van de prevalentie van agressie in de psychiatrie en van de gevolgen voor medewerkers en patiënten.

De voorspelbaarheid van het risico wordt besproken met aandacht voor verschillende relevante theoretische standpunten, onderzoek naar risicofactoren, methoden voor het voorspellen van risico en ethische vraagstukken die samenhangen met risicobeoordeling.

Deze achtergrondinformatie vormt de basis voor de onderzoeksvragen in dit proefschrift.

Deel I (Hoofdstuk 1 tot en met 3) omvat onderzoek naar de omvang van het probleem in de acute klinische psychiatrie in Duits-sprekend Zwitserland.

In Hoofdstuk 1 wordt verslag gedaan van een onderzoek naar de ervaringen met en de perceptie van agressie onder psychiatrisch verpleegkundigen. 729 Verpleegkundigen, werkzaam op klinische afdelingen van psychiatrische ziekenhuizen in het Duitstalige deel van Zwitserland, vulden de 32 items onvattende POAS (Perception of Aggression 
Scale) in. Data-analyse bestond uit factoranalyse, groepsvergelijkingen en multivariate covariantie-analyse. Bijna driekwart $(72,4 \%)$ van de ondervraagden heeft zich tijdens het werk één of meerdere keren ernstig bedreigd gevoeld en ongeveer $70 \%$ is één of meerdere keren daadwerkelijk slachtoffer geweest van fysiek geweld. Voor ervaringen in hun privé-leven waren deze cijfers respectievelijk $47,0 \%$ (één of meerdere keren ernstig bedreigd), en $40,5 \%$ (één of meerdere keren slachtoffer van fysiek geweld geweest). Met betrekking tot de perceptie van agressie, liet factoranalyse twee factoren zien. Deze twee factoren verklaren samen $35 \%$ van de variantie. Agressie wordt gezien als disfunctioneel / ongewenst en als een functioneel / begrijpelijk fenomeen. In de waarneming van agressie werden slechts kleine verschillen gevonden ten aanzien van persoonskenmerken of de werkomgeving van de verpleegkundigen. De resultaten van dit onderzoek bevestigden de hoge prevalentie van agressie tegen psychiatrisch verpleegkundigen, tijdens het werk. De onafhankelijkheid van de perceptie van geweld van kenmerken waarvan verwacht werd dat zij met die perceptie zouden samenhangen, zoals opleidingsniveau, en werkervaring, en de prevalentie van blootstelling aan geweld in het privé-leven ondersteunen de stelling dat er een sterk verband bestaat tussen agressie in de psychiatrie, en deze fenomenen in de maatschappij als geheel. Bovendien ondersteunen zij de veronderstelling dat agressie niet moet worden gezien als specifiek probleem van de psychiatrie of psychiatrische patiënten.

In hoofdstuk 2 wordt verslag gedaan van een onderzoek waarin representatieve gegevens werden verzameld van structurele kenmerken van agressiehantering binnen acute psychiatrische opnameafdelingen in het Duitssprekende deel van Zwitserland. Alle acute psychiatrische opnameafdelingen in dit gebied werden ondervraagd over hun wijze van agressiehantering en het oordeel van de verpleegkundige staf daarover. Van de 87 afdelingen die voor deelname aan dit onderzoek werden uitgenodigd, participeerden 82 afdelingen (94\%)in het onderzoek. Dit komt neer op 30 van de 32 instellingen (94\%) in het studiegebied. Ongeveer eenderde van de stafverpleegkundigen zag geweld als ernstig of zeer ernstig probleem. De voorzieningen van $22 \%$ van de afdelingen werden ontoereikend geacht. Er bestonden aanzienlijke verschillen in zowel voorzieningen als in het omgaan met geweld. De grootste tekortkomingen bestonden op het gebied van praktische en theoretische kennis, registratiesystemen, op het gebied van nazorg voor slachtoffers van geweld, een tekort aan separeervoorzieningen, en het ontbreken van een systematische inschatting van het risico op geweld. Ongeveer de helft van de afdelingen beoordeelt het risico op geweld bij alle patiënten, terwijl dit bij de andere helft van de afdelingen alleen op indicatie gebeurt. Twee afdelingen voeren nooit een risicobeoordeling uit. 
Zevenenzeventig van de afdelingen (94\%) gebruiken de klinische indruk voor de inschatting van het risico, terwijl 3 van de afdelingen (4\%) een lokaal ontwikkeld en gestructureerd instrument voor risicobeoordeling gebruiken. Drieëndertig afdelingshoofden (40\%) beoordeelden de huidige praktijk van risicobeoordeling als ontoereikend. De meeste kritiek in het aanvullend commentaar verwijst naar het gebrek aan een eensluidende gestructureerde methode, en naar problemen die voortkomen uit de verschillende zienswijzen van verpleegkundigen en medische staf. De resultaten lieten zien dat een algemeen geaccepteerde set van minimum standaarden voor agressie-hantering ontbreekt. Dit feit baart zorgen, gezien de huidige eisen aan evidence-based practice. De resultaten toonden aan dat het noodzakelijk is om praktijken te ontwikkelen voor een meer systematische benadering van risicobeoordeling.

Hoofdstuk 3 beschrijft een prospectief multicenter onderzoek naar de frequentie en de ernst van agressie-incidenten op 24 acute psychiatrische opnameafdelingen in het Duitssprekende deel van Zwitserland. In Zwitserland is er een tekort aan onderzoek naar agressie onder psychiatrische patiënten op opnameafdelingen. Ook is er behoefte aan informatie over de verschillende voorzieningen, en zorgvisies, die internationale vergelijkingen mogelijk maakt .. Het verzamelen van deze informatie ondersteunt een internationale samenwerking om het hanteren van agressief gedrag te verbeteren. Tot op heden bemoeilijken de verschillen in onderzoeksopzet, voorzieningen, populaties, en de methoden van gegevensverzameling een goede vergelijking van de prevalentie van agressief gedrag in voorzieningen met een sterk verhoogd risico. Daarom was het doel van deze studie om robuuste en vergelijkbare gegevens te verkrijgen over de prevalentie van agressie-incidenten op psychiatrische opnameafdelingen binnen het onderzoeksgebied, die tegemoet komen aan de methodologische problemen van bestaande studies. De agressie-incidenten werden geregistreerd met behulp van de herziene versie van de Staff Observation Aggression Scale, (SOAS-R). De gegevensverzameling is op mogelijke onderrapportage gecontroleerd. De steekproef bestond uit 2344 behandel-periodes van 2017 patiënten met een totaal van 41'560 opnamedagen. In totaal werden 760 agressie-incidenten geregistreerd. De incidentie per 100 opnamedagen lag tussen 0,60 (95\% Cl $0.10-1.78)$ voor fysiek geweld en 1,83 (95\% Cl 1.70-1.97) voor alle agressie-incidenten (met inbegrip van puur verbale agressie). De gemiddelde ernst score bedroeg $8.80 \pm 4.88$ punten op de 22-punts-schaal van de SOAS-R-. Van de zuiver verbale agressie werd $46 \%$ als ernstig ( $\geq 9$ punten) beoordeeld. 
Op 53\% van de agressie-incidenten volgde een dwangmaatregel, meestal separatie of separatie plus medicatie. $13 \%$ van de patiënten was verantwoordelijk voor één of meerdere incidenten, en $6,9 \%$ was betrokken bij één of meerdere incidenten met fysiek geweld. Onvrijwillige opname (OR 2.2; 1.6-2.9), een langere verblijfsduur (OR 2.7; 2.0-3.8) en diagnose van schizofrenie (ICD-10 F2) (OR 2.1; 1.5-2.9) bleken samen te hangen met een hoger risico op agressie. Een dergelijk verband werd niet gevonden voor leeftijd of geslacht.

Deze resultaten leidden tot de conclusie dat agressie op acute opnameafdelingen een veel voorkomend en ernstig probleem vormen. Door de aard van de onderzoeksopzet werden de incidentie-cijfers beschouwd als robuust en representatief voor acute opnameafdelingen in Duits-sprekend Zwitserland. Daarmee zijn zij goed bruikbaar als referentiegegevens voor vergelijkend en interventie-onderzoek op acute opnameafdelingen. De studie bevestigde de noodzaak om onderscheid te maken tussen verschillende soorten van agressief gedrag bij het rapporteren en vergelijken van incidentiegegevens.

Deel II (Hoofdstuk 4 tot en met 6) handelt over de ontwikkeling, het testen en de klinische toepassing van een instrument voor een systematische beoordeling van het korte-termijn risico op geweld op acute afdelingen.

Hoofdstuk 4 bevat een studie over de validering van een Duitse versie van een instrument om het risico op fysiek geweld op psychiatrische afdelingen in te kunnen schatten. De Noorse Brøset-Violence-Checklist (BVC) is één van de weinige instrumenten die geschikt zijn voor het op korte termijn voorspellen van geweld bij psychiatrische patiënten op opnameafdelingen die door stafleden routinematig kan worden toegepast. Het instrument beoordeelt de aanwezigheid of afwezigheid van zes gedragingen of stemmingen die vaak voorafgaan aan een ernstig incident. Het doel van de studie was nader te onderzoeken of de voorspelbare eigenschap van de BVC blijft bestaan in andere psychiatrische instellingen en settings dan in de oorspronkelijke Noorse setting. Tijdens hun opnameperiode werd een reeks van 219 patiënten, opgenomen op 6 verschillende acute psychiatrische afdelingen, beoordeeld op het risico op geweld met behulp van een Duitse versie van de BVC (BVC-G). De gegevens over preventieve maatregelen werden gelijktijdig verzameld. De agressie-incidenten werden geregistreerd met behulp van een instrument dat gelijkwaardig is aan de SOAS-R.

Er werden veertien aanvallen op personeel gerapporteerd, met ernstscores variërend van 5 tot 18 op een maximale score van 22 punten. De sensitiviteit bedroeg $64,3 \%$, en de specificiteit $93,9 \%$. De positieve predictieve validiteit bedroeg $11,1 \%$, en het gebied 
onder de Receiver Operating Characteristic (ROC) curve was 0,88 . In sommige fout positieve gevallen werden intensieve preventieve maatregelen getroffen. De predictieve validiteit van de BVC-G bleek overeen te komen met de originele Noorse versie. Deze veelbelovende resultaten vormden de aanleiding tot een verdere ontwikkeling en evaluatie van dit instrument.

Hoofdstuk 5 beschrijft een studie die tot doel had om de nauwkeurigheid van de kortetermijn- voorspelling van geweld op acute opnameafdelingen te verbeteren. Hiertoe werd de Brøset-Violence-Checklist (BVC) gecombineerd met een globale subjectieve klinische risico-inschatting, en werd de toepassing van deze gecombineerde maten in de dagelijkse praktijk getest. De studie werd opgezet als een prospectieve cohortstudie met twee steekproeven van recentelijk opgenomen psychiatrische patiënten. Een steekproef voor de instrumentenontwikkeling (219 patiënten) en voor de klinische toepassing (300 patiënten). Het risico op fysiek geweld werd ingeschat met behulp van een combinatie van de 6-item BVC en een 6-punts score, afgeleid uit een Visuele Analoge Schaal. De incidenten werden geregistreerd met behulp van de SOAS-R. De nauwkeurigheid van de test werd gedefinieerd als het gebied onder de curve (Area under the curve $A U C$ ) van de Receiver Operating Characteristic (ROC) analyse (AUCROC). De AUCROC van de nieuwe, met de VAS-aangevulde, BVC-versie (BVC-CH) was 0,95 en 0,89 in de respectievelijk afgeleide en confirmerende studie. De bevredigende nauwkeurigheid van het gecombineerde instrument en de acceptatie daarvan door verpleegkundigen benadrukt de bruikbaarheid in de dagelijkse praktijk. Het toevoegen van een visuele analoge schaal voor subjectieve risicobeoordeling bleek de compliance voor systematische risicoinschatting onder stafleden te vergroten. Dit biedt ook de mogelijkheid om extra risicofactoren toe te voegen (b.v. historische, dynamische en milieufactoren). De uitkomsten van de onderzoeken duiden erop dat de BVC-CH een makkelijk te gebruiken en nauwkeurig instrument is voor systematische risicoinschatting van geweld op korte termijn op acute opnameafdelingen.

Hoofdstuk 6 beschrijft een gerandomiseerde, gecontroleerde interventiestudie met als doel te onderzoeken of een systematische risicotaxatie met behulp van de nieuw ontwikkelde Zwitserse BVC-CH leidt tot een afname van geweld en dwangmaatregelen. Deze trial omvatte 9 willekeurige acute psychiatrische opnameafdelingen en 5 extra afdelingen, die medewerking aan de randomisatie afwezen (de "preference arm" of voorkeursgroep binnen dit onderzoek). De interventie bestond uit een gestandaardiseerde risicotaxatie tijdens de eerste opnamedagen, met een verplichte evaluatie van preventie bij patiënten met een sterk verhoogd risico. 
De incidentie verminderde substantieel op de interventieafdelingen, terwijl er weinig verandering optrad op de controleafdelingen. Door de interventie verminderde het aantal ernstige agressie-incidenten substantieel (adjusted risk reduction 41\%) en verminderde ook de noodzaak tot het toepassen van dwangmaatregelen (adjusted risk reduction $27 \%$ ). Een nog groter effect werd waargenomen bij die afdelingen die niet met de randomisatie instemden maar deelnamen aan de studie als "preference arm" (voorkeursgroep). Een vermindering van de incidentie van agressie en dwangmaatregelen van een omvang zoals die in deze studie werd gevonden, wordt beschouwd als klinisch relevant voor zowel patiënten als personeel. De resultaten zijn met name bemoedigend omdat de interventie vrij eenvoudig is uit te voeren, goedkoop is en gemakkelijk is te integreren in de dagelijkse praktijk. De studieresultaten wijzen op het belang van voortdurende risicotaxatie en vormen een ondersteuning voor aanbevelingen die voortkomen uit recente richtlijnen.

Tot slot worden in het algemene discussiehoofdstuk de belangrijkste bevindingen van het proefschrift samengevat en kritisch besproken met betrekking tot de methodologische beperkingen van de beschreven studies. De resultaten en de beperkingen van de gepresenteerde studies in ogenschouw nemend, worden verschillende aanbevelingen gedaan voor verder onderzoek. Deze aanbevelingen hebben betrekking op de aard van de gegevens waarop epidemiologisch onderzoek naar agressie in de psychiatrie zich moet richten; op de verdere verbetering van het BVC-CH-Instrument; op onderzoek naar de doeltreffendheid van preventieve maatregelen en tenslotte, op de betrokkenheid van ervaringsdeskundigen als een veelbelovende benadering om zowel risicotaxatie als de preventie van agressie te verbeteren. 



\section{Acknowledgements}

In the completion of this dissertation I have been supported by persons and organizations to whom and to which I owe heartfelt thanks.

For their encouragement, interest (and patience), I thank my supervisors Professor $\mathrm{H}$. Philipsen (Universiteit Maastricht, NL), Professor Theo Dassen (Humboldt University, Berlin, D) and Assoc. Prof. Ruud Halfens (Universiteit Maastricht, NL). For his valuable advice on social and ethical aspects I thank Hans Philipsen. Ruud Halfens I thank for his gentle reminders when I dawdled and for his constant accessibility for feedback and suggestions. Theo Dassen's introduction to the European Violence in Psychiatry Research Group EViPRG was decisive for the development of my project.

The membership in the EViPRG and the collaboration with researchers from across Europe opened completely new horizons and count among the greatest enrichments in my involvement with violence in psychiatry. For their important stimuli and assistance I thank in particular Roger Almvik (Broset Hospital, Trondheim, N), Prof. Len Bowers (London UK), Dr. Gerard Jansen (University of Groningen, NL), Prof. Henk Nijman (De Kijvelanden Poortugal NL), Nico Oud (Connecting, Amsterdam, NL), Prof. Tom Palmstierna (Karolinska Institute, Stockholm, S), and Dr. Bert van der Werf (De Geestgronden, NL).

Most of the studies described in this dissertation were planned and conducted within the framework of an interdisciplinary team. The interdisciplinary collaboration with Prof. Hans-Joachim Haug (Klinik Schlössli and Universität Zürich, $\mathrm{CH}$ ) and Prof. Joachim E. Fischer (Universität Heidelberg, Mannheim, D) was an extraordinarily positive, instructive and inspiring experience for which I am very grateful. One of the members of this team, Dr. Ian Needham (Rheinau, CH) has been a friend for more than 30 years. Without lan's sensitive and uncomplicated collaboration and support, my dissertation would not have been possible. I am particularly and deeply grateful for this, and I very much look forward to the new projects upon which we are embarked.

Decisive for the realization of my studies has been the tremendous good will shown these projects by the nursing and physicians' administrations in the psychiatric clinics of German-speaking Switzerland. Without the energetic support especially of the Conference of Nursing Administrators of Psychiatric Institutions KPP these multicentric studies would not have been realizable. Special thanks are due the several hundred colleagues who contributed to these studies through the collection of data and the completion of questionnaires. 
The research projects described in this dissertation have been generously supported by the following organizations: the Swiss Academy of Medical Science SAMW, the Swiss National Science Foundation SNF, the Swiss Association of Nursing Experts PES, the Swiss Network for Psychiatric Nursing Research NFPF, the Horten Institute of Research, the Institute of Behavioral Sciences and the Swiss Federal Institute of Technology $(\mathrm{ETH})$, and not least by my current employer, the University of Bern Psychiatric Services.

The completion of this dissertation experienced several lengthy delays. I am grateful to those friends who spurred me on from time to time. The decisive impulse came however from Manuela Eicher and Dr. Claus Jacobs during the fall 2007 vacation in our Dietschwil farmhouse. Manuela and Claus, that was terrific!

The course of this dissertation was marked by two profound events in my life. Shortly after the commencement of the project, my parents, Ernst and Dorothea AbderhaldenFischli, died in close succession at an advanced age. And the completion of the final study coincided with my marriage to my partner of many years, Monika Saxer. I dedicate this dissertation to the memory of my parents, who took a lively interest in my plans to the very end, and to you, dear Moni, for your belief in my project, your support and companionship. 


\section{Curriculum vitae}

Christoph Abderhalden was born on the 2nd of March 1954 in St.Gallen, Switzerland. In 1976 he completed training in psychiatric nursing at the Nursing School in Wil, Switzerland. In the following years he worked as a psychiatric nurse on acute and rehabilitation wards in the psychiatric hospitals in Wil and Herisau. After obtaining a diploma as a nurse tutor in psychiatric nursing at the School for post-diploma education for Nursing in Zurich in 1983 he held a teaching position in the School for psychiatric Nursing in Herisau. From 1987 until 1990 he worked as a clinical expert in the Psychiatriezentrum Hard in Embrach and achieved a diploma as Clinical Nursing Expert in 1989. From 1990 to 2003, he concurrently led a post-diploma education in psychiatric nursing in Embrach and worked as a lecturer, consultant and researcher at the School for post-diploma education for Nursing in Aarau. He received his Masters Degree in Health Sciences (Nursing Science) from the Universiteit Maastricht in 1999 and he started his PhD study at the Humboldt University of Berlin (Prof. Dr. T. Dassen) and the Universiteit Maastricht (Dr. R. Halfens and Prof. Dr. H. Philipsen) in 2000. From 2003 - 2005 he was a part time research fellow at the Swiss Federal Institute of Technology Zurich, Institute of Behavioural Sciences (Prof. Dr. K. Frey) and, concurrently, he was appointed as head of a newly established Nursing Research Unit at the University Bern Psychiatric Services in 2003. From 2005 to 2006, he also worked as a psychiatric nurse in the crisis intervention centre of the University Berne Psychiatric Services.

Christoph Abderhalden is coordinator of the Swiss Network for Psychiatric Nursing Research, a founding member of the Akademische Fachgesellschaft Psychiatrische Pflege in Switzerland, and a Swiss representative within the European Violence in Psychiatry Research Group EViPRG. 